RPP-6499

Revision 0

\title{
Business System Planning Project, Alternatives Analysis
}

S. Evosevich

Lockheed Martin Services, Inc.

Date Published

October 2000

Prepared for the U.S. Department of Energy

Assistant Secretary for Environmental Management

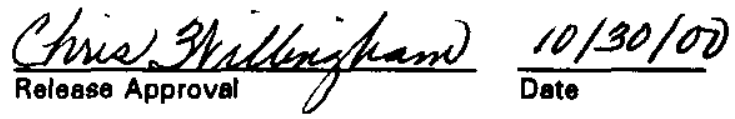

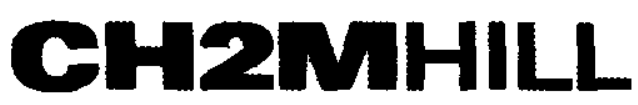

Hanford Group, Inc.

Richland, Washington

Contractor for the U.S. Depertment of Energy

Office of River Protection under Contract DE-AC06-89RL 14047

Approved for Public Release; Further Dissemination Unlimited 


\section{LECAL DIBCLAMER}

This report was prepared es an account of work sponeored by on agency of the United States Government. Neither the United States Government nor any agency thereof, nor any of their omployees, nor ony of their contractors, subcontrectors or their employees, makes any worranty, oxpress or impliod, or assumes any logal liability or responsibility for the accuracy, completeness, or any third party's use of the results of such use of any information, apparatus, product, or process disclosed, or represents that its use would not infringe privately owned rights. Reference herein to any specific commerciel product, process, or service by trede name, trademark, manufecturer, or otherwise, does not necessarily constitute or imply its ondorsement, recommendation, or fevoring by the United States Government or any agency thereof or its contractore or subcontractors. The viows and opinions of authors expressed herein do not necessarily state or reflect those of the United States Government or any egency theroof.

This report hes been reproduced from the best available copy. Available in paper copy

Printed in the United States of Amorice 


\section{INFORMATION CLEARANCE FORM}

\begin{tabular}{ll}
\multicolumn{2}{c}{ A. Information Category } \\
$\square$ Abstract & $\square$ Journal Article \\
$\square$ Summary & $\square$ Internet \\
$\square$ Visual Aid & $\square$ Software \\
$\square$ Full Paper & $\square$ Report \\
$\square$ Other &
\end{tabular}

B. Document Number RPP-6499

C. Title

Business Systems Planning Pooject, Alternatives Analysis

D. Internet Address

E. Required Information

1. Is document potentially Classified? $\bigotimes$ No $\square$ Yes (MANDATORY)

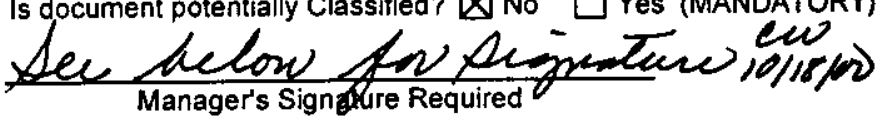

If Yes

$\square$ No $\square$ Yes Classified ADC Signature Required

$\square$ No $\bigotimes$ Yes

2. Internal Review Required?
If Yes, Document Signatures Below

Counsel

Program

3. References in the Information are Applied Technology $\triangle$ No $\square$ Yes Export Controlled Information $\triangle$ No $\square$ Yes

4. Does Information Contain the Following: (MANDATORY)

a. New or Novel (Patentable) Subject Matter? $\bigotimes$ No $\square$ Yes If "Yes", Disclosure No.:

b. Information Received in Confidence, Such as Proprietary and/or Inventions?

$\bigotimes$ No $\square$ Yes If "Yes", Affix Appropriate Legends/Notices.

c. Copyrights? $\bigotimes$ No $\square$ Yes If "Yes", Attach Permission.

d. Trademarks? $\square$ No $\square$ Yes If "Yes", Identify in Document.

5. Is Information requiring submission to OSTI? $\quad$ No $\square$ Yes

If Yes $U C-$

6. Release Level? $\bigotimes$ Public $\square$ Limited

7. Charge Code $1 / 2656,1060$

F. Complete for a Journal Articie

1. Title of Journal

G. Complete for a Presentation

1. Title for Conference or Meeting

2. Group Sponsoring

3. Date of Conference

5. Will Information be Published in Proceedings? $\square$ No $\square$ Yes

4. City/State

H. Author/Requestor (Print and Sign)

6. Will Material be Handed Out? $\square$ No $\square$ Yes

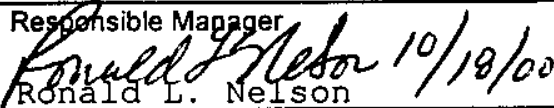

(Print and Sign)

I. Reviewers Yes Print Signature

General Counsel $\bigotimes \quad$ Stan Bensussen

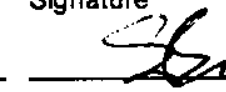

Public Y/N (If $N$, complete J)

Office of External Affairs

DOE-RL

区

Kevin Ensign

(Y) $/ \mathrm{N}$

$\mathrm{Y} / \mathrm{N}$

Other

$\square$

ב.

Other

$\square$

C._.

J. If Information Includes Sensitive Information and is not to be released to the Public indicate category below.
$\square$ Applied Technology
$\square$ Protected CRADA
$\square$ Personal/Private
$\square$ Export Controlled
$\square$ Proprietary
$\square$ Business-Sensitive
$\square$ Procurement-Sensitive
$\square$ Predecisional
$\square$ Patentable
$\square$ UCNI
$\square$ Other (Specify)

K. If Additional Comments, Please Attach Separate Sheet 


\section{INFORMATION CLEARANCE FORM}

\begin{tabular}{ll|l}
\hline \multicolumn{2}{c|}{ A. Information Category } & B. Document Number RPP-6499 \\
\cline { 2 - 2 } & $\square$ Journal Article & C. Title \\
$\square$ Summary & $\square$ Internet & Business Systems Planning PGoject, Alternatives Analysis \\
$\square$ Visual Aid & $\square$ Software & \\
$\square$ Full Paper & $\square$ Report & \\
$\square$ Other & & \\
\hline
\end{tabular}

E. Required Information

1. Is document potentially Classified? $\square$ No $\square$ Yes (MANDATORY) Lee Melow $_{\text {Manager's Signgure Required }}$ If Yes $\square$ No $\square$ Yes Classified ADC Signature Required

2. Internal Review Required? If Yes, Document Signatures Below

$\square$ No $\bigotimes$ Yes

Counsel

Program

3. References in the Information are Applied Technology $\bigotimes$ No $\square$ Yes Export Controlled Information $\triangle_{\text {No }} \square$ Yes
4. Does Information Contain the Following: (MANDATORY)

a. New or Novel (Patentable) Subject Matter? $\bigotimes$ No $\square$ Yes

If "Yes", Disclosure No.:

b. Information Received in Confidence, Such as Proprietary and/or Inventions? $\square$ No $\square$ Yes If "Yes", Affix Appropriate Legends/Notices.

c. Copyrights? $\bigotimes$ No $\square$ Yes If "Yes", Attach Permission.

d. Trademarks? $\square$ No $\square$ Yes If "Yes", Identify in Document.

5. Is Information requiring submission to OSTI? $\quad$ No $\square$ Yes

If Yes $U C^{-}-$and $B \& R-$

6. Release Level? $\bigotimes$ Public $\square$ Limited

7. Charge code $1 / 2656,106$

F. Complete for a Journal Article

1. Title of Journal

G. Complete for a Presentation

1. Title for Conference or Meeting

2. Group Sponsoring

3. Date of Conference

5. Will Information be Published in Proceedings? $\square$ No $\square$ Yes

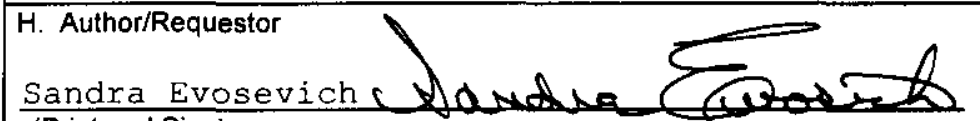
(Print and Sign)

I. Reviewers

General Counsel

Office of External Affairs

DOE-RL

区

Kevin Ensign

Other

Other
4. City/State

6. Will Material be Handed Out? $\square$ No $\square$ Yes

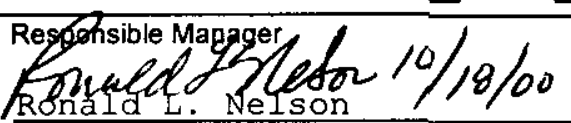

(Print and Sign)

Signature
Public $Y / N$ (If $N$, complete J)
$\mathrm{Y} / \mathrm{N}$
$\mathrm{Y} / \mathrm{N}$
$\mathrm{Y} / \mathrm{N}$
$\mathrm{Y} / \mathrm{N}$
$\mathrm{Y} / \mathrm{N}$

J. If Information Includes Sensitive Information and is not to be released to the Public indicate category below.
$\square$ Applied Technology
$\square$ Protected CRADA
$\square$ Personal/Private
$\square$ Export Controlled
$\square$ Proprietary
$\square$ Procurement-Sensitive
$\square$ Business-Sensitive
$\square$ Patentable
D] Predecisional
$\square$ Other (Specify)
$\square$ UCNI

K. If Additional Comments, Please Attach Separate Sheet 


\title{
Business Systems Planning Project
}

\section{Alternatives Analysis}

\author{
Prepared for
}

CH2M HILL Hanford Group, Inc.

R. L. Nelson Fonald Ditelar Date: $9 / 25 / 00$

Manager, Information Resource Management / Chief Information Officer, CH2M HILL Hanford Group, Inc.

P. B. Isaacs $P B$ Date: $9 / 25 / 00$

Project Lead, Lockheed Martin Services, Inc.

Prepared by

Lockheed Martin Services, Inc. 


\section{Table of Contents}

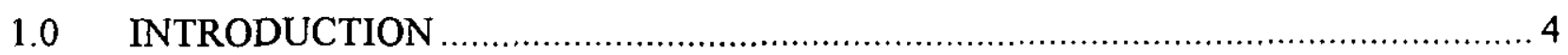

1.1 PURPOSE

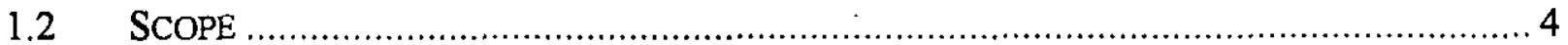

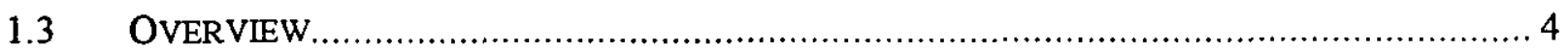

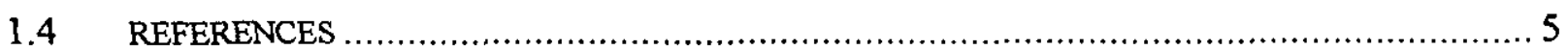

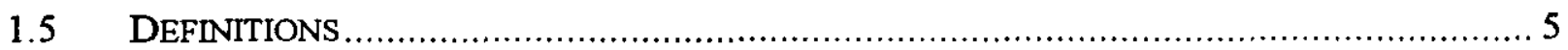

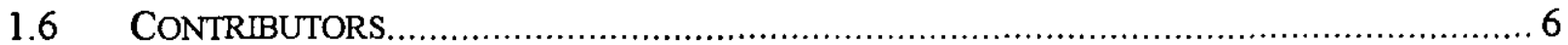

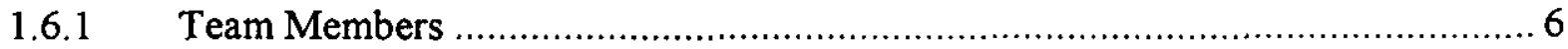

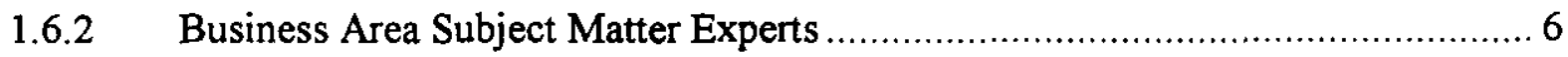

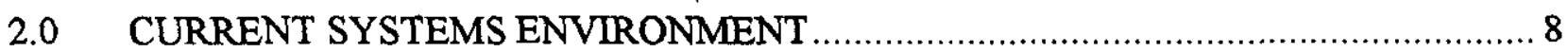

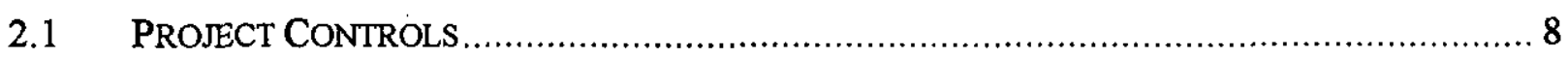

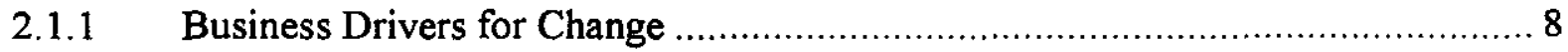

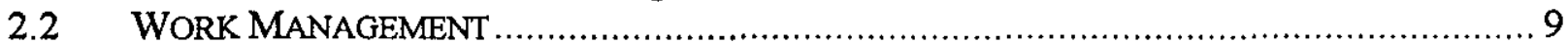

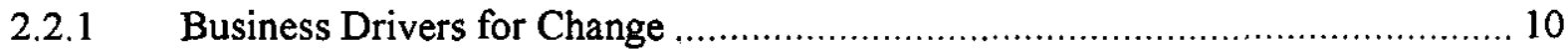

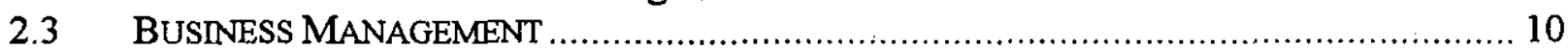

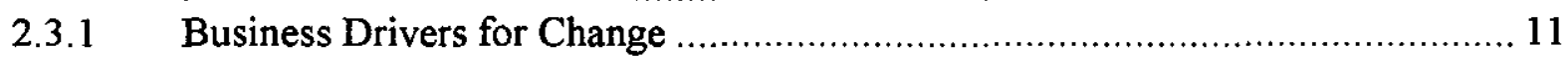

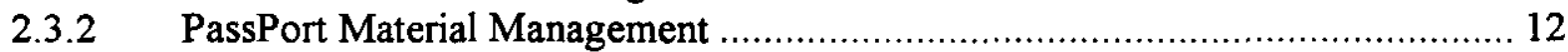

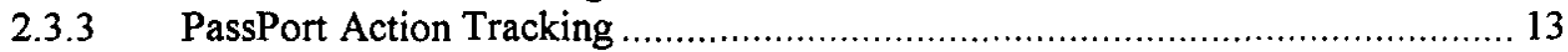

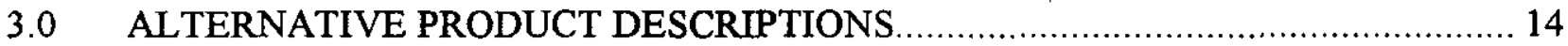

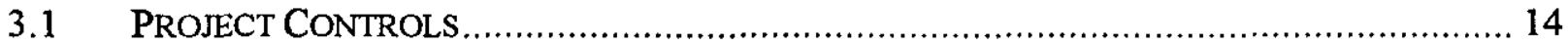

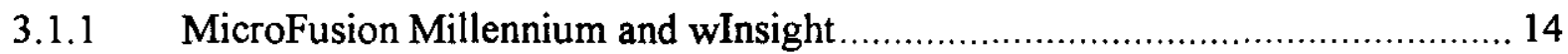

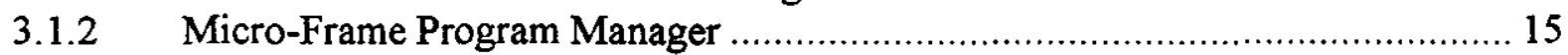

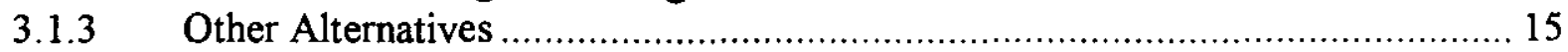

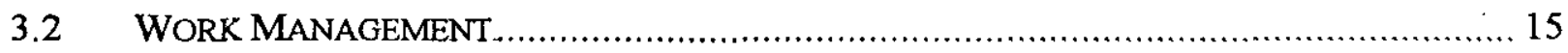

3.2.1 MAXIMO Work Management …................................................................. 15

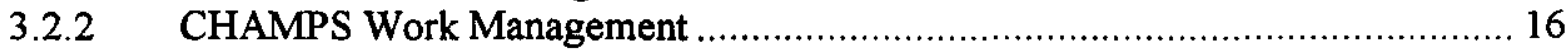

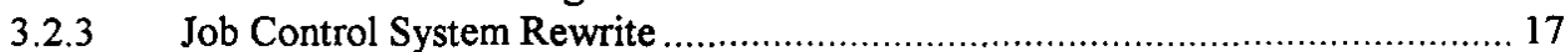

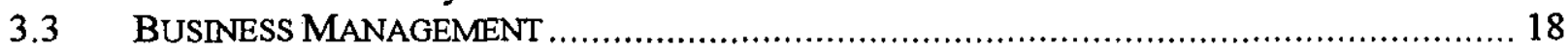

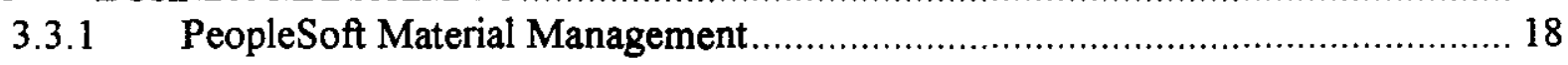

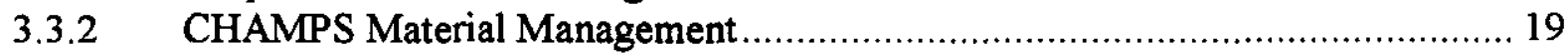

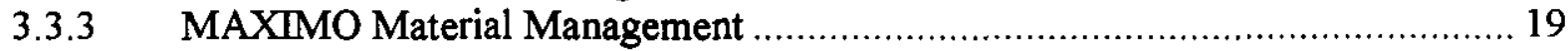

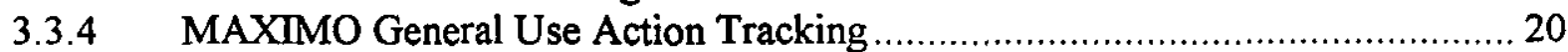

3.3.5 Hanford Action Tracking System Rewrite ..................................................... 21

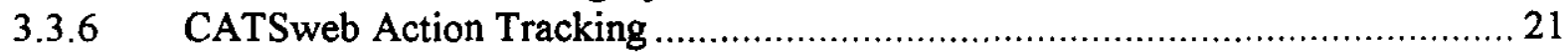

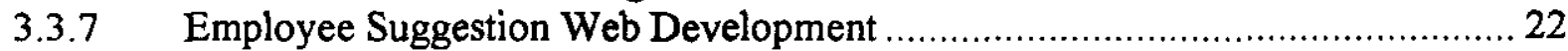

3.3.8 Other Action Tracking Alternatives ……...................................................... 22

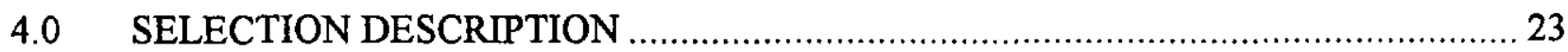

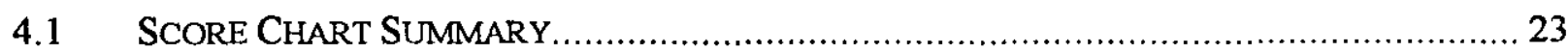




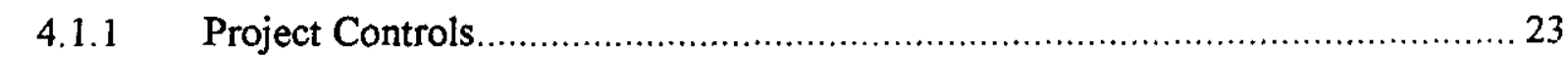

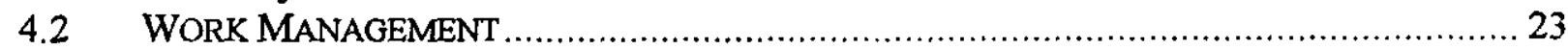

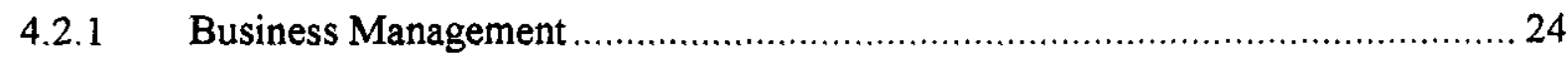

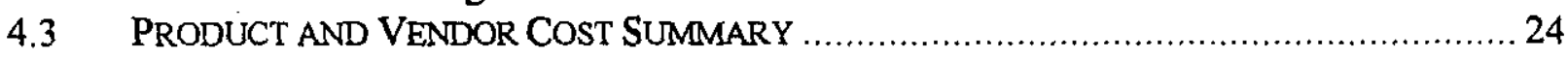

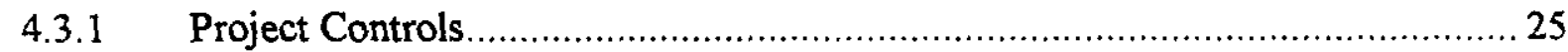

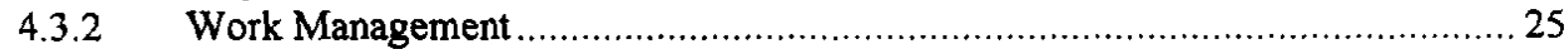

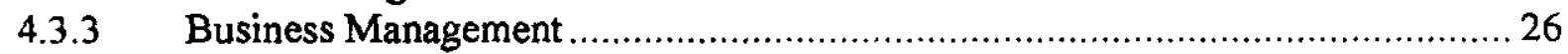

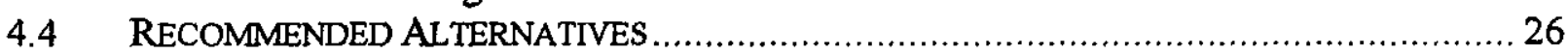

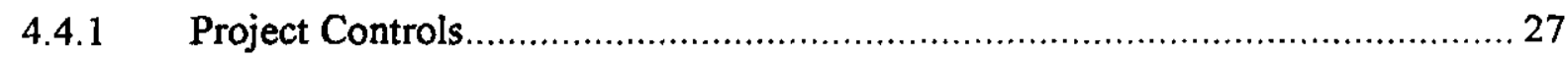

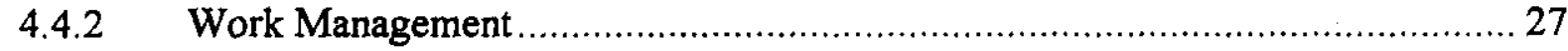

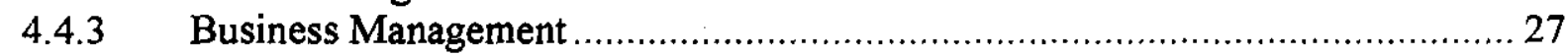

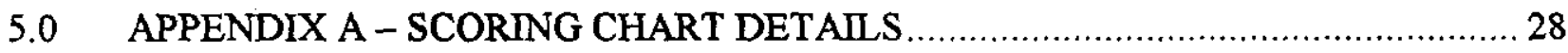

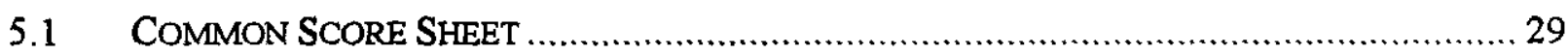

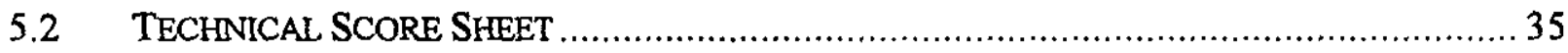

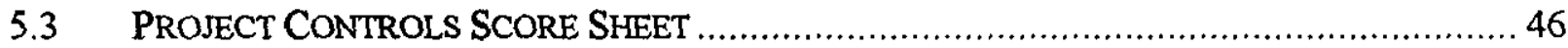

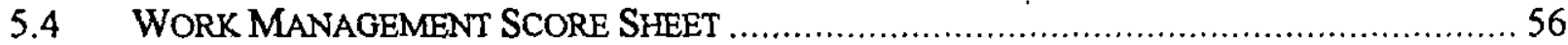

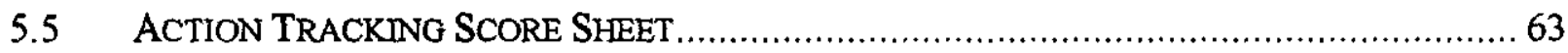

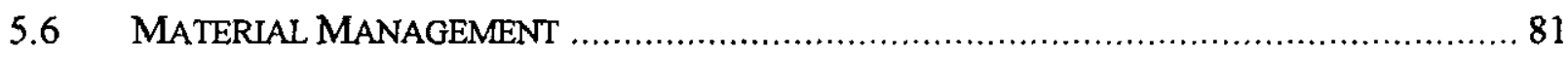




\subsection{INTRODUCTION}

CH2M HILL Hanford Group, Inc. (CHG) is currently performing many core business functions including, but not limited to, work control, planning, scheduling, cost estimating, procurement, training, and human resources. Other core business functions are managed by or dependent on Project Hanford Management Contractors including, but not limited to, payroll, benefits and pension administration, inventory control, accounts payable, and records management. In addition, CHG has business relationships with its parent company CH2M HILL, U.S. Department of Energy (DOE), Office of River Protection (ORP) and other River Protection Project (RPP) contractors, government agencies, and vendors.

\subsection{PURPOSE}

The CHG Chief Information Officer (CIO) requested a study of alternatives to the current business system computing environment. This Business Systems Planning (BSP) Project Alternatives Analysis document presents an analysis of the current Project Controls, Work Management, and Business Management systems environment and alternative solutions that support the business functions.

\subsection{SCOPE}

The project team has collected requirements and priorities from stakeholders in each business area and documented them in the BSP System Requirements Specification (SRS), RPP-6297. The alternatives analysis process identifies and measures possible solutions in each of the business process areas against the requirements as documented in the SRS. The team gathered input from both internal and external sources to identify and grade the possible solutions. This document captures the results of that activity and recommends a suite of software products. This study was to select the best product based on how well the product met the requirements, not to determine the platform or hardware environment that would be used. Additional analysis documentation can be found in BSP project files.

\subsection{OVERVIEW}

CHG was awarded the prime contract, by the U.S. Department of Energy, Office of River Protection, for the River Protection Project to perform the planning and operations necessary for tank waste storage, retrieval, treatment and delivery of waste to and from the Waste Treatment Contractor.

As part of this contract CHG will work to achieve ORP objectives to reduce the administrative costs of doing business and apply the savings to mission related work to move forward with waste retrieval and to achieve autonomy where practical. To achieve the contractual requirement, the CHG CIO requested a study of alternatives to the current systems environment.

Effective information architectures provide the tools to support decision making and information sharing. For an enterprise such as CHG, a well designed and well managed information architecture can help bring efficiencies to the project delivery objectives by providing the capability to readily acquire, share, protect, disseminate, store, and retrieve accurate, timely and 
reliable information. The products recommended in this document were chosen because of their potential to provide such an information architecture.

\subsection{REFERENCES}

- Business Systems Planning Project System Requirements Specification, RPP-6297, Rev.0.

- Lockheed Martin Services, Inc. Organization Standard Software Practices, Version 3.2.

- Institute of Electrical and Electronics Engineers Standard 8340-1984.

\subsection{Definitions}

\begin{tabular}{|l|l|}
\hline BCros & R. \\
\hline BCR & Baseline Change Request \\
\hline BMS & Business Management System \\
\hline BSP & Business Systems Planning \\
\hline CEIS & Cost Estimating Input Sheets \\
\hline CHG & CH2M HIIL Hanford Group, Inc \\
\hline CIO & Chief Information Officer \\
\hline CMM & Central Milestone Module \\
\hline COTS & Commercial-Off-The-Shelf \\
\hline DOE & Department of Energy \\
\hline FH & Fluor Hanford, Inc. \\
\hline HANDI & Hanford Data Integrator \\
\hline HATS & Hanford Action Tracking System \\
\hline HRIS & Human Resources Information System \\
\hline HSTD & Hanford Site Technical Database \\
\hline INFOT & InfoTech West, Inc. \\
\hline IPARS & Integrated Planning and Reporting System \\
\hline IPS & Indirect Planning System \\
\hline IRM & Information Resource Management \\
\hline JCS & Job Control System \\
\hline LMSI & Lockheed Martin Services, Inc. \\
\hline MPM & Micro-Frame Program Manager \\
\hline MS & Microsoft \\
\hline MYWP & Multi-Year Work Plan \\
\hline NISI & Northwest Instrument Systems, Inc. \\
\hline ORP & Office of River Protection \\
\hline P3 & Primavera Project Planner \\
\hline PACS & Program Analysis and Control System \\
\hline PERF & Performance Module \\
\hline PHMC & Project Hanford Management Contract \\
\hline QA & Quality Assurance \\
\hline RPP & River Protection Project \\
\hline
\end{tabular}




\begin{tabular}{|l|l|}
\hline SME & Subject Matter Expert \\
\hline SRS & System Requirements Specification \\
\hline TIS & Time Information System \\
\hline WBS & Work Breakdown Structure \\
\hline
\end{tabular}

\subsection{CONTRIBUTORS}

The CHG CIO has a core team that evaluated, ranked and documented the analysis for the BSP Project. The CHG management provided primary Subject Matter Experts (SMEs) for contributing in the evaluation of products and ranking how well the products met the requirements for their specific business area needs.

\subsubsection{Team Members}

\section{Team Member}

Ronald L. Nelson

$P$. Brian Isaacs

Joyce A Caldwell

Kelly A. Crace

Sandra Evosevich

Jimmy K. Hamilton

Melody J. Kendall

Eldon C. Ladd

Diana L. Marquez
Business Area

Information Resource Management / CIO

Project Lead

Business Management

Work Management

Business Management

Work Management

Business Management

Project Controls

Project Controls
Company

CHG

LMSI

LMSI

LMSI

LMSI

CHG

LMSI

NISI

INFOT

\subsubsection{Business Area Subject Matter Experts}

Projects Controls

Work Management
Joseph C. Annunziato

Chance S. Blank

James B. Blethen

W. F. Greenway

Walter S. Hood

Eldon C. Ladd

Michael R. Lewis

P. Magallones

Rocky L. Brooks

Jimmy K. Hamilton

Gail L. Rensink 


\section{Business Management}

Claudia R. Burr Joyce G. Etheridge Greg A. Gardner Alice R. Hendrickson

Kristi A. Samifua

Cathy S. Spears 


\subsection{CURRENT SYSTEMS ENVIRONMENT}

This section describes the current systems environment.

\subsection{PROJECT CONTROLS}

The current CHG Project Controls environment includes the functional areas of planning, estimating, scheduling, reporting and risk analysis. For the purposes of this alternative analysis, risk analysis was not included in the scope. The current Project Controls configuration was evaluated and rated as an alternative. Below describes the AS-IS environment.

Many systems support Project Controls functions, but only significant ones that CHG utilize are addressed. The current Project Controls environment is a combination of Microsoft (MS) Access based systems, MS Word, MS Excel and Hanford Data Integrator (HANDI), which is a custom built application using a PowerBuilder front-end with an Oracle database engine.

The majority of the proposed technical scope and cost data are in MS Access based systems. The Cost Estimating Input Sheets (CEIS) system contains the cost estimates for activities and the resources for direct budgeting. Program Analysis and Control System (PACS) contains the technical scope and related process information such as risk, issues, and enabling assumptions data. MS Word is used by some organizations instead of PACS. Currently, CHG also uses Indirect Planning System (IPS) for budgeting data relating to indirect budget planning.

The baseline schedule is currently in Primavera Project Planner (P3). Changes to the baseline schedule are controlled following the approval of a Baseline Change Request (BCR). The BCR management process utilizes MS Word and MS Excel.

HANDI is a site wide data warehouse system used to store and report planning, budget, and cost performance data. HANDI has the ability to segregate some CHG reports from Project Hanford Management Contractor (PHMC). HANDI is not the source of any data. Rather, it receives data from a variety of systems such as the Performance Module (PERF), Hanford Site Technical Database (HSTD), Integrated Planning and Reporting System (IPARS) and Business Management System (BMS). PERF contains performance measurement data from the financial system and P3 schedules in a central database. HSTD contains data used to support the MultiYear Work Plan (MYWP) preparation. IPARS uses the Central Milestone Module (CMM) for tracking and storing milestones. BMS supplies finance and invoice data to HANDI. Insight is used as a secondary reporting system, as it contains other pertinent Project Controls data.

\subsubsection{Business Drivers for Change}

Currently, P3 is the CHG standard scheduling tool and is considered satisfactory, therefore, evaluation of alternative scheduling tools was not pursued. Insight is the standard site repository for reporting and was not investigated for replacement. 
Below are the business drivers for change in regard to Project Controls.

1) Automation support for Project Controls process is fragmented, resulting in a complex and labor intensive environment.

2) Lack of integration in current systems does not support the Project Control organization or the Information Resource Management (IRM) strategic goal of a single point of entry.

3) Several process improvements are needed to effectively manage CHG project lifecycle.

4) Current systems do not meet management needs in controlling the CHG project lifecycle.

5) Requirement for more timely cost performance information.

6) Desire to align with the $\mathrm{CH} 2 \mathrm{M}$ HILL corporate project delivery methodology.

\subsubsection{Pros}

Below are the Pros for the current Project Controls environment as an alternative.

1) Implementation costs have already been incurred.

2) Systems and data are known and understood by users.

\subsubsection{Cons}

Below are the Cons for the current Project Controls environment as an alternative.

1) Shared environment with other prime contractors, constrains the ability to control systems, data or processes.

2) Multiple data repositories make it difficult to determine the validity of the information.

3) Fragmented data repositories result in redundant storage of similar data in multiple locations.

4) HANDI does not provide the level of the Work Breakdown Structure (WBS) reporting necessary for effective project management.

5) Inability to provide CHG the flexibility to do "what if" scenarios, in regard to schedule and baseline changes.

6) Current systems do not meet the $\mathrm{CHG}$ requirements for drilldown capabilities and reporting flexibility.

7) Inability to support web browser delivery and interface.

\subsection{WORK MANAGEMENT}

The current Work Management environment provides users with the ability to identify work, plan jobs, conduct work, record results, and document completion. The current Work Management configuration was evaluated and rated as an alternative. Below describes the AS-IS environment.

The Job Control System (JCS) provides support for work management functions by providing information on installed equipment, identifying preventative and corrective maintenance tasks, work package development and status tracking. The JCS also provides support for plan of the day/week scheduling, lock and tag requirements and task completion documentation. The JCS is administered centrally, but implemented independently for each major facility, resulting in 25 separate instances. 
JCS is a custom application which was built using the Advanced Revelation programming and database development products.

\subsubsection{Business Drivers for Change}

1) JCS uses outdated technology that is becoming increasingly more difficult to support.

2) Lack of integration in current systems does not support the Work Management organizations or the IRM strategic goal of a single point of entry.

\subsubsection{Pros}

Below are the Pros for the current Work Management environment as an alternative.

1) JCS has an internal scheduling module and can produce schedules used for daily and weekly planning.

2) JCS is well known and accepted by the users, as it has been the site work management system since $1989^{\circ}$.

3) JCS implementation costs have already been incurred and maintenance costs are low.

\subsubsection{Cons}

Below are the Cons for the current Work Management environment as an alternative.

1) JCS is dependent on continued support of old technology, specifically DOS and Advanced Revelation. With fewer applications using this technology, support will be increasingly diminished.

2) The current system and technology does not support the CHG mission, which extends beyond 2034.

3) JCS does not provide the ability to allocate resources such as materials and/or labor to the job.

4) There are no external interfaces with Finance, Human Resources, P3 or Material Management systems.

\subsection{Business Management}

Business Management functions include Action Tracking, Accounting, Time Recording, Payroll, Contracts, Procurement, Inventory, Human Resource Management and Training.

The current systems supporting business management is the Business Management System (BMS), which is comprised of Finance, Human Resources Information System (HRIS), Time Information System (TIS), Supply Management and Action Tracking modules. Finance includes General Ledger and General Finance. HRIS includes Human Resources, Training and Payroll. Supply Management includes Contracts, Purchasing, Inventory and Accounts Payable. The remainder of this document will refer to Supply Management as Material Management, which is the standard industry term. Action Tracking includes General Use Action Tracking, Deficiency Tracking and Employee Suggestions.

The current time recording system is TIS, which is a custom built application using a Visual Basic front-end with a MS SQL Server database engine. An alternative to TIS was evaluated, based on existing and additional requirements that $\mathrm{CHG}$ had identified. It became readily 
apparent that TIS meets CHG's requirements for time recording more effectively than the Commercial-Off-The-Shelf (COTS) available software. Further discussion of an alternative for TIS is not warranted at this time, however, the ratings of TIS and PeoplseSoft Time and Labor module can be found in Appendix A.

The current Business Management configuration of Material Management and Action Tracking were evaluated and rated as an alternative. Below describes the AS-IS environment.

The Contracts, Purchasing, Inventory, Accounts Payable, General Use Action Tracking, Deficiency Tracking and Employee Suggestion Program functions are currently utilizing Indus International's PassPort software. Employee Suggestion also utilizes a custom web interface.

Material Management business functions consist of Contracts, Procurement, Inventory and Accounts Payable with the software to support them. The COTS vendors generally group this software because of the tight interaction between purchasing, receiving and managing the purchased equipment and the paying of the vendors for services rendered.

For purposes of this study, the Inventory focus has been on CHG's internal needs, not the entire site's needs. The needs of CHG are the end use of inventory, which is to effectively manage the equipment in place in the field, purchasing and receiving parts for repairs and/or installations, staging of the parts for work to be performed and the removal and disposition of equipment.

Action Tracking encompasses three areas with common and unique business functions. The three areas are Deficiency Tracking, Employee Suggestions and General Use Action Tracking. Deficiency Tracking and Employee Suggestions are the two areas that have unique business functions and requirements. The General Use Action Tracking contain the common functions and requirements for all three areas, but can be used for tracking general actions in any business area.

PassPort is a COTS product using a Visual Basic front-end with an Oracle database engine.

\subsubsection{Business Drivers for Change}

CHG is satisfied with the current PeopleSoft products that support the business areas of General Ledger, General Finance, Human Resources, Payroll and Training, therefore, alternatives for these areas were not investigated. However, over the long term, an implementation separate from PHMC is recommended.

The following are business drivers for change in regard to the remaining business management functions.

1) Originally a major factor in selecting PassPort as an integrated solution was the intent to use PassPort for Work Management. Neither Fluor Hanford, Inc. (FH) or CHG currently have plans to expand the use of PassPort. The goal to have a minimum set of commercial products brings into question the continued use of PassPort. 
2) Shared environment with other prime contractors, constrains the ability to control systems, data or processes.

\subsubsection{PassPort Material Management}

The current Material Management software is a COTS solution called PassPort from Indus International, which was implemented into production on October 1, 1998. The software consists of Contracts, Purchasing, Inventory and Accounts Payable modules. The PassPort delivered product had to be customized prior to implementation, particularly in the Contracts and Accounts Payable areas. The current system utilizes a Finance Integration product from PassPort to interact with PeopleSoft Finance.

The Contracts and Purchasing modules are used by $\mathrm{CHG}$ on a day-to-day basis for procurement of materials and services.

PassPort's Inventory module has been implemented to focus on warehouse management functions and storage of convenient supplies and/or materials, functions that are performed by DynCorp Tri-Cities Services, Inc. as a supplier. The needs of CHG extend beyond standard warehouse functions, down to the lower level of staging materials for work in the field. The majority of CHG material purchases are direct purchases, not as a replenishment of inventory. Inventory evaluations were based solely on CHG's requirements and did not address any site needs.

Currently, FH is managing the day-to-day Accounts Payable functions in regard to using PassPort. Beginning October 2000, CHG will be using PassPort's Accounts Payable module to pay vendors, reimburse non-employee expenses and to process accruals in a shared environment.

\subsubsection{Pros}

Below are the Pros for the current Material Management environment as an alternative.

1) Implementation costs have already been incurred.

2) System and data are known and understood by users.

3) The CHG personnel using the Contracts and Purchasing modules, from an end-user standpoint, say the product functions well for them.

\subsubsection{Cons}

Below are the Cons for the current Material Management environment as an alternative.

1) Various users of the PassPort product modules state that something may work well today and then after a patch or upgrade is applied, the feature no longer works. The vendor appears to lack adequate testing prior to production releases.

2) The overall vendor responsiveness and support is inadequate.

3) Because $\mathrm{CHG}$ operates in a shared environment with $\mathrm{FH}$ requesting system changes impacts both contractors, requiring major coordination efforts and sometimes impossible to make changes in business processes.

4) Software is technically complex and expensive to maintain, requiring major analysis prior to modification. 
5) Vendor support is generally needed to make a modification to the software, due to the complexity of the software, which is neither cost effective nor timely.

6) Product architecture is too technically integrated and not modular.

7) The Finance Integration product has greatly extended the timeline for version upgrades across the PassPort and PeopleSoft finance products.

8) Accounts Payable is not within the same product suite as other finance modules.

9) PassPort is more labor intensive to use than other applications, when compared to applications used in the past or evaluated as a potential replacement.

\subsubsection{PassPort Action Tracking}

The current Action Tracking software is a COTS solution from PassPort, which is integrated with the Material Management suite. PassPort is the current application being used for Deficiency Tracking, and some of the Employee Suggestion Program functionality. A portion of the Employee Suggestion module uses a web interface to meet functions not provided by PassPort. PassPort is not used for General Use Action Tracking, leaving each organization to determine how to manage and track actions.

\subsubsection{Pros}

Below are the Pros for the current Action Tracking environment as an alternative.

1) Implementation costs have already been incurred.

2) System and data are known and understood by users.

\subsubsection{Cons}

Below are the Cons for the current Action Tracking environment as an alternative.

1) Because PassPort does not allow efficient or cost-effective modification to the data or functionality, it has become a constraint for meeting the data input, processing and reporting functions for Action Tracking.

2) Does not provide the functionality, nor is it cost-effective to be used for General Use Action Tracking, which can span multiple business areas.

3) Does not provide adequate functionality for the Employee Suggestion Program, so it must be supplemented by the web add-on to meet the business need.

4) PassPort is more labor intensive to use than other applications when compared to applications used in the past or evaluated as a potential replacement. 


\subsection{ALTERNATIVE PRODUCT DESCRIPTIONS}

This section presents the product descriptions that were evaluated or considered as an alternative to the current systems environment.

\subsection{PROJECT CONTROLS}

This section describes the alternative product descriptions for the Project Controls environment.

\subsubsection{MicroFusion Millennium and wInsight}

The commercial product of Integrated Management Concept's MicroFusion Millennium and the $\mathrm{C} / \mathrm{S}$ Solutions' wInsight product were installed and evaluated. Millennium provides a common repository for the resource pricing/cost estimating information, project performance and earned value analysis. wInsight is a reporting product that compliments Millennium with a comprehensive set of performance reports providing drill down capabilities.

Millennium software uses MS Access as a front-end with an Oracle or MS SQL Server as the database engine. Millennium's user interface is tree based similar to Windows Explorer with the ability to define custom user views. The wInsight product is Windows-based and used as a reporting tool by extracting information from the Millennium database engine.

\subsubsection{Pros}

1) Vendor supplied integration of P3, Millennium, and wInsight products.

2) Supports industry standard project management and earned value methodologies.

3) Supports weekly performance reporting.

4) Vendor delivered evaluation software was easy to install.

5) Vendor technical support through the evaluation process was good.

6) System can handle current project lifecycle data.

7) Vendor provides a robust product for storing cost and pricing data.

8) Appears to support sophisticated rates, overhead, and burdens build-up process.

9) The wInsight component provides flexible performance reporting capabilities.

10) Provides web browser delivery and interface.

\subsubsection{Cons}

1) Text fields are limited to 250 characters and cannot hold paragraph formatting. Conversion from the CEIS system narrative will require significant restructure and summarization.

2) The Millinium and wInsight products require data to be validated upon entry, which may require significant data validation and possible restructuring in $\mathrm{P} 3$ prior to implementation.

3) Product can only handle five charge codes per WBS element. This is limiting, but better than other products. 


\subsubsection{Micro-Frame Program Manager}

Micro-Frame Program Manager (MPM) from Business Engine, Inc. was installed and evaluated in Spring 2000 by CHG, independent from the BSP Project. The results were used for the purposes of this analysis.

MPM is a work breakdown structure based system used for integrating proposals, cost estimating, and program management. It has various modules that allow for proposals and cost estimating, "what-if" analysis, baseline planning/estimates to complete, performance measurement, earned value reporting, and subcontract management.

The MPM product is Windows-based product using a Btrieve database engine.

\subsubsection{Pros}

1) Supports industry standard project management and earned value methodologies.

2) Supports weekly performance reporting.

3) Vendor delivered evaluation software was easy to install.

4) Vendor technical support through the evaluation process was good.

5) Per the vendor, MPM meets government proposal/reporting requirements.

\subsubsection{Cons}

1) P3 interfaces are done through the use of flat files, not a direct linkage.

2) Cannot handle the current project lifecycle data, due to large file sizes.

3) Software is not supported by vendor for future upgrades.

4) Utilizes Betrieve database engine which is not current technology and not as reliable as Oracle or MS SQL Server.

5) Product can only handle one charge code per WBS element.

6) No web interface.

\subsubsection{Other Alternatives}

PRISM from Applied Research \& Engineering Sciences, COBRA from Welcom, and Dekker TRAKKER from Dekker, Ltd. were evaluated in early 2000 separate from the BSP Project. The products were evaluated by various organizations independent of each other. The evaluations and related documentation are available in the BSP Project files. The primary reason these alternatives were not considered was their lack of a $\mathrm{P} 3$ interface.

\subsection{WORK MANAGEMENT}

This section describes the alternative product descriptions for the Work Management environment.

\subsubsection{MAXIMO Work Management}

MAXIMO from Project Software and Development, Inc. is an integrated suite of modules that support the equipment maintenance function. In addition to equipment maintenance, MAXIMO includes functionality for inventory, procurement, lock out/tag out, scheduling, as well as 
integration to external systems such as PeopleSoft Financials. MAXIMO is designed to allow local tailoring to adjust for customer specific needs. MAXIMO has workflow capabilities that can be designed to support work management processes.

MAXIMO is a Windows-based product, using an Oracle or MS SQL Server database engine.

\subsubsection{Pros}

1) MAXIMO is very flexible and can be easily tailored to $\mathrm{CHG}$ business processes.

2) Vendor supplied integration with $P 3$ available.

3) Vendor supplied integration with PeopleSoft available.

4) MAXIMO provides additional functionality in other work areas not currently served by JCS, such as warehouse and inventory management, procurement, time reporting.

5) MAXIMO is very scalable and can be implemented with varying levels of functionality on both the Oracle and MS SQL Server database platforms.

6) The vendor has a good reputation for delivering a quality product.

7) Customer Support is available by telephone during business hours seven days a week, per the maintenance agreement. Online web support provides access to documented problems and resolutions, as well as the ability to email problems to the vendor 24 hours a day.

8) MAXIMO's equipment history tracking efficiently meets DOE requirements.

9) Resources such as material and labor, used to perform work can be planned and financially accounted for.

10) MAXIMO can incorporate safety planning such as lock-out/tag-out, hazards, precautions and permits in the work package.

11) Preventative Maintenance can be triggered by meter readings and inspection results.

12) A single jọ plan can be referenced by multiple Work Orders.

13) Purchasing and Inventory integration within MAXIMO or in conjunction with PeopleSoft allows material lead times to be incorporated in the schedule.

14) Business processes can be modeled to match CHG workflows including multi-level approvals, enforced process steps, routing, and tracking.

15) MAXIMO is currently implemented on site for DynCorp and Pacific Northwest National Laboratory.

\subsubsection{Cons}

1) MAXIMO is relatively expensive compared to other alternatives.

2) Tailoring MAXIMO will require significant upfront planning and design to best utilize the product.

3) MAXIMO is not the primary system used on site for Work Management.

\subsubsection{CHAMPS Work Management}

CHAMPS from CHAMPS Software, Inc. is an integrated suite of modules that support the equipment maintenance function. In addition to equipment maintenance, CHAMPS provides modules for inventory, procurement, lock out/tag out, scheduling, work force management, 
accounts payable, and hazardous materials. CHAMPS is designed to allow local tailoring to adjust for customer specific needs.

CHAMPS software is a Windows-based product, using an Oracle or MS SQL Server database engine.

\subsubsection{Pros}

1) CHAMPS is very flexible and can be easily tailored to $\mathrm{CHG}$ business processes.

2) CHAMPS provides additional functionality in other work areas not currently served by JCS, such as warehouse and inventory management, procurement, lock-out/tag-out, accounts payable, and time reporting.

3) CHAMPS is very scalable and can be implemented with varying levels of functionality on both the Oracle and MS SQL Server and database platforms.

4) CHAMPS offers site licensing agreements that would allow $\mathrm{CHG}$ to share software costs with other contractors who are interested in the solution.

5) The vendor has a good reputation for delivering a quality product.

6) CHAMPS equipment history tracking efficiently meets DOE requirements.

7) Resources such as material and labor, used to perform work can be planned and financially accounted for.

8) Purchasing and Inventory integration within CHAMPS allows material lead times to be incorporated in the schedule.

9) CHAMPS includes sophisticated lock-out/tag-out functionality.

\subsubsection{Cons}

1) Tailoring CHAMPS will require significant upfront planning and design to best utilize the product.

2) Vendor does not provide integration with $P 3$.

3) Vendor does not provide integration with PeopleSoft.

4) Customer Support is available by telephone between $5 \mathrm{AM}$ and $3 \mathrm{PM}$ on the west coast five days a week per the maintenance agreement, additional support would be at an added cost.

5) CHAMPS is not the primary system used on site for Work Management.

\subsubsection{Job Control System Rewrite}

In Spring 2000, the JCS site administration team proposed rewriting JCS in newer technology recognizing the current technology could not be sustained long term. This proposed alternative would provide the current functionality of JCS, plus some additionally functionality inherent to Windows applications, with enhanced features planned for future releases.

The JCS Rewrite will use a Visual Basic front-end and MS SQL Server as the database engine. The rewrite has recently started with the first release expected by end of FYO1.

\subsubsection{Pros}

1) Custom development allows a very tailored product to be developed. 
2) Users are familiar with JCS processes and functions.

3) Site standard software will be used in the development of JCS.

4) The current JCS scheduling feature will be replaced with a P3 interface.

5) The Windows environment allows electronic document linking and application launching from within the application.

6) The JCS Rewrite equipment history tracking is expected to meet DOE requirements.

\subsubsection{Cons}

1) The ratings for this alternative are based on conceptual functionality that may or may not be incorporated in a delivered product.

2) The initial release of JCS will not incorporate interfaces to financial or material management systems.

3) Does not support the CHG IRM principle of using COTS products where feasible.

\subsection{Business MANAGEMENT}

This section describes the alternative product descriptions for the Business Management environment.

\subsubsection{PeopleSoft Material Management}

PeopleSoft Material Management is an integrated suite of modules consisting of Purchasing, Inventory, and Accounts Payable. The Purchasing module encompasses the Contracts function. The Material Management modules are sold separately and can be implemented as a total integrated suite or grouped as required.

PeopleSoft is a $\mathrm{C}++$ front-end based product, using an Oracle or MS SQL Server database engine.

\subsubsection{Pros}

1) Same product as other financial modules General Ledger and Project Costing, which allows automatic updates to offsetting accounting entries and corresponding accounts.

2) PeopleSoft has proven technology and architecture.

3) Vendor has a good reputation for delivering a quality product.

4) Customer Support is available by telephone during business hours seven days a week, per the maintenance agreement. Online web support provides access to documented problems and resolutions, as well as the ability to email problems to the vendor 24 hours a day.

5) Accessibility to ad-hoc reporting using Crystal report writer, which is a standard tool of choice.

6) Utilized at four other DOE sites (Rocky Flats, Lawrence Berkley, Brookhaven, and Allied Signal in KC).

7) PeopleSoft has been successfully implemented at numerous DOE sites, where other Enterprise Resource Planning (ERP) type solutions have failed.

8) PeopleSoft is designed to allow local tailoring to meet customer specific needs. 
9) PeopleSoft combines Contracts into the Purchasing module, which minimizes cross training in the buyer organization.

\subsubsection{Cons}

1) Vendor sells modules separately and cost is relatively expensive.

\subsubsection{CHAMPS Material Management}

CHAMPS from CHAMPS Software, Inc. is a suite of modules that support the Material Management functions and integrates with CHAMPS Work Management modules. CHAMPS Material Management contains Purchasing, Inventory and Accounts Payable modules. The Purchasing module includes the Contracts function. CHAMPS has an Accounts Payable module which contains a Chart of Accounts, but it does not formulate or pass debit and credit detail transactions or journal entries to a General Ledger or General Finance system.

CHAMPS software is a Windows-based product, using an Oracle or MS SQL Server database engine.

\subsubsection{Pros}

1) CHAMPS is designed to allow local tailoring to meet customer specific needs.

2) CHAMPS combines Contracts into the Purchasing module, which minimizes crosstraining in buyer organization.

\subsubsection{Cons}

1) Not the same product suite as other finance applications, which introduces potential issues with data mapping for interface definitions.

2) Inability to track the levels of inspection required for receipt of goods.

3) Not as robust of a product as MAXIMO or PeopleSoft Material Management.

4) Customer Support is available by telephone between $5 \mathrm{AM}$ and $3 \mathrm{PM}$ on the west coast five days a week per the maintenance agreement, additional support would be at an added cost.

\subsubsection{MAXIMO Material Management}

MAXIMO Material Management from Project Software and Development, Inc. is a suite of modules that integrate with MAXIMO's Work Management modules. MAXIMO Material Management suite contains Purchasing and Inventory. The Purchasing module includes the Contracts function. MAXIMO does not contain an Accounts Payable module, but does provide a "MAXIMO for PeopleSoft" and "MAXIMO for ERP" that provides integration options with financial applications.

MAXIMO is a Windows-based product, using an Oracle or MS SQL Server database engine.

\subsubsection{Pros}

1) All modules are included in MAXIMO purchase price.

2) MAXIMO is designed to allow local tailoring to meet customer specific needs. 
3) MAXIMO combines Contracts into the Purchasing module, which minimizes crosstraining in the buyer organization.

4) Customer Support is available by telephone during business hours seven days a week, per the maintenance agreement. Online web support provides access to documented problems and resolutions, as well as the ability to email problems to the vendor 24 hours a day.

\subsubsection{Cons}

1) Product cannot standalone as a Material Management solution, but needs an Integration product to interface with PeopleSoft Finance.

2) Integration product is available only in an Oracle environment, which is an expensive environment and limits implementation infrastructure options.

3) Integration products extend upgrade timelines.

\subsubsection{MAXIMO General Use Action Tracking}

MAXIMO from Project Software and Development, Inc. was evaluated as an Action Tracking application. While MAXIMO does not come with a base Action Tracking module, MAXIMO has the flexibility to define new modules or clone existing modules. MAXIMO demonstrated the ability to clone the work management module and modify it to become an action tracking module. This module could then be tailored to encompass all Action Tracking business areas and functions in one module, with unique identifiers allowing them to function independent of the other business areas.

MAXIMO is a Windows-based product, using an Oracle or MS SQL Server database engine.

\subsubsection{Pros}

1) Work Management and Action Tracking are part of the same application, therefore, it more easily integrates business processes.

2) MAXIMO is integrated with work management, which enhances the corrective action capability.

3) MAXIMO has the flexibility to be tailored to meet user needs and changing business drivers.

4) Unique business functions can be met while making use of the common elements which promotes a single point of input.

5) All modules are included in the MAXIMO purchase price.

6) The vendor supports most enhancements/modification without additional cost.

7) Customer Support is available by telephone during business hours seven days a week, per the maintenance agreement. Online web support provides access to documented problems and resolutions, as well as the ability to email problems to the vendor 24 hours a day.

8) The vendor has a good reputation for delivering a quality product. 


\subsubsection{Cons}

1) The design and development of the new modules will impact implementation cost and schedule.

2) Unless MAXIMO is purchased for Work Management capabilities, the cost of MAXIMO just for Action Tracking is high.

\subsubsection{Hanford Action Tracking System Rewrite}

The Hanford Action Tracking System (HATS) Rewrite alternative is based on a system that was retired when PassPort was implemented in October 1998. Multiple requests from the users prompted re-examination of rewriting the application as an alternative. This system would be a custom application to meet specific user needs for each of the action tracking systems and is not limited by user licenses.

The HATS rewrite estimate was based on a Visual Basic front-end, using a MS SQL server database engine.

\subsubsection{Pros}

1) Knowledge and documentation exist from retired system.

2) Adheres to the procedures for deficiency tracking.

3) Customized for users based on previously and currently defined requirements.

4) Ability to modify as needed to meet changing business drivers/functions.

\subsubsection{Cons}

1) Availability would be delayed due to the time required to redevelop the system.

2) Initial cost would be significantly higher than COTS because it would be a custom built and maintained system.

3) Does not support the CHG IRM principle of using COTS products where feasible.

4) Application would not be integrated with work management, which does not support integrated business functions having a single point of input.

\subsubsection{CATSweb Action Tracking}

CATSweb from AssurX.com, Inc. was evaluated. CATSweb has the capability to automate the documentation of the deficiencies through a web form, which is currently a manual process. The centralized corrective action group performs the validation, tracking and monitoring of the deficiency and associated corrective actions. The application uses colors throughout the application as indicators to easily identify various user functions and status of actions.

CATSweb is a COTS product with a web front-end and a MS SQL Server database engine.

\subsubsection{Pros}

1) Easily accessed through the web front-end.

2) Vendor appears to be responsive to customer's requests and needs. 
3) Meets most requirements without significant tailoring. It has built in system administration capabilities to tailor the application to assist in meeting specific business needs.

\subsubsection{Cons}

1) Data fields are limited to 40 fields per form on the initial application, but additional fields can be added if appropriate under the maintenance contract.

2) Licensing is costly for General Use Action Tracking and Employee Suggestion Program.

\subsubsection{Employee Suggestion Web Development}

The Employee Suggestion Program currently has partial functionality on the web and was evaluated as a potential alternative. This alternative would require additional development to include the functions currently available in PassPort and the defined requirements used for this analysis. The web application could be modified to encompass General Use and Employee Suggestion functions. An add-on tool would be required to meet the reporting requirements.

The Web Development would be a custom application with a web front-end and a MS SQL Server database engine.

\subsubsection{Pros}

1) Web front-end provides ease of access and usage.

2) Customized to the user's specific business needs.

3) Independent of other systems.

4) Unlimited user access.

\subsubsection{Cons}

1) Initial cost is high due to custom development.

2) Reporting would need an add on tool, otherwise reporting would have limited functionality.

3) Would not meet the Deficiency Tracking without major enhancements, which were not part of the analysis or estimate.

4) Does not support the CHG IRM principle of using COTS products where feasible.

\subsubsection{Other Action Tracking Alternatives}

The Air Force Workflow Management System was also evaluated, but did not meet requirements sufficiently to be considered a viable alternative for Deficiency Tracking and Employee Suggestion. The Air Force Workflow Management System, Version 1.0 met most of the General Use Action Tracking requirements. However, it was eliminated as an alternative, because it was in a development state and not a released product.

There were several Deficiency Tracking applications used at various DOE sites that had been evaluated by CHG Quality Assurance (QA) personnel. The applications were determined by QA personnel not to be adequate to be considered as an alternative for Deficiency Tracking. 


\subsection{SELECTION DESCRIPTION}

This section includes the Score Chart Summaries, Product and Vendor Cost Summaries and the Recommended Alternatives.

\subsection{SCORE CHART SUMMARY}

These score charts are a summarized version of all the requirements that are detailed in Appendix A.

\subsubsection{Project Controls}

\begin{tabular}{|l|c|c|c|}
\hline \multicolumn{1}{|c|}{ Requirement } & $\begin{array}{c}\text { Millennium } \\
\text { Score }\end{array}$ & $\begin{array}{c}\text { MPM } \\
\text { Score }\end{array}$ & $\begin{array}{c}\text { Current PC } \\
\text { Score }\end{array}$ \\
\hline Common & 343 & 287 & 180 \\
\hline General & 364 & 384 & 405 \\
\hline Estimating & 312 & 350 & 226 \\
\hline Planning & 470 & 484 & 406 \\
\hline Scheduling & 90 & 120 & 90 \\
\hline Reporting & 1047 & 1073 & 768 \\
\hline Technical & 807 & 564 & 673 \\
\hline Totals & $\mathbf{3 4 3 3}$ & $\mathbf{3 2 6 2}$ & $\mathbf{2 7 4 8}$ \\
\hline Evaluated Percentage & $\mathbf{8 0}$ & $\mathbf{7 6}$ & $\mathbf{6 4}$ \\
\hline Functional Ranking & $\mathbf{1}$ & $\mathbf{2}$ & $\mathbf{3}$ \\
\hline
\end{tabular}

\subsection{WORK MANAGEMENT}

\begin{tabular}{|l|c|c|c|c|}
\hline \multicolumn{1}{|c|}{ Requirement } & $\begin{array}{c}\text { MAXIMO } \\
\text { Score }\end{array}$ & $\begin{array}{c}\text { JCS Rewrite } \\
\text { Score }\end{array}$ & $\begin{array}{c}\text { CHAMPS } \\
\text { Score }\end{array}$ & $\begin{array}{c}\text { JCS } \\
\text { Score }\end{array}$ \\
\hline Common & 371 & 298 & 353 & 237 \\
\hline Planning & 651 & 671 & 717 & 483 \\
\hline Scheduling & 216 & 194 & 115 & 132 \\
\hline Work Performance & 196 & 186 & 216 & 162 \\
\hline Work Control/Admin & $\mathbf{7 3 0}$ & 747 & 659 & 615 \\
\hline Technical & 949 & 899 & 927 & 669 \\
\hline Totals & $\mathbf{3 1 1 3}$ & $\mathbf{2 9 9 5}$ & $\mathbf{2 9 8 7}$ & $\mathbf{2 2 9 8}$ \\
\hline Evaluated Percentage & $\mathbf{9 2}$ & $\mathbf{8 9}$ & $\mathbf{8 9}$ & $\mathbf{6 8}$ \\
\hline Functional Ranking & $\mathbf{1}$ & $\mathbf{2}$ & $\mathbf{3}$ & $\mathbf{4}$ \\
\hline
\end{tabular}




\subsubsection{Business Management}

\begin{tabular}{|l|c|c|c|c|}
\hline \multicolumn{5}{|c|}{ Material Management Score Summary } \\
\hline \multicolumn{1}{|c|}{ Requirement } & $\begin{array}{c}\text { PeopleSoft } \\
\text { Score }\end{array}$ & $\begin{array}{c}\text { CHAMPS } \\
\text { Score }\end{array}$ & $\begin{array}{c}\text { PassPort } \\
\text { Score }\end{array}$ & $\begin{array}{c}\text { MAXIMO } \\
\text { Score }\end{array}$ \\
\hline Common & $\mathbf{3 7 2}$ & 353 & 171 & 371 \\
\hline Accounts Payable & $\mathbf{8 6 8}$ & 750 & 721 & 0 \\
\hline Purchasing and Service Orders & 1043 & 900 & 926 & 999 \\
\hline Material Purchasing & $\mathbf{3 1 9}$ & 261 & 263 & 311 \\
\hline Inventory & $\mathbf{4 5 6}$ & $\mathbf{4 4 6}$ & $\mathbf{3 1 4}$ & 456 \\
\hline Technical & $\mathbf{9 8 4}$ & $\mathbf{9 2 7}$ & 767 & 949 \\
\hline Totals & $\mathbf{4 2 9 9}$ & $\mathbf{3 6 3 7}$ & $\mathbf{3 1 3 2}$ & $\mathbf{3 0 8 6}$ \\
\hline Evaluated Percentage & $\mathbf{8 8}$ & $\mathbf{7 5}$ & $\mathbf{6 4}$ & $\mathbf{6 3}$ \\
\hline Functional Ranking & $\mathbf{1}$ & $\mathbf{2}$ & $\mathbf{3}$ & $\mathbf{4}$ \\
\hline
\end{tabular}

\begin{tabular}{|l|c|c|c|c|c|}
\hline \multicolumn{7}{|c|}{ Action Tracking Score Summary } \\
\hline Requirement & $\begin{array}{c}\text { MAXIMO } \\
\text { Score }\end{array}$ & $\begin{array}{c}\text { HATS } \\
\text { Score }\end{array}$ & $\begin{array}{c}\text { PassPort } \\
\text { Score }\end{array}$ & $\begin{array}{c}\text { CATSweb } \\
\text { Score }\end{array}$ & $\begin{array}{c}\text { Employee } \\
\text { Suggestion } \\
\text { Web } \\
\text { Score }\end{array}$ \\
\hline Common & 371 & 353 & 171 & 245 & 299 \\
\hline General Use & 344 & 368 & 211 & 218 & 369 \\
\hline Deficiency & $\mathbf{3 2 4 8}$ & 3278 & 2341 & 2648 & 0 \\
\hline Employee Suggestions & 1573 & 0 & 1347 & 0 & 1676 \\
\hline Technical & $\mathbf{9 4 9}$ & 990 & 767 & $\mathbf{8 4 1}$ & 936 \\
\hline Totals & $\mathbf{6 4 8 5}$ & $\mathbf{4 9 8 9}$ & $\mathbf{4 8 3 7}$ & $\mathbf{3 9 5 2}$ & $\mathbf{3 2 8 0}$ \\
\hline Evaluated Percentage & $\mathbf{9 4}$ & $\mathbf{7 2}$ & $\mathbf{7 0}$ & $\mathbf{5 7}$ & $\mathbf{4 8}$ \\
\hline Functional Ranking & $\mathbf{1}$ & $\mathbf{2}$ & $\mathbf{3}$ & $\mathbf{4}$ & $\mathbf{5}$ \\
\hline
\end{tabular}

\subsection{PROdUCT AND VENDOR COST SUMmaRY}

The below costs are related to the cost of the products, an estimate of vendor support and product technical support costs. The costs do not address hardware costs or user licenses needed for items such as a database management system. The costs also do not include LMSI labor costs, except where custom development is an alternative. Many of the alternatives have options for an Oracle or MS SQL Server environment. User license costs can vary greatly depending on the environment. The focus of this study was to select the best product based on how well the product met the requirements, not to determine the platform that would be used. Should a 
project be developed based upon the recommendations provided, a platform environment will be determined and a cost estimate will be provided for implementation.

\subsubsection{Project Controls}

\section{MicroFusion Millennium and wInsight}

Millennium

118,140

Maintenance and Technical Support

35,442

Millennium Consulting (320 hours)

48,000

WInsight Consulting (80 hours)

12,000

P3 Connect and wInsight

60,640

Tools

40,952

Total \$315,174

Micro-Frame Program Manager

MPM (already incurred)

Maintenance and Technical Support

$\begin{array}{r}0 \\ 10,000 \\ 70,400 \\ 4,900 \\ \hline \mathbf{\$ 8 5 , 3 0 0}\end{array}$

\subsubsection{Work Management}

\section{MAXIMO}

MAXIMO Enterprise

271,300

Maintenance and Technical Support

54,800

Tools and Technical Support

50,034

Consulting (800 hours)

168,000

MAXIMO for Primavera and Technical Support

45,000

Workflow and Technical Support

29,600

Web Tools and Technical Support

4,683

Total $\lcm{\$ 623,417}$

\section{CHAMPS}

Maintenance Module

116,000

Maintenance and Technical Support

19,720

9,588

Tools \& Technical Support

108,000

Consulting (800 hours)

85,800

Develop P3 Interface

Total $\begin{array}{r}85,800 \\ \$ \$ 339,108\end{array}$




\section{JCS Rewrite (Hanford site cost, not CHG)}

$$
\text { Total } \$ 412,200
$$

\subsubsection{Business Management}

\section{PeopleSoft Material Management}

Account Payables

Purchasing

Inventory

Consulting (320 hours)

\begin{tabular}{rr}
171,500 \\
224,000 \\
224,000 \\
64,000 \\
\hline $\mathbf{\$ 4 5 9 , 5 0 0}$
\end{tabular}

MAXIMO Material Management and Action Tracking product costs are included in the MAXIMO Work Management product cost summary, which is section 4.2.2.

CHAMPS Material Management product costs are included in the CHAMPS Work Management product cost summary, which is section 4.2.2.

\section{HATS Rewrite}

HATS Development and Technical Support

698,630

Tools and Technical Support

Total

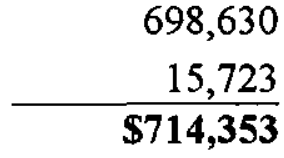

\section{CATSweb}

CATSweb software and licenses

321,995

Maintenance and Technical Support

48,299

Tools

Total

$\begin{array}{r}321,995 \\ 48,299 \\ 15,723 \\ \hline \mathbf{\$ 3 8 6 , 0 1 7}\end{array}$

\section{Employee Suggestion Web Development}

Development and Maintenance

165,550

Tools and Technical Support

Total
15723

$\$ 181,273$

\subsection{RECOMMENDED ALTERNATIVES}

This section describes the alternative that is recommended for each business area. 


\subsubsection{Project Controls}

A suite of commercial products referred to as the "Earned Value Pack" is recommended to meet the Project Controls requirements. The Earned Value Pack includes Primavera P3 for planning and scheduling, MicroFusion Millennium for pricing and cost management, and the $\mathrm{C} / \mathrm{S}$ Solutions' wInsight product for consolidating and reporting earned value management data. Millennium proved superior to other products due to the ability to support CHG project lifecycle and the $\mathrm{P} 3$ interface.

As with all COTS solutions that implement industry standard processes, companies must adopt the processes the products support. Although today's COTS products offer some flexibility in the implementation of business rules, they may require significant process change. Analysis of CHG's requirements for Project Controls indicate that a more streamlined and disciplined approach is needed to effectively use a COTS product. Many of these processes have been identified and are in a process improvement cycle around the current environment. The process improvements will need to be aligned with the strengths of the COTS solution.

\subsubsection{Work Management}

MAXIMO is recommended as the work management solution. MAXIMO offers products which integrate with P3 for scheduling information, and PeopleSoft for financial, human resources and procurement information.

\subsubsection{Business Management}

The PeopleSoft offerings for Procurement and Accounts Payable are recommended. It is recommended that $\mathrm{CHG}$ use the inventory module of MAXIMO. Procurement and Accounts Payable will work well with the other PeopleSoft components, whether in a shared or independent implementation, and will interface with MAXIMO as needed. For action tracking needs such as Deficiency Tracking, the recommended alternative is MAXIMO utilizing the capability to create a module that meets the requirements for this area. 


\subsection{APPENDIX A - SCORING CHART DETAILS}

Scoring chart characteristics:

Weight $=$ the importance assigned to the requirement.

- Mandatory $=10$

- Essential $=8$

- Desirable $=1$

Rank $=$ ability to fulfill requirement

- Did not meet requirement $=0$

- Partially met requirement with workaround $=1$

- Satisfactorily met requirement $=2$

- Efficiently met requirement $=3$

Score $=$ calculated score for the requirement $($ Score $=$ Weight $x$ Rank $)$

Evaluation percentage $=$ each alternative is formulated by (total of Scores/total of Weights) $\times 1$ 







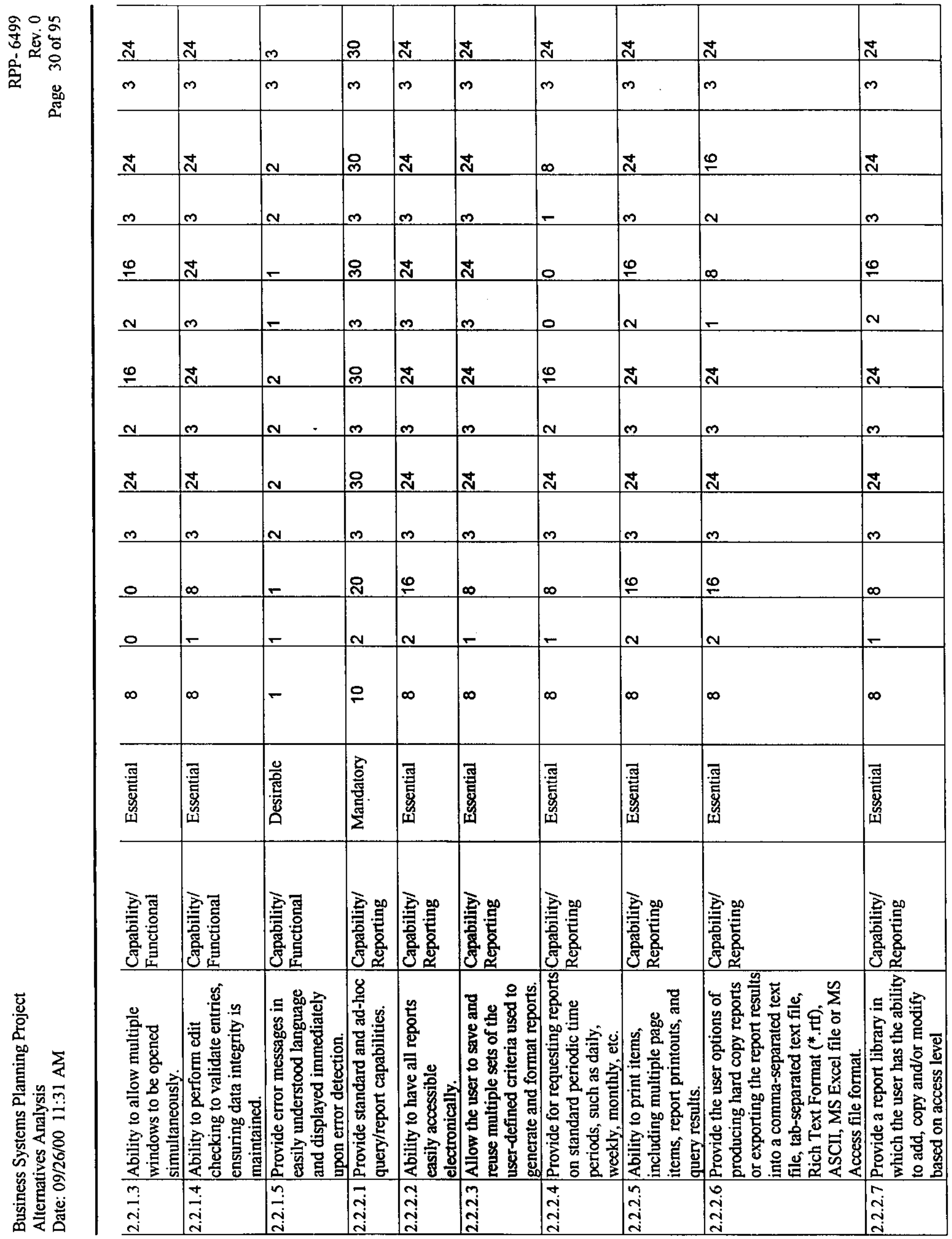




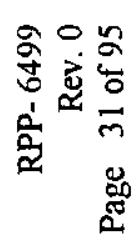

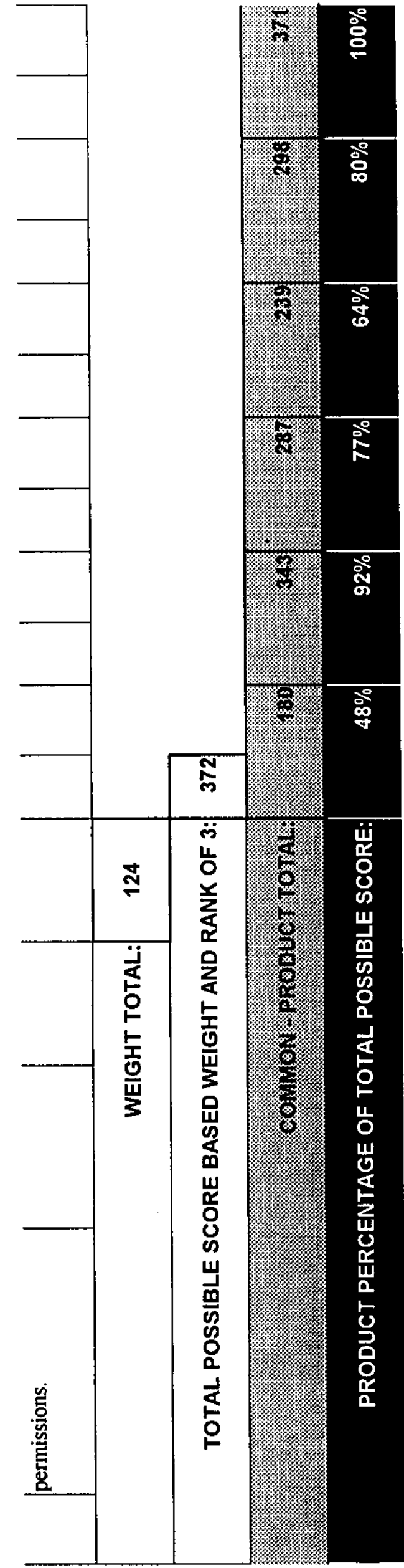




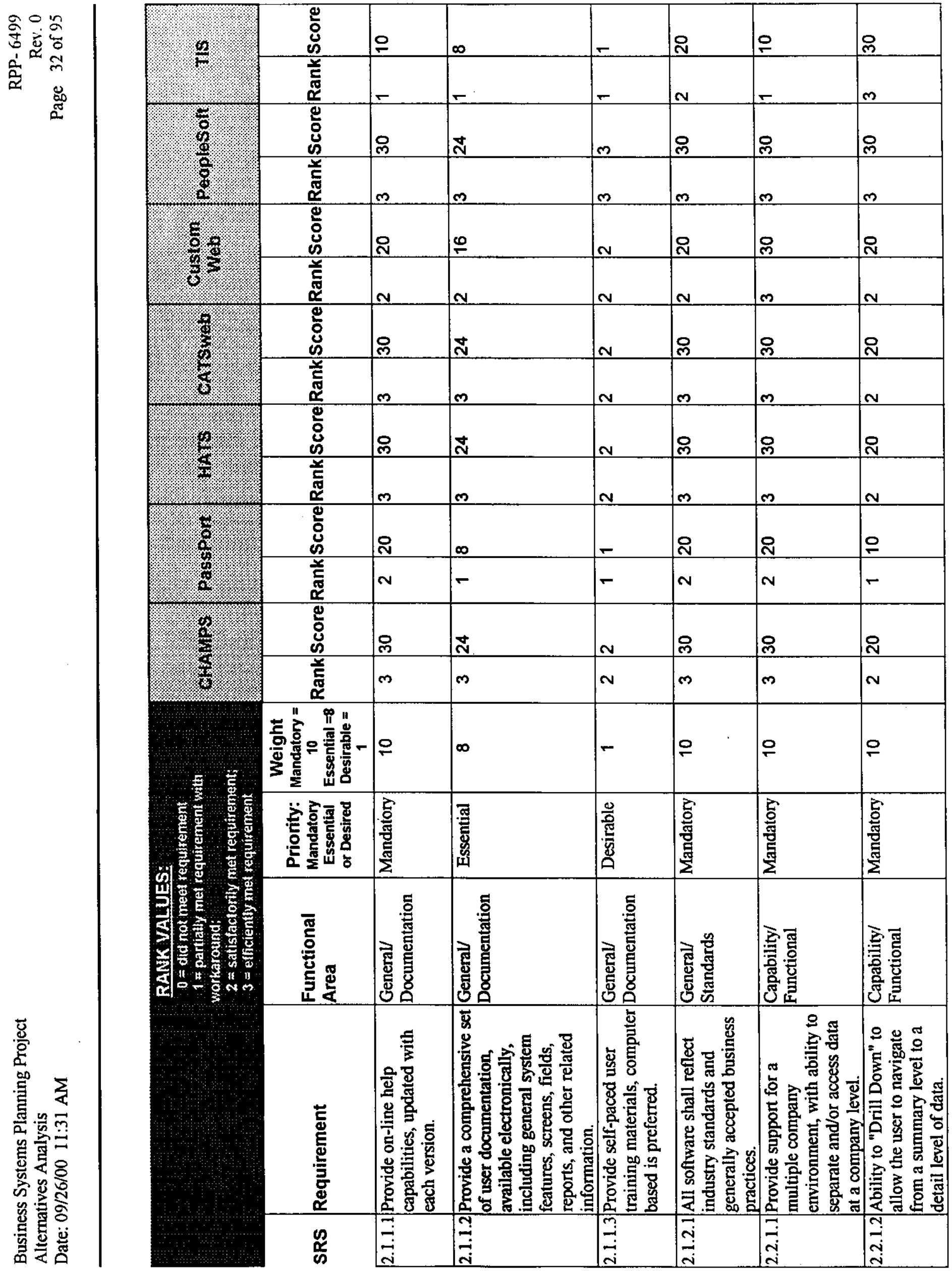




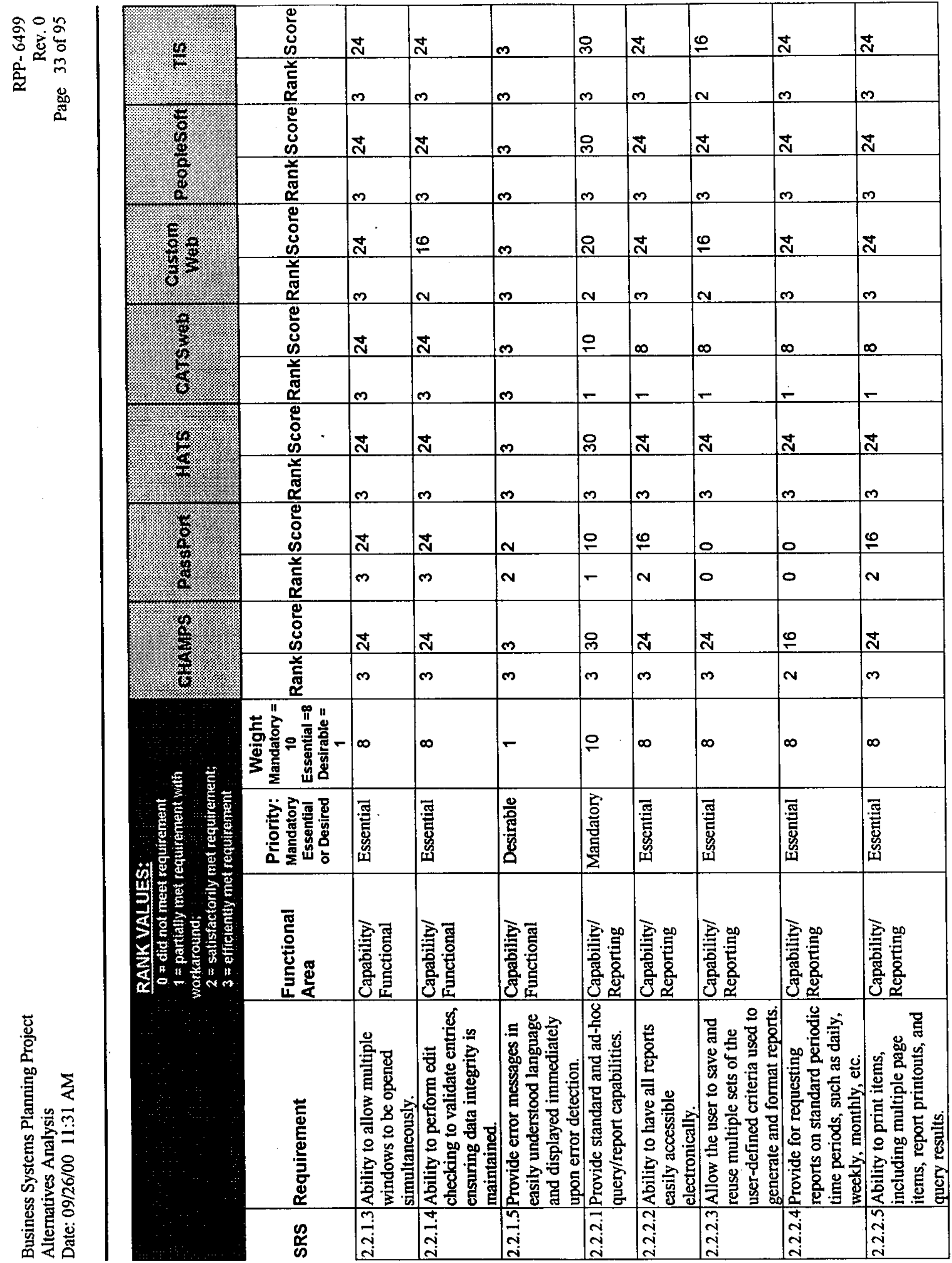




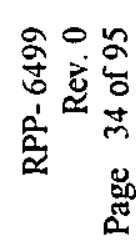

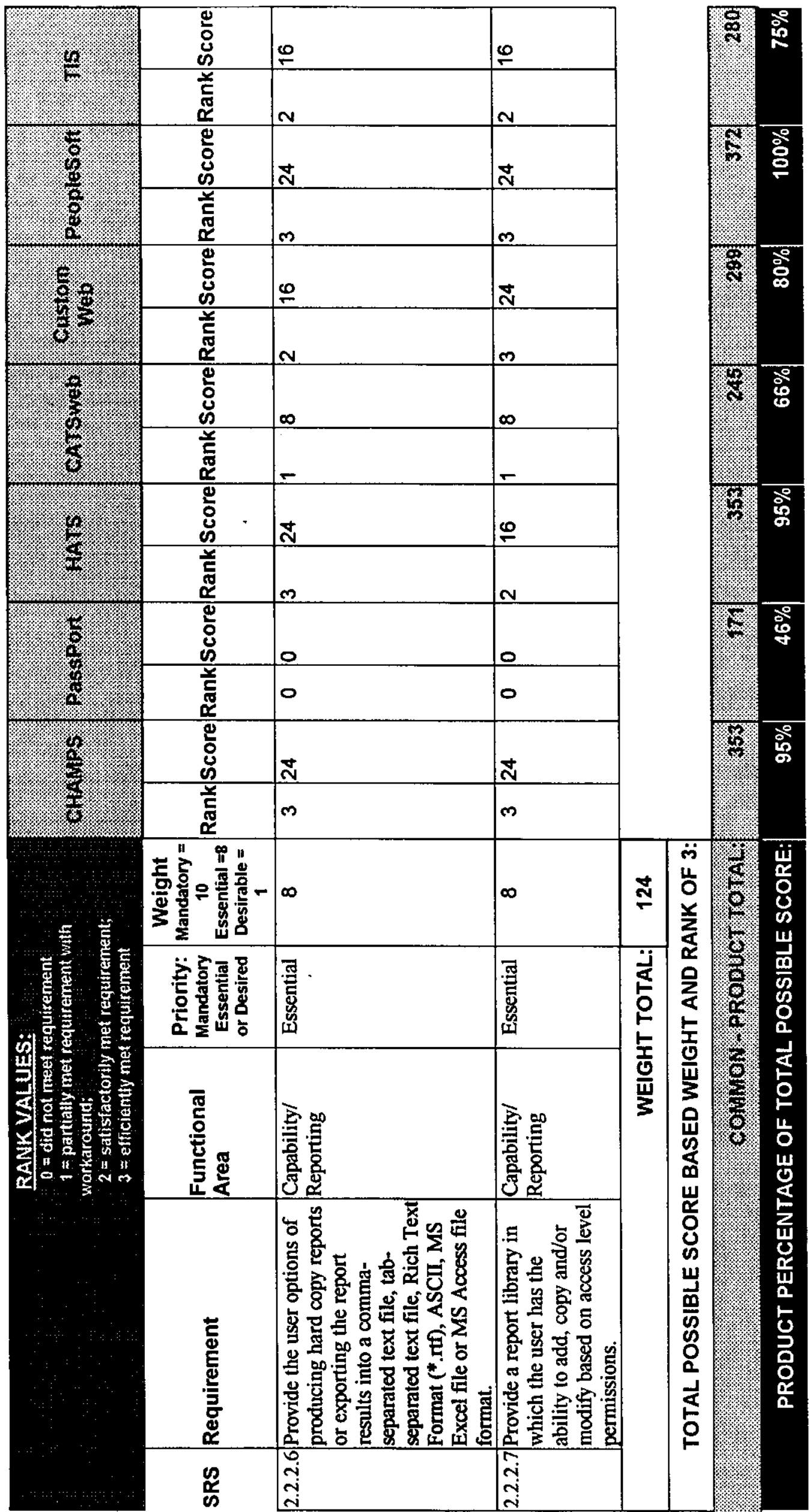




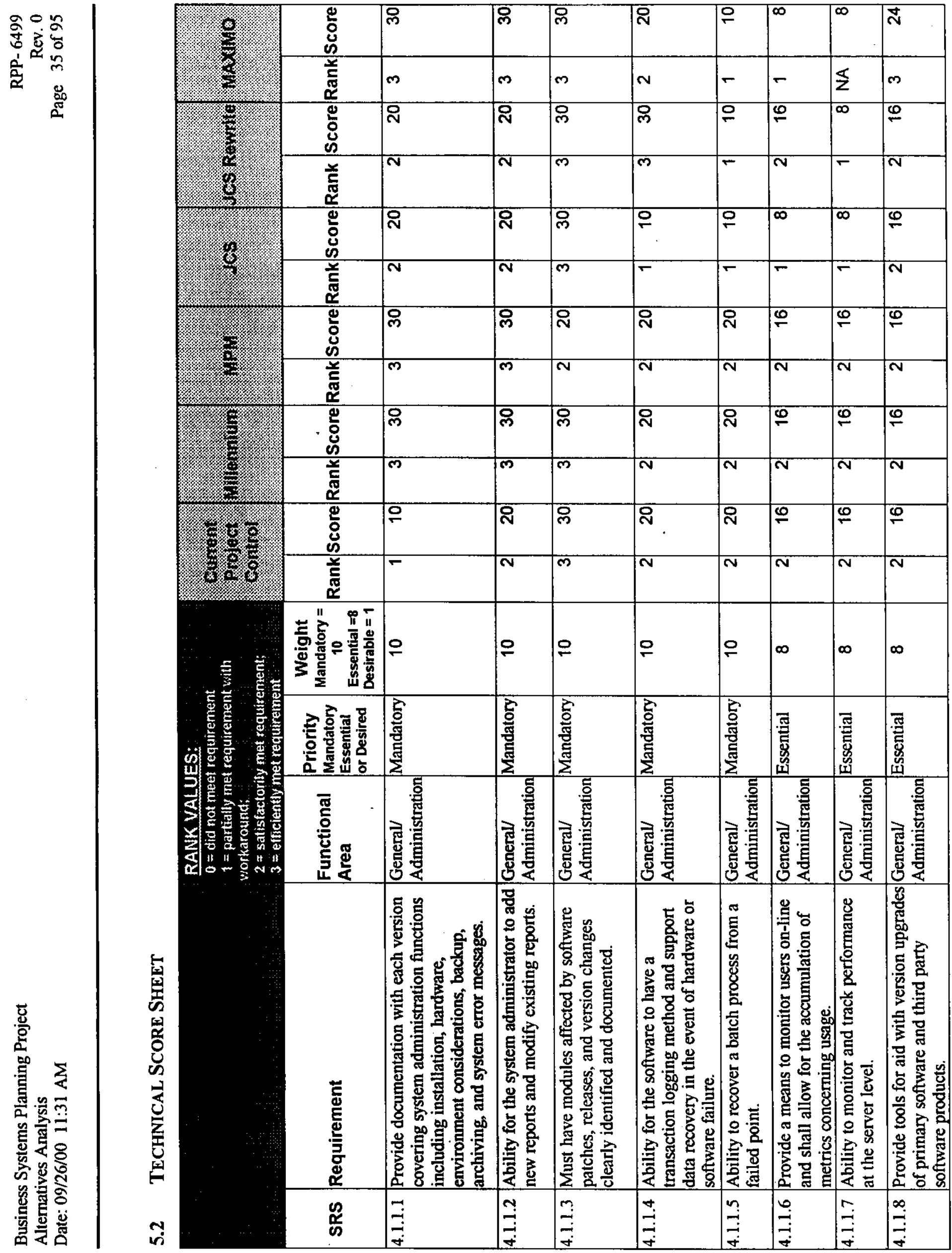




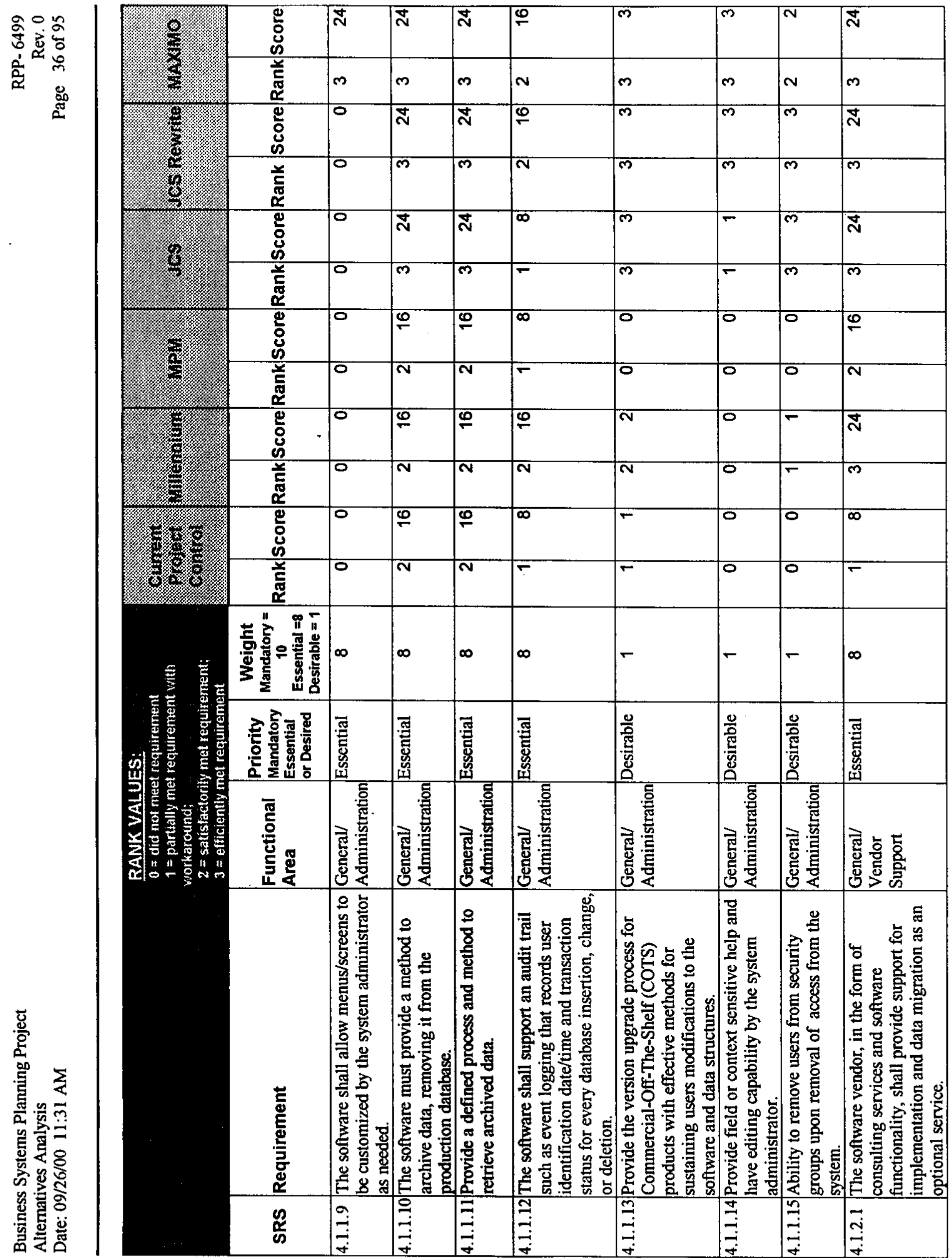




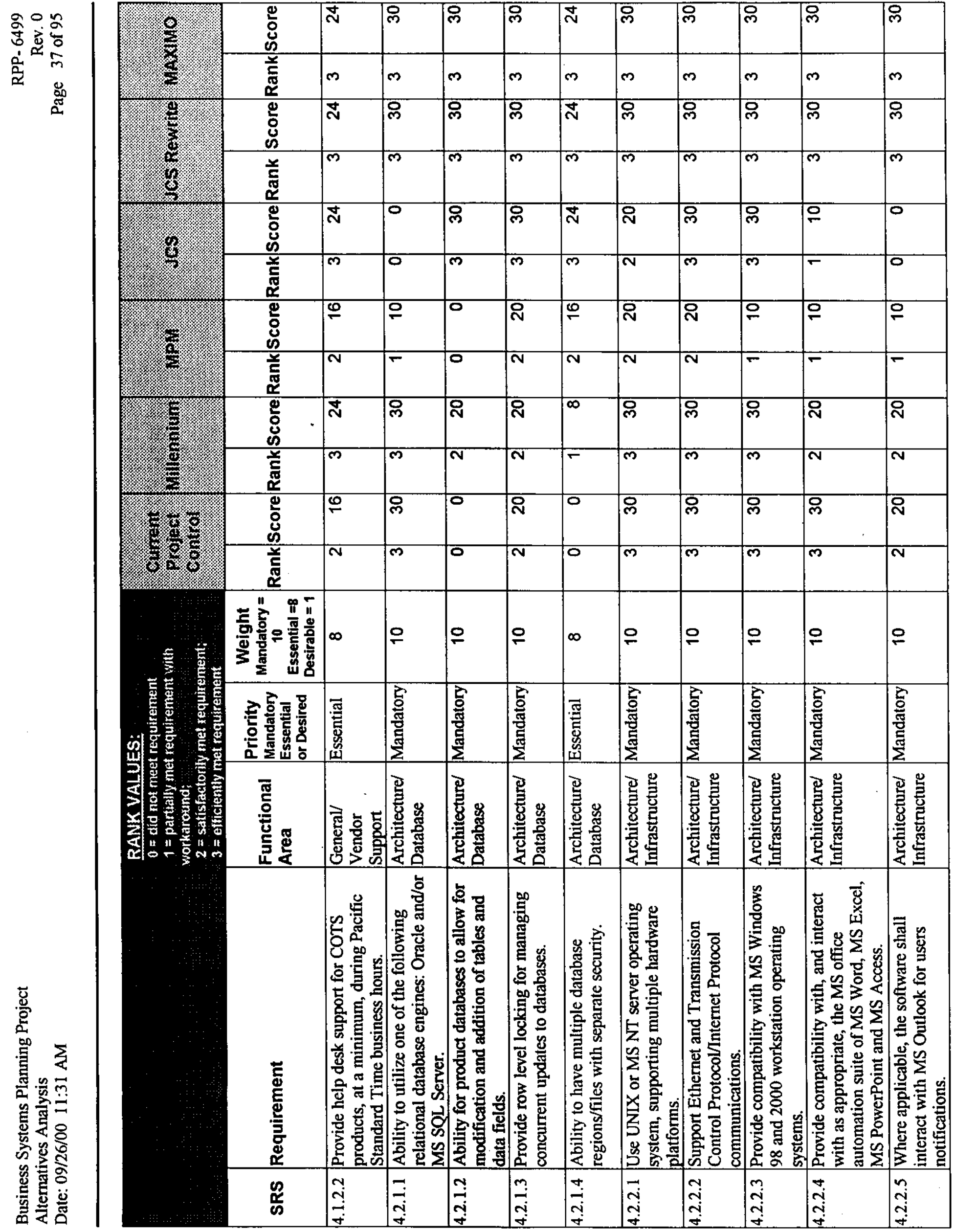




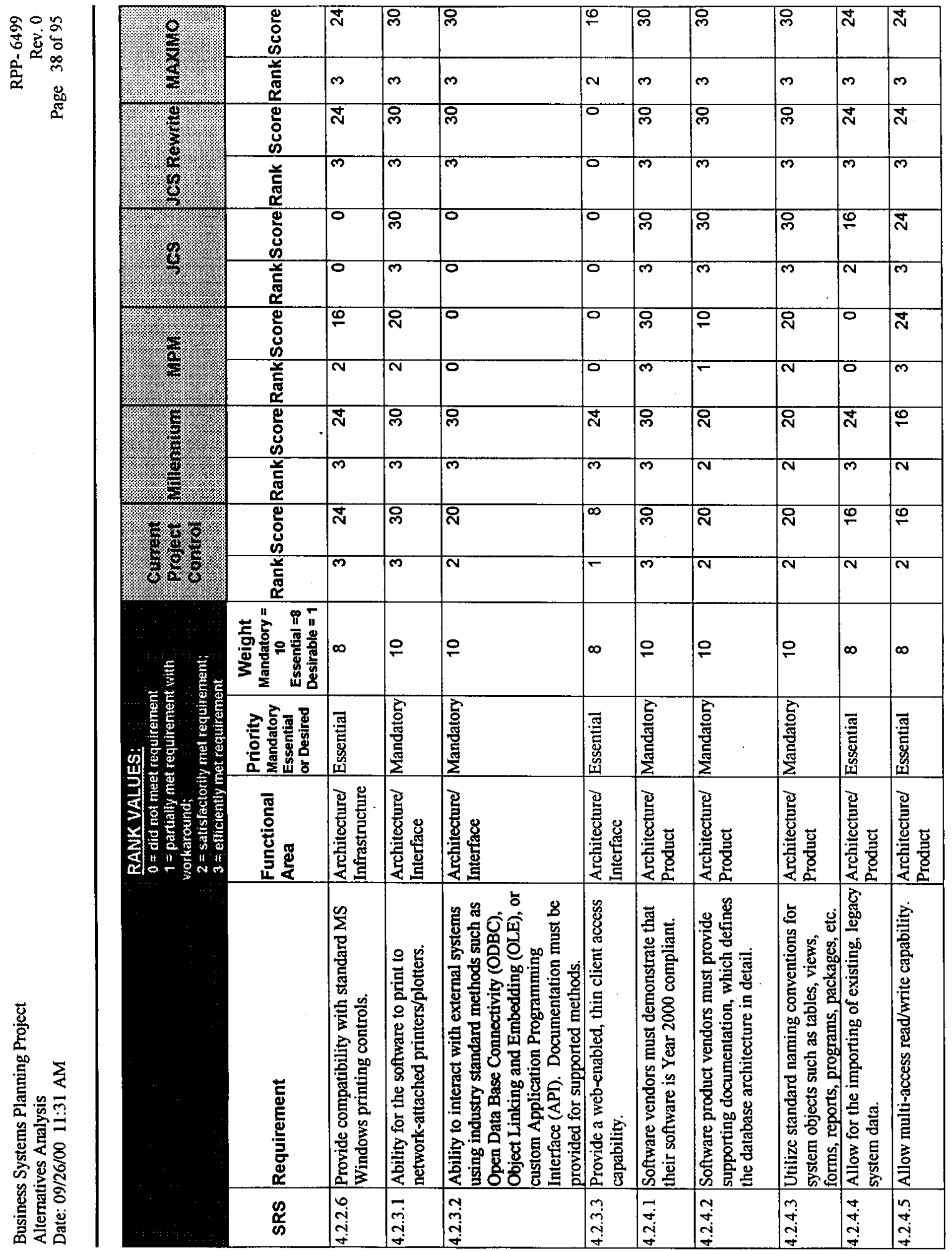




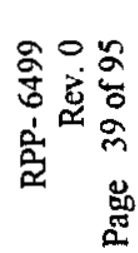

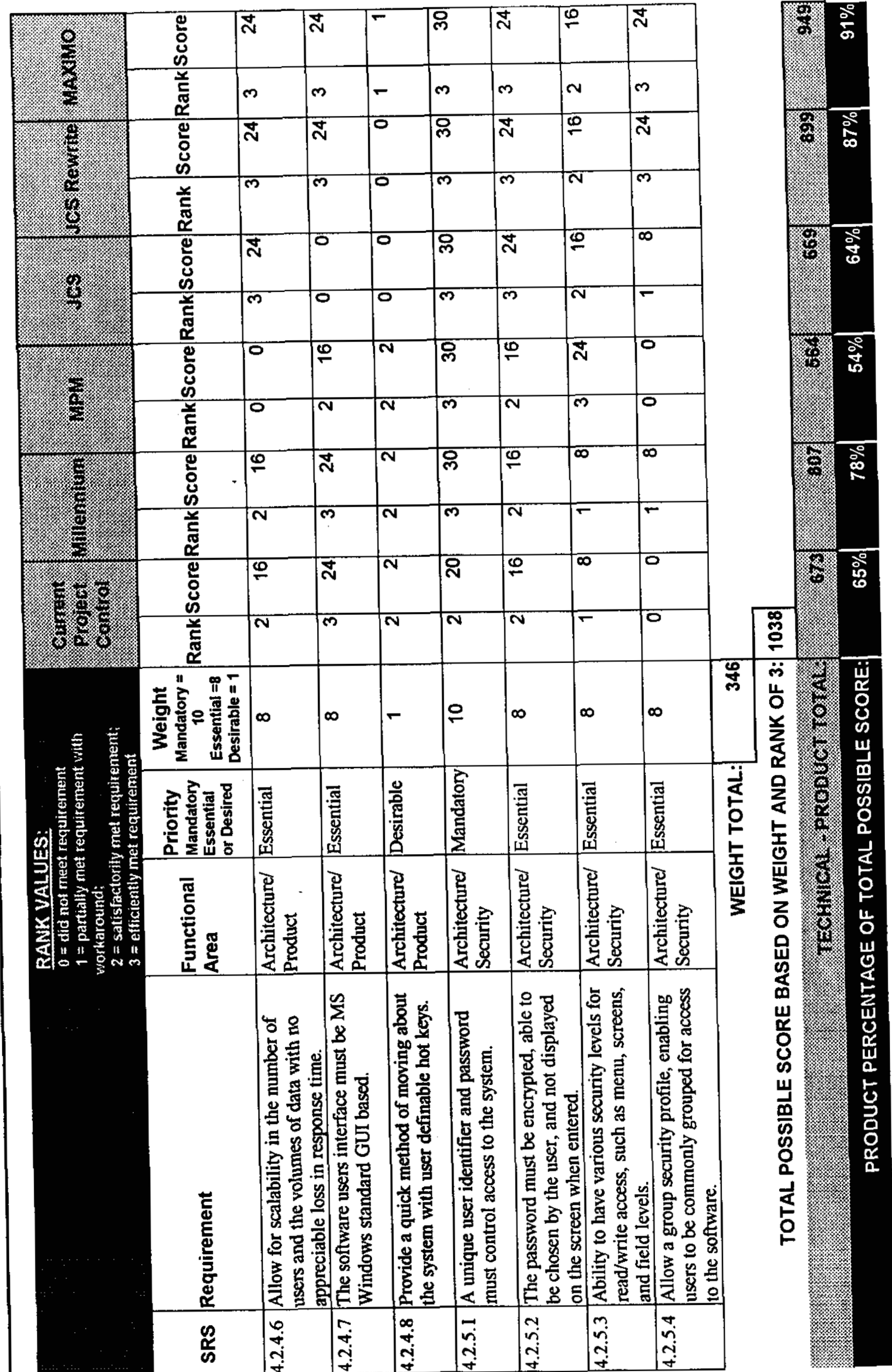




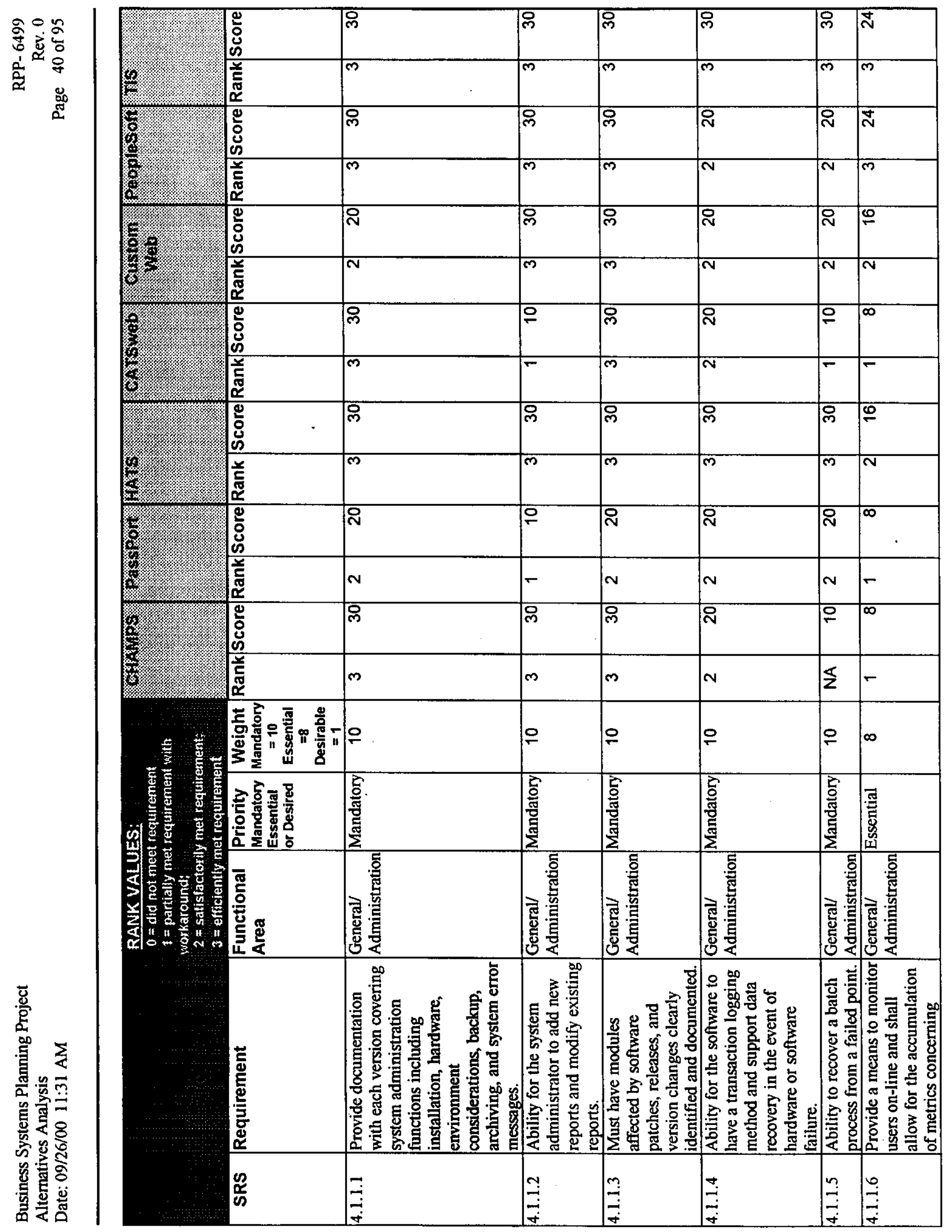




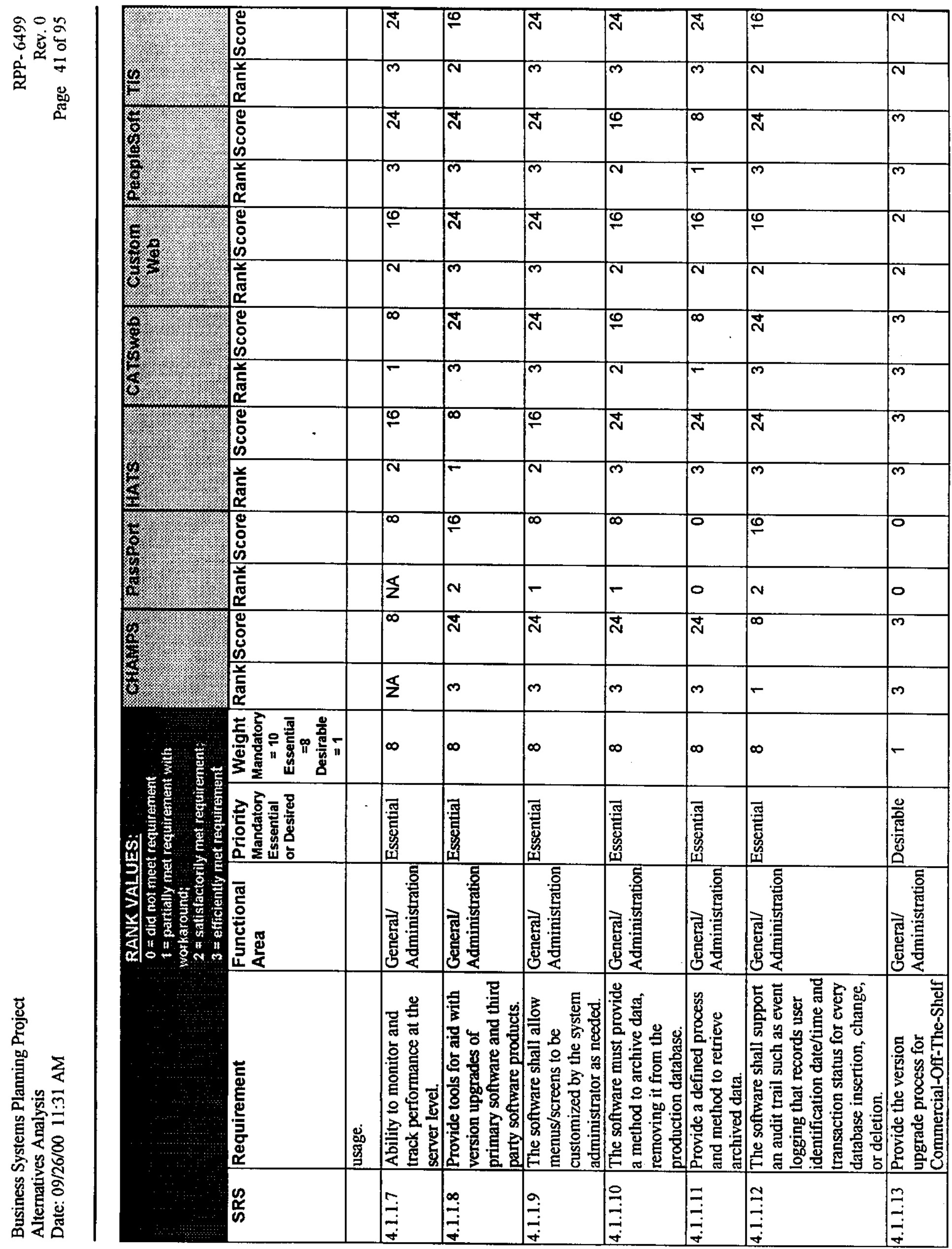




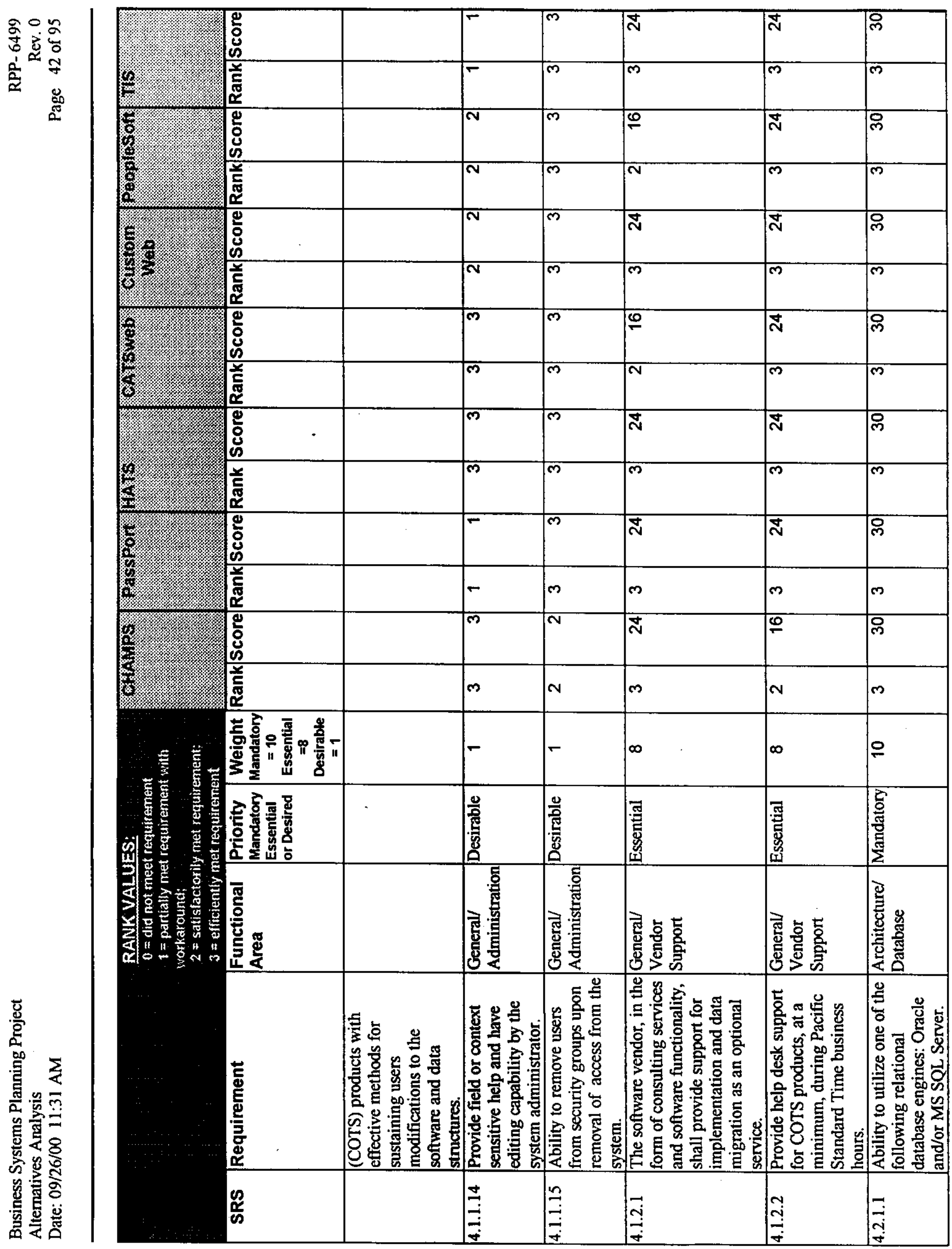




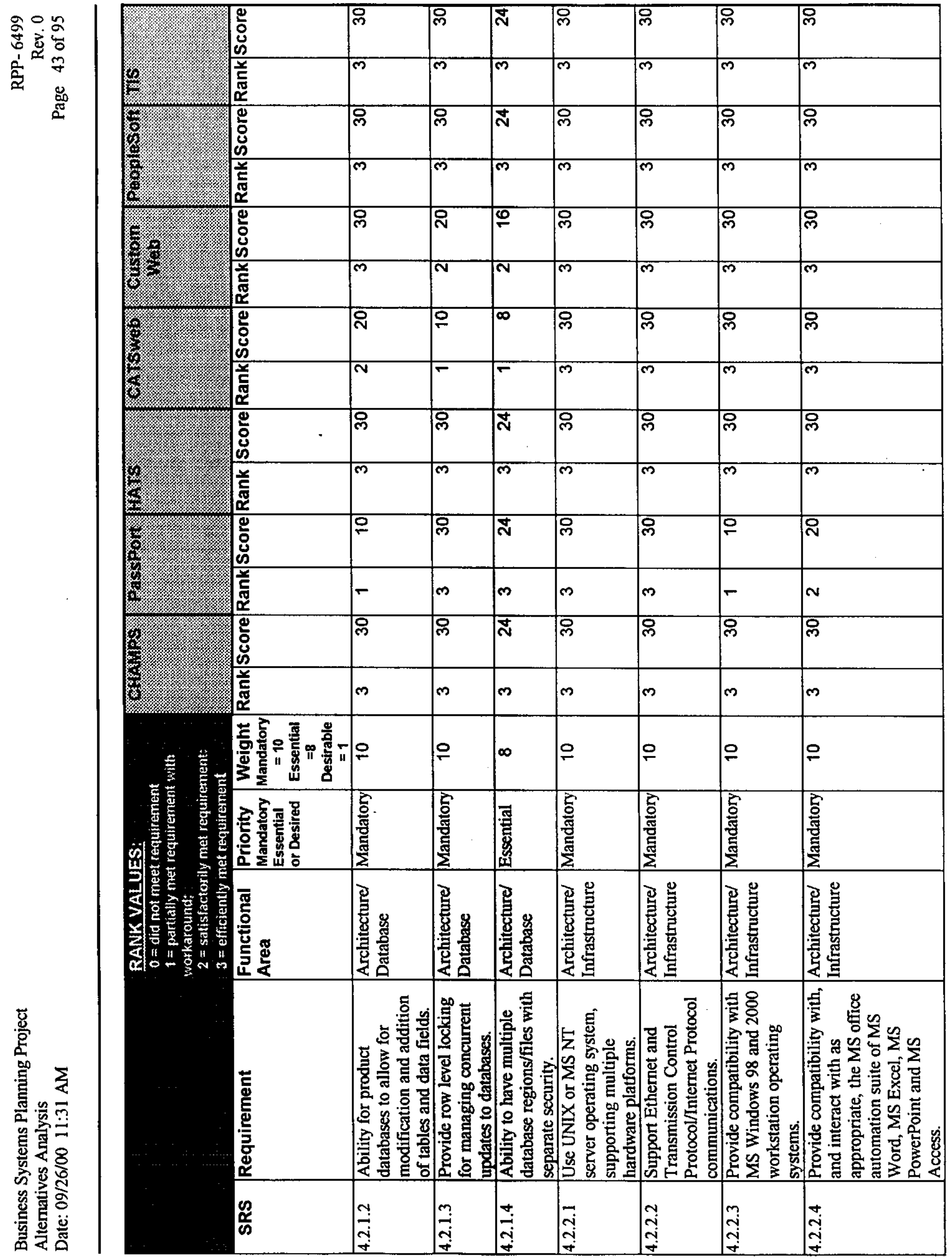




\begin{tabular}{|c|c|c|c|c|c|c|c|c|}
\hline 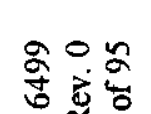 & & 峞 & 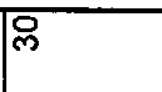 & $\sqrt{n}$ & 戹 & 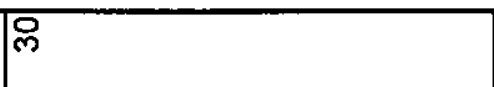 & & (্) \\
\hline 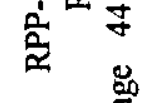 & (2.: & 恖 & $m$ & m & $m$ & m & 0 & m \\
\hline & $\frac{F}{6}$ & 产 & 宛 & 市 & D্ল & ले & $\frac{4}{4}$ & 足 \\
\hline & $\frac{1}{8}$ & 总 & $m$ & m & m & m & m & m \\
\hline & 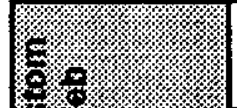 & 总 & న & 位 & 戹 & 品 & $\sqrt{2}$ & 戹 \\
\hline & $\left(\frac{3}{6}=\right.$ & 总 & $\sqrt{N}$ & m & ल & m & m & m \\
\hline & 6 & 总 & 戹 & $\sqrt[4]{4}$ & P & 启 & A & D্লি \\
\hline & 6 & 总 & $m$ & $\left.\right|^{\infty}$ & {$[m$} & $m$ & $m$ & $m$ \\
\hline & $\sqrt{-2}$ & 莕 & 戹 & $\bar{N}$ & 扁 & 戹 & $\sqrt{n}$ & 戹 \\
\hline & 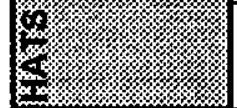 & 蒿 & $m$ & ल & ल & m & m & m \\
\hline & 6. & 总 & 戹 & $\%$ & 戹 & D্ল & $\%$ & 戹 \\
\hline & $f^{2}$ & 胥 & $\infty$ & $N$ & m & $m$ & N & $m$ \\
\hline & $\frac{2}{2}=$ & 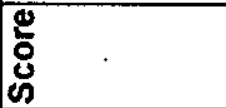 & 屏 & A & 戹 & 戹 & $\infty$ & 戹 \\
\hline & $\sqrt{8}$ & 总 & $m$ & $m$ & $m$ & $m$ & - & $m$ \\
\hline & 言蓄 & 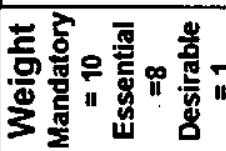 & ? & $\infty$ & ? & 앙 & $\infty$ & 으 \\
\hline & 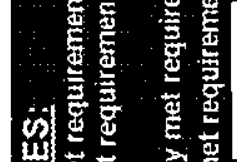 & 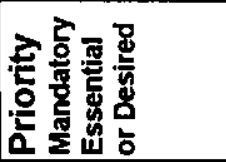 & 总. & 墨 & 产 & $\mid$ & & 部 \\
\hline & 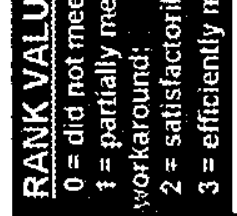 & 咲 & 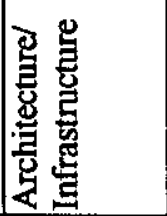 & 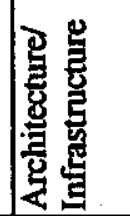 & 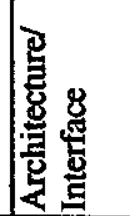 & 迡 & & 递 \\
\hline 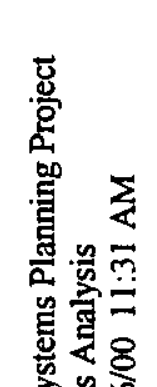 & & 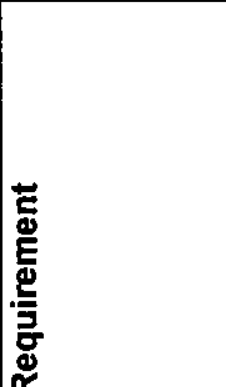 & 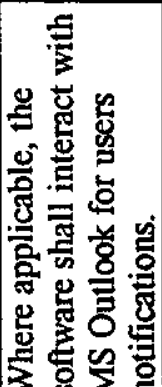 & 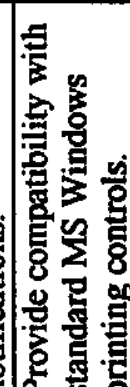 & 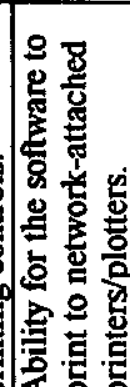 & 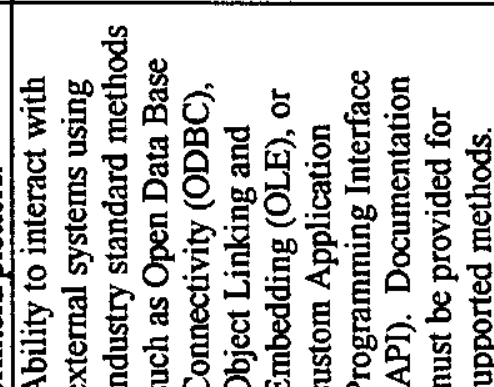 & 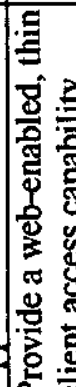 & 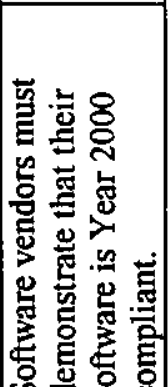 \\
\hline 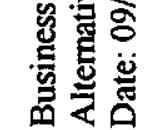 & & $\mid \begin{array}{l}\mathscr{L} \\
\mathbb{E}\end{array}$ & 幽 & $\mid$ & $\underset{5}{2}$ & 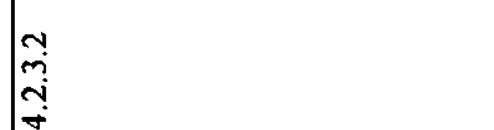 & 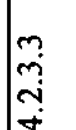 & 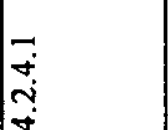 \\
\hline
\end{tabular}




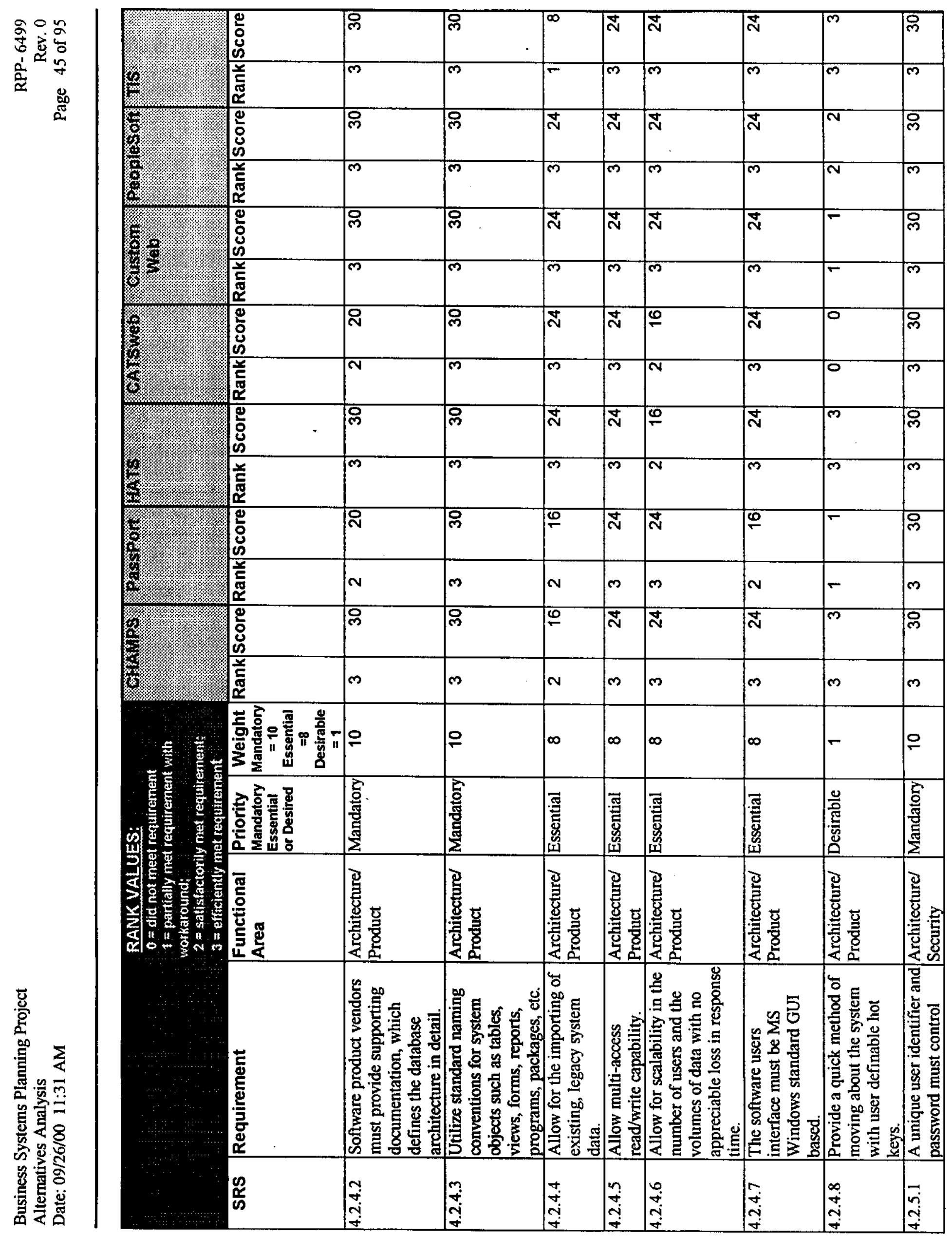




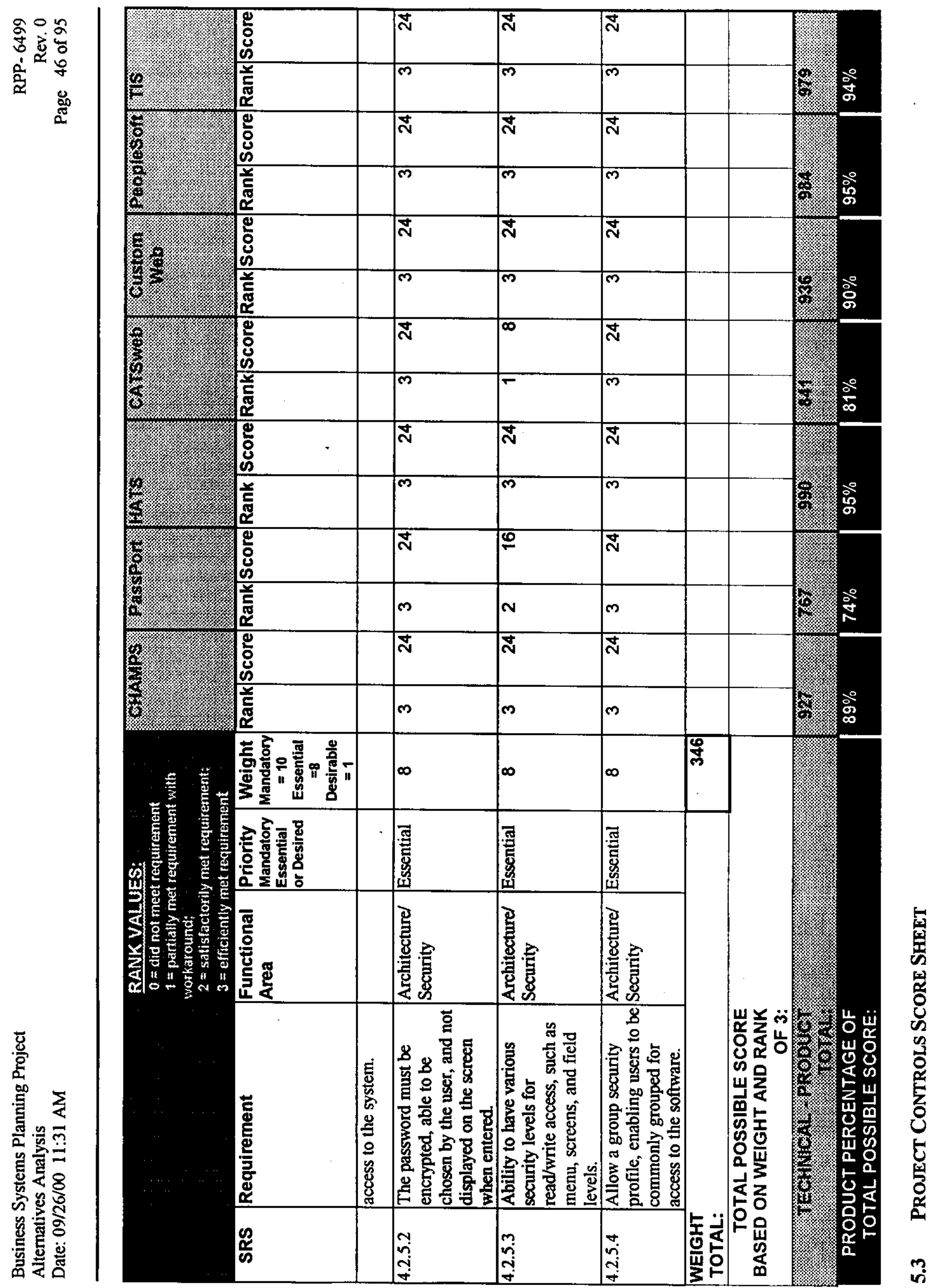




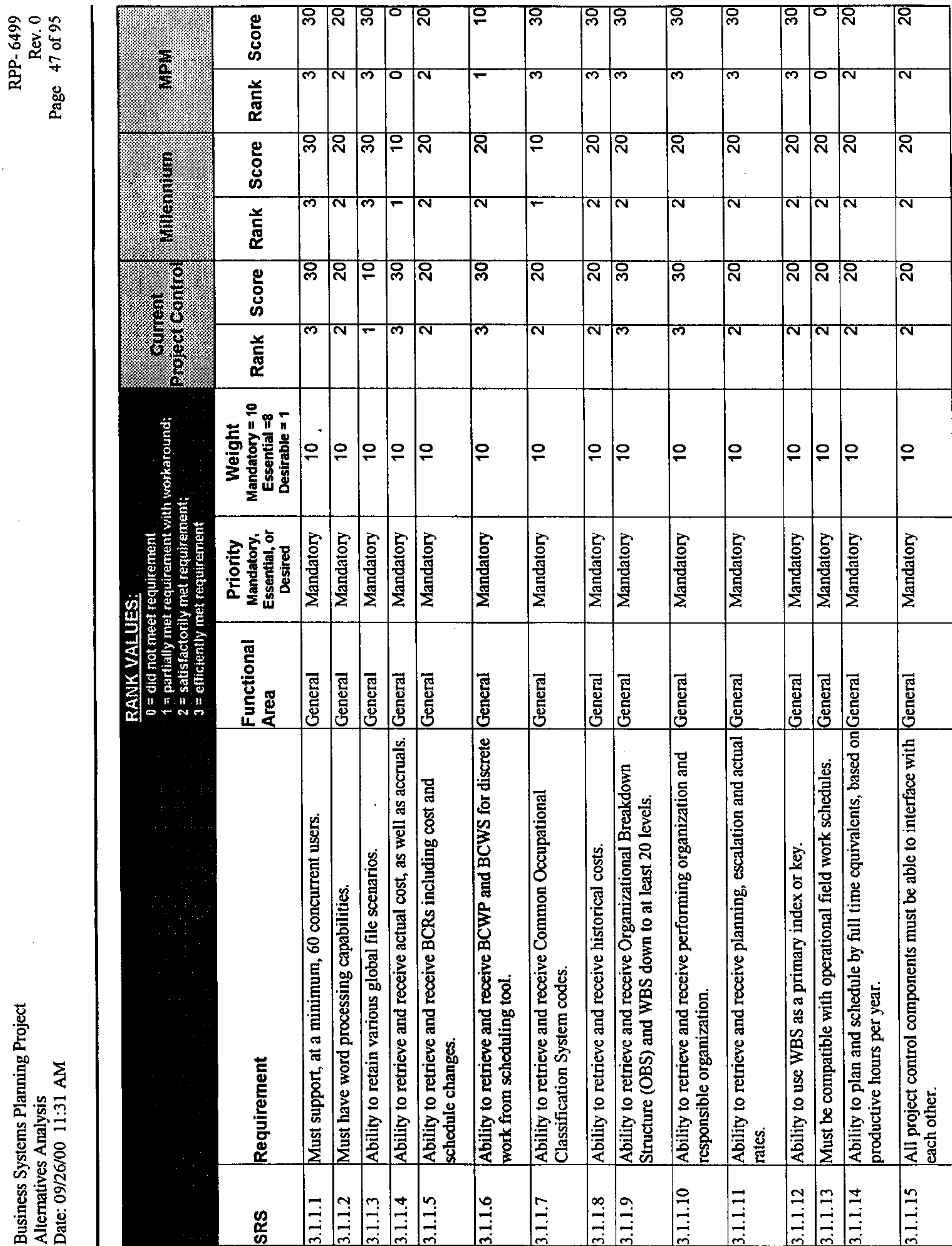




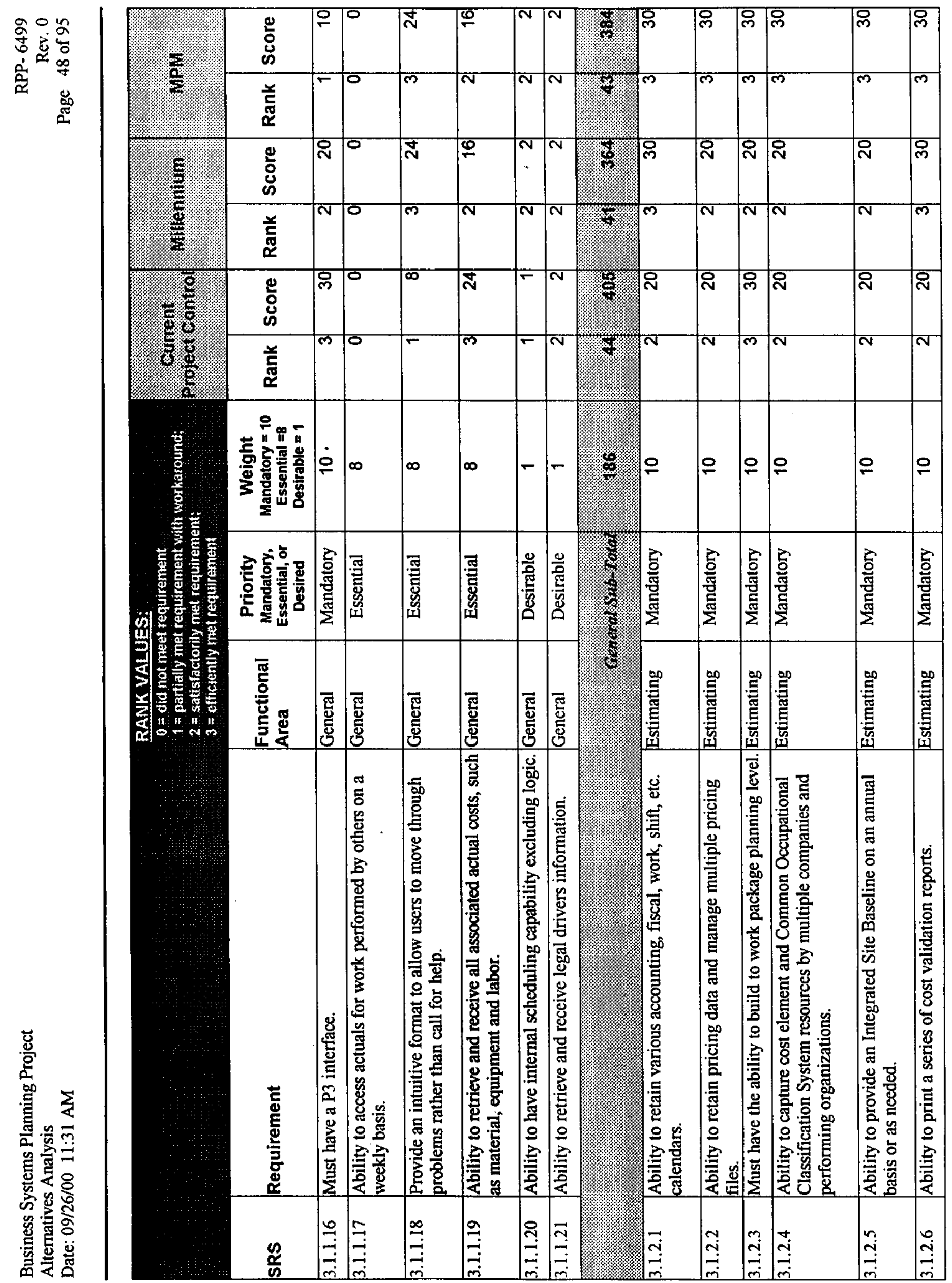




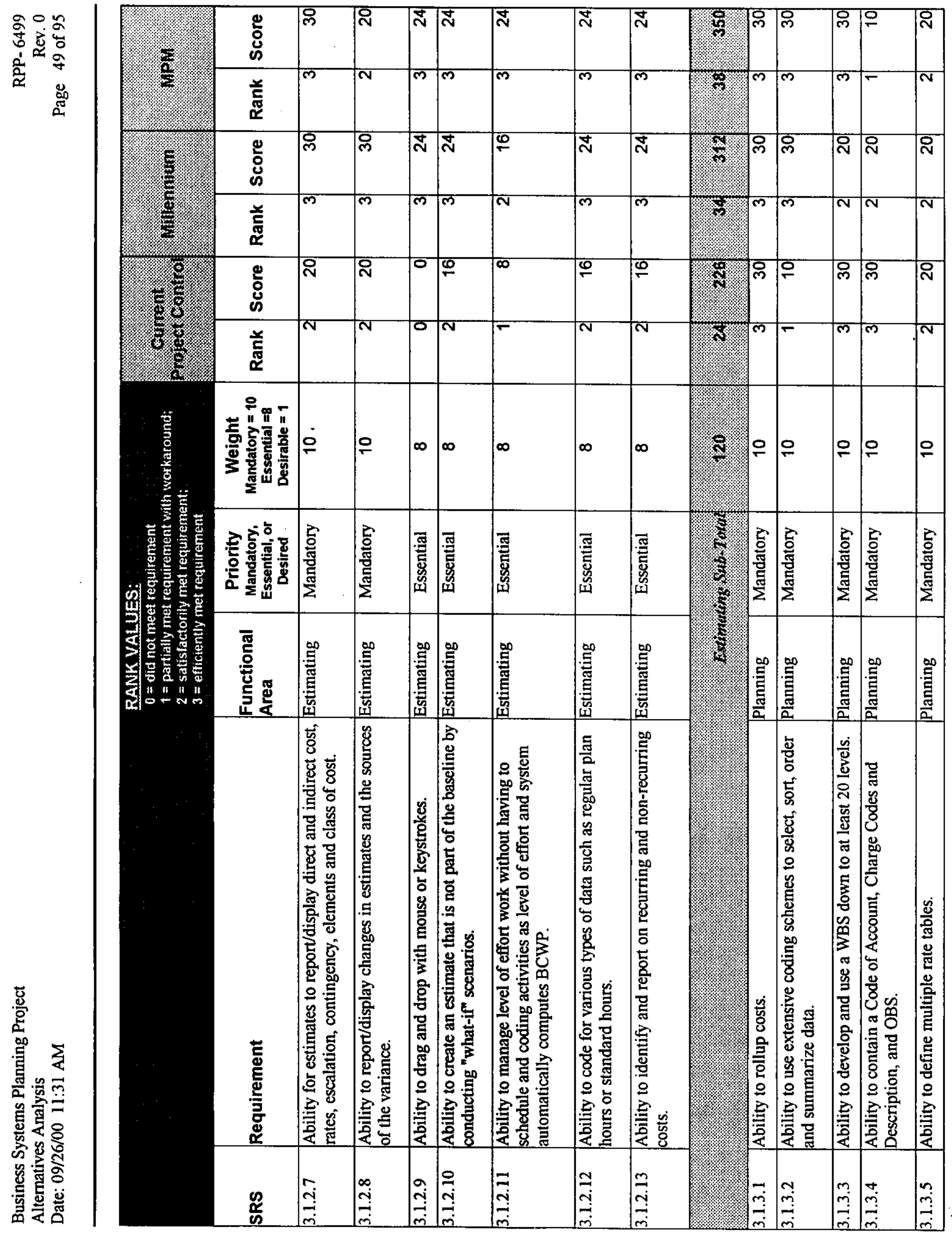




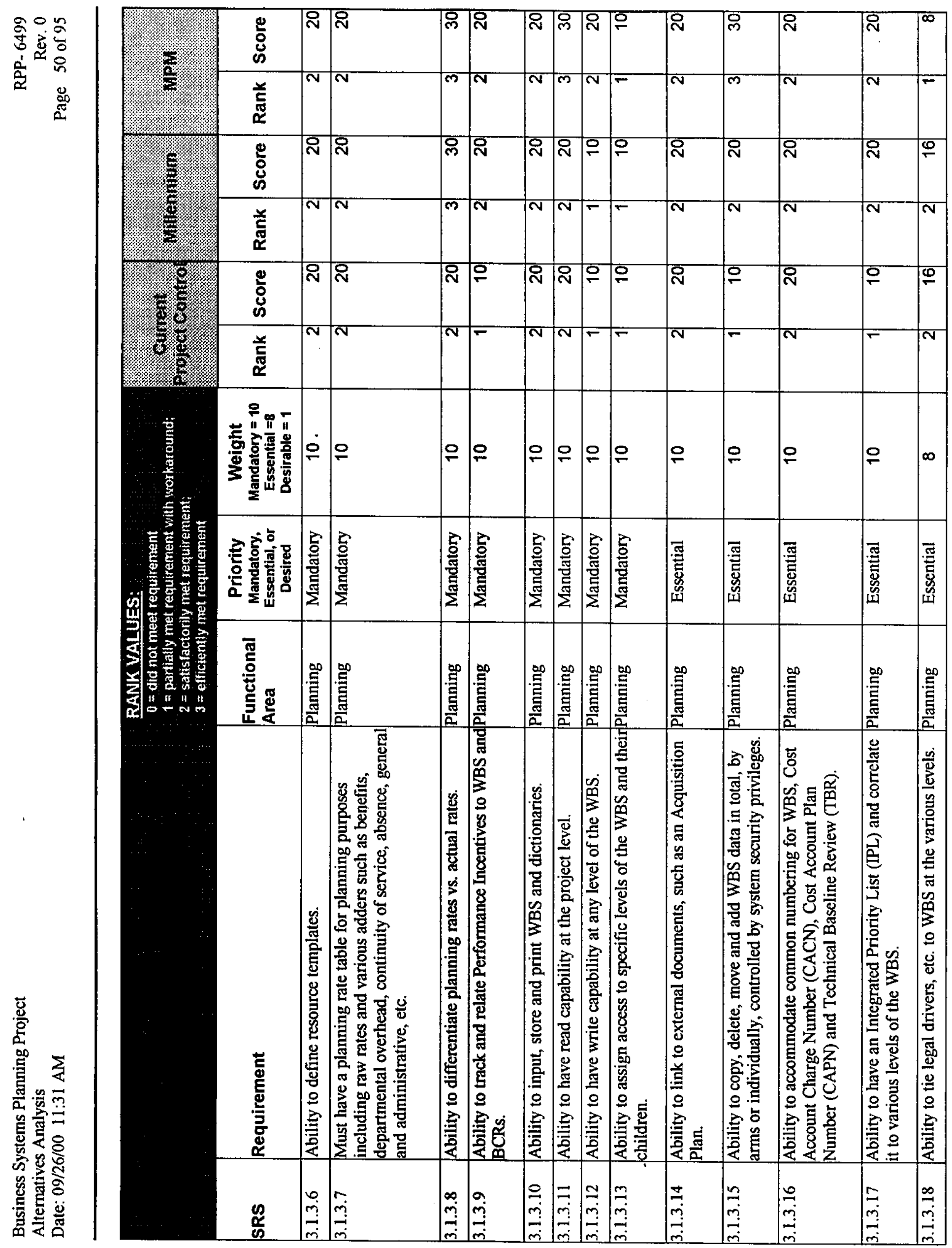




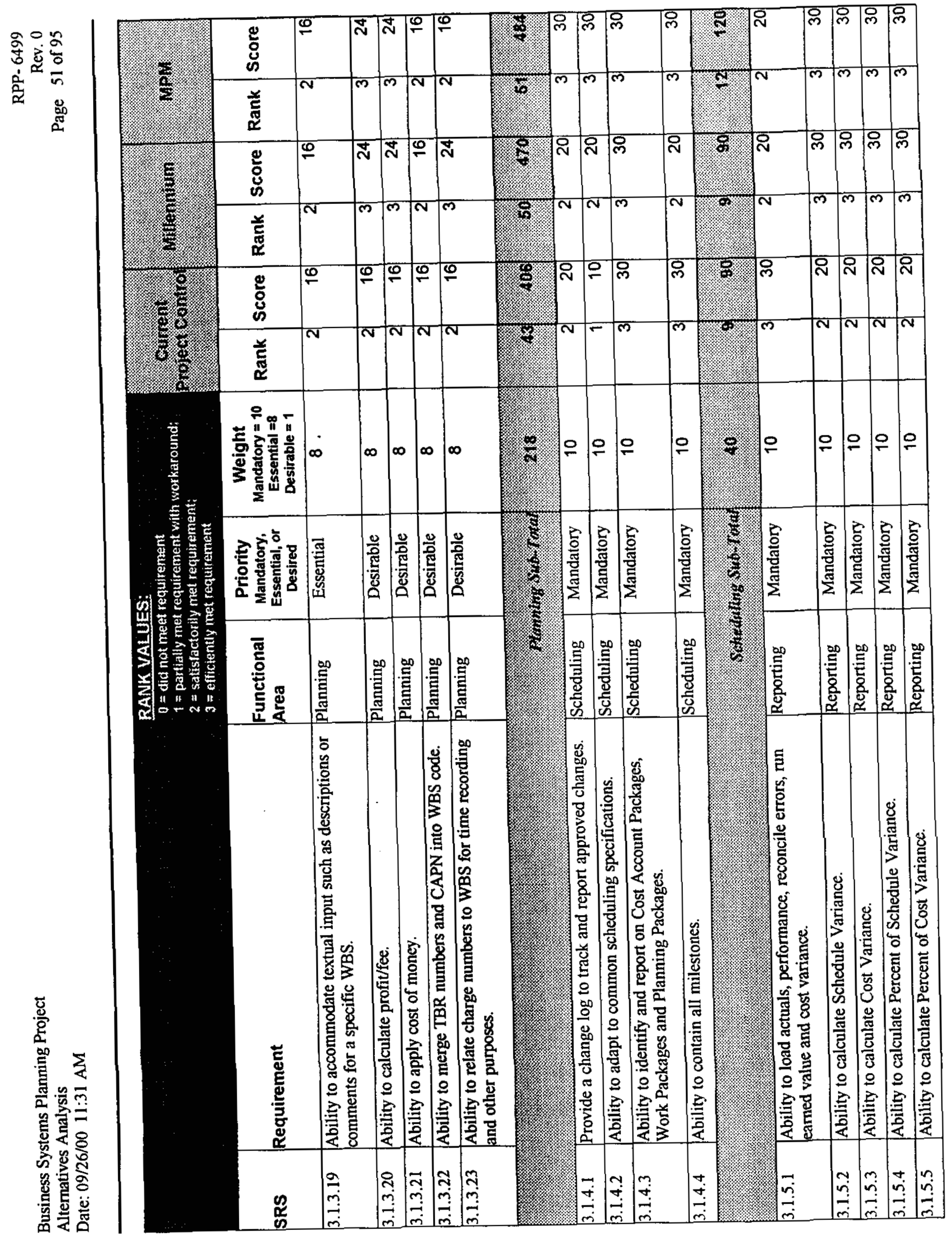




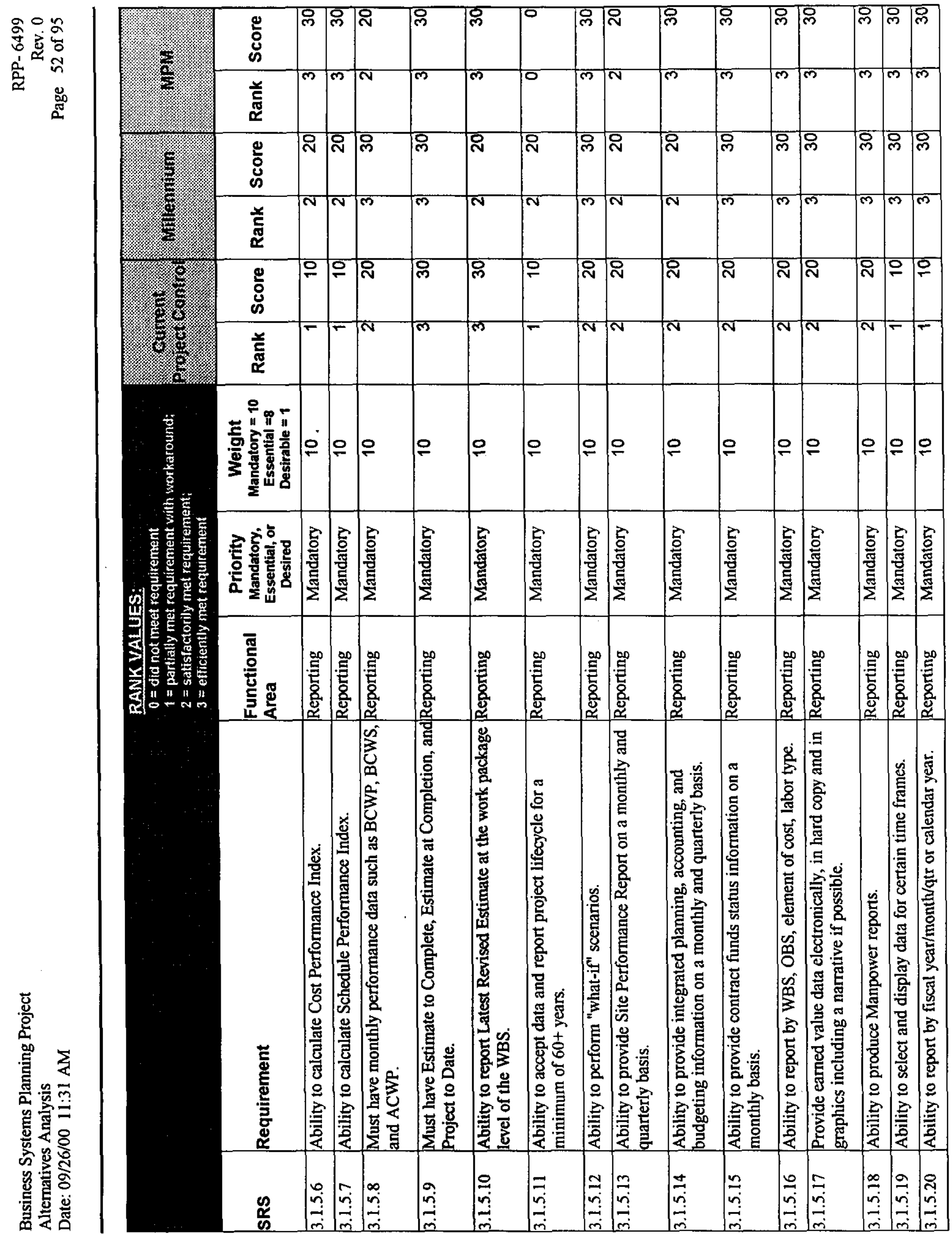




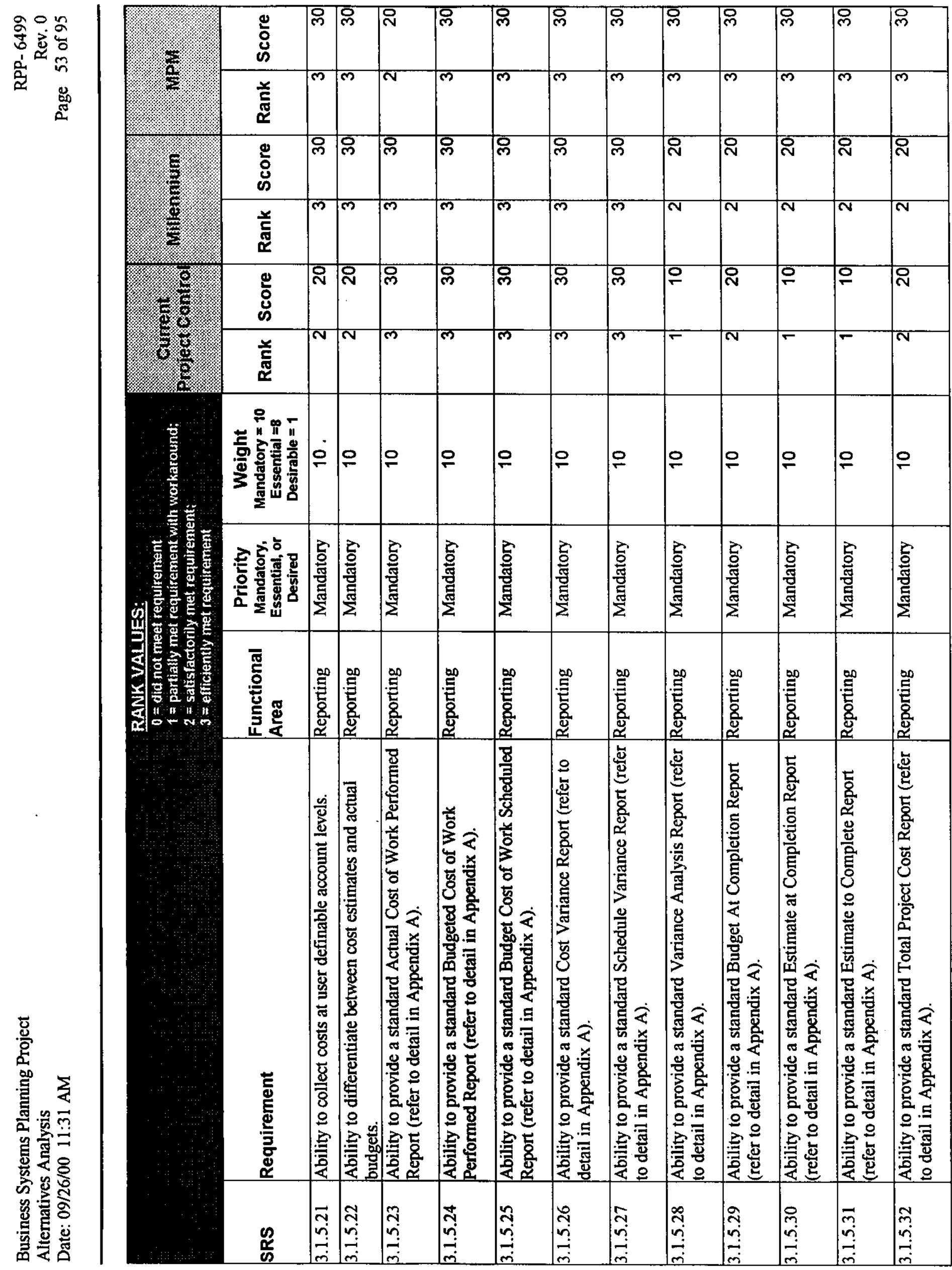




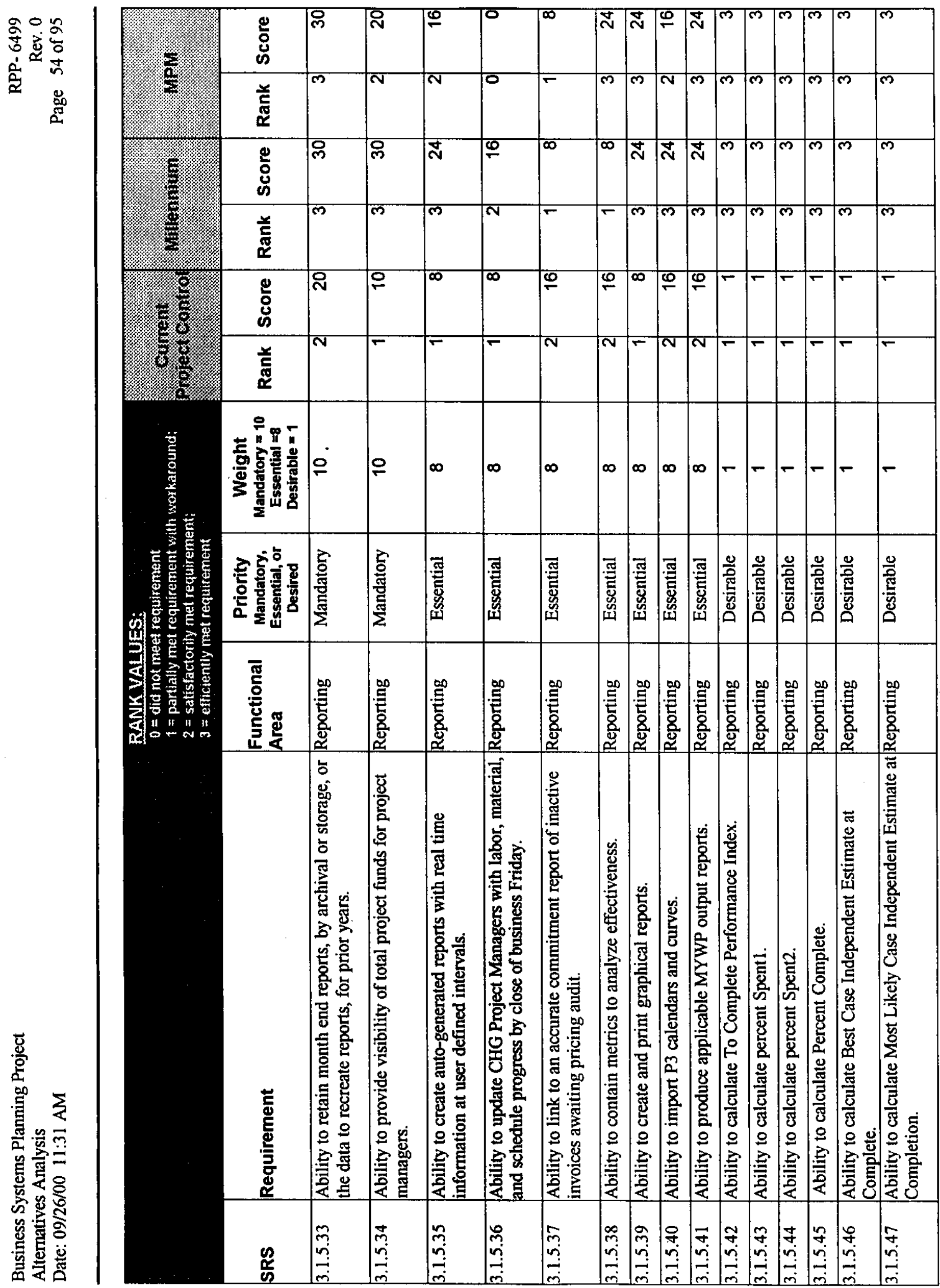




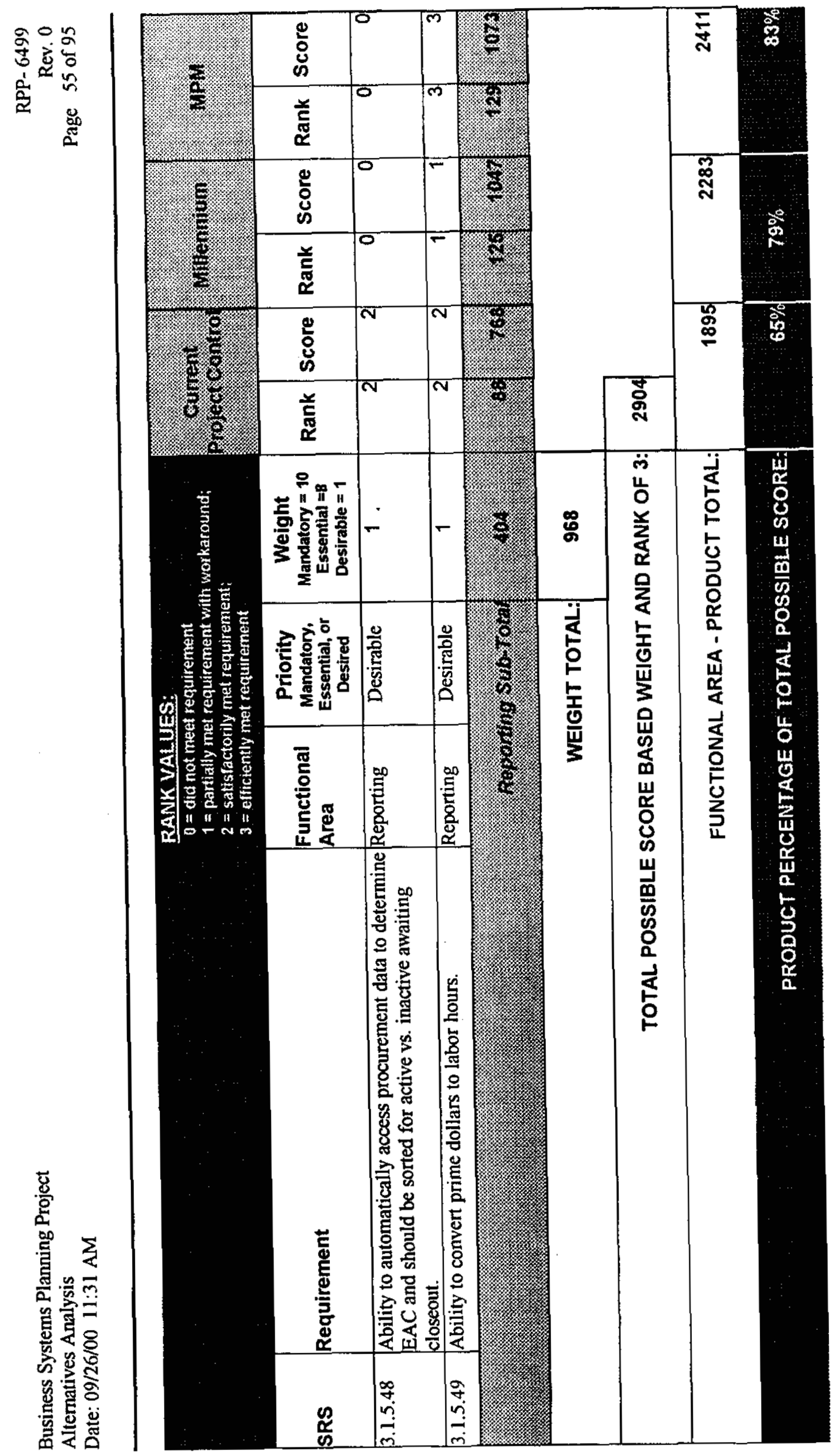




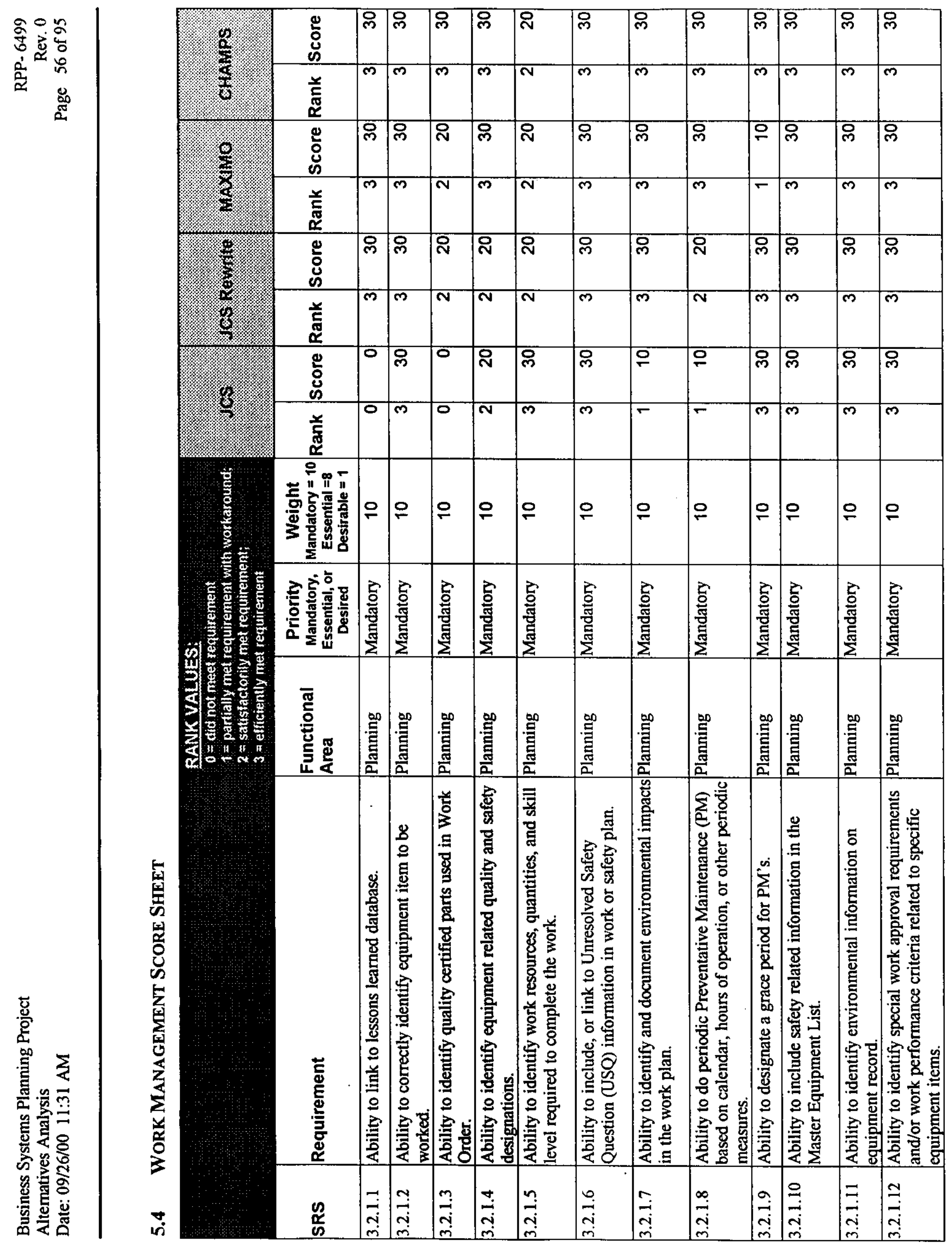




\begin{tabular}{|c|c|c|c|c|c|c|c|c|c|c|c|c|c|}
\hline 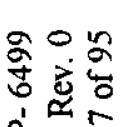 & th. & $\begin{array}{l}0 \\
\end{array}$ & 요 & স্লি & ম & ম & 芯 & ম & $\stackrel{\sim}{\sim}$ & 茫 & $\stackrel{\Delta}{N}$ & $\stackrel{6}{2}$ & $\stackrel{\mathbb{N}}{\mathbf{N}}$ \\
\hline 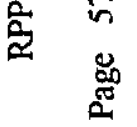 & is. & $\begin{array}{l}\text { 兰 } \\
\text { 获 } \\
\end{array}$ & $m$ & $m$ & m & m & $m$ & m & $m$ & $m$ & $m$ & 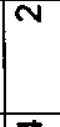 & $m$ \\
\hline & s. & ஹू & י্লি & স্লি & N & ম & $\stackrel{+}{N}$ & $\stackrel{\oplus}{\circ}$ & $\stackrel{d}{\sim}$ & $\stackrel{ \pm}{N}$ & $\stackrel{i}{\sim}$ & $\stackrel{\Delta}{N}$ & $\dot{N}$ \\
\hline & s. & 弟 & $m$ & $m$ & $m$ & $m$ & $m$ & $N$ & $m$ & $m$ & $m$ & $m$ & $m$ \\
\hline & . & 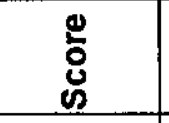 & ్․ & 음 & ম & $\mathscr{\sigma}$ & $\dot{N}$ & i & $\dot{N}$ & $\dot{N}$ & N & 竎 & ম \\
\hline & in & 兰 & m & $\sigma$ & m & $N$ & $m$ & m & $m$ & $m$ & $m$ & $m$ & $m$ \\
\hline & 8 & $\begin{array}{l}0 \\
0 \\
0 \\
0\end{array}$ & 이 & 으 & ম & 0 & $\oplus$ & $\bar{N}$ & 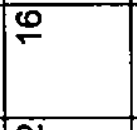 & $\infty$ & 吕 & $\mathscr{O}$ & $\infty$ \\
\hline & 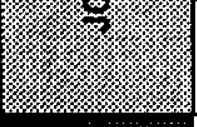 & $\begin{array}{l}\text { X } \\
\text { E } \\
\text { D }\end{array}$ & $m$ & $F$ & $m$ & 0 & $N$ & m & $N$ & $\sigma$ & $m$ & $N$ & $r$ \\
\hline & 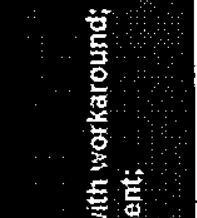 & 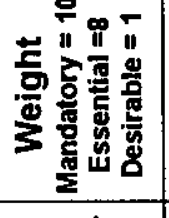 & 운 & 웅 & $\infty$ & $\infty$ & $\infty$ & $\infty$ & $\infty$ & $\infty$ & $\infty$ & $\infty$ & $\infty$ \\
\hline & 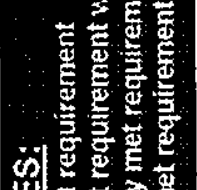 & 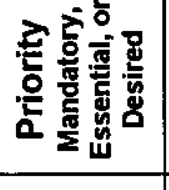 & 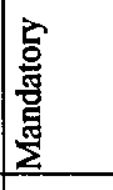 & 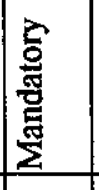 & 悪 & 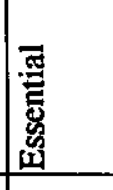 & 晜 & 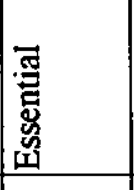 & 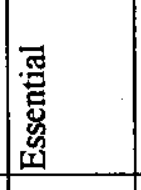 & 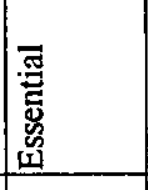 & 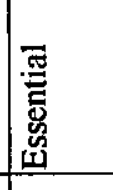 & 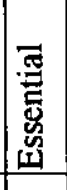 & 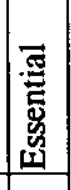 \\
\hline & 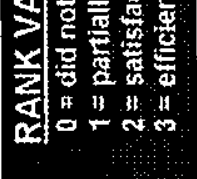 & 을 & 篂 & 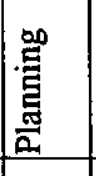 & 量 & 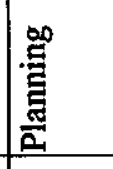 & 昜 & 量 & 昜 & 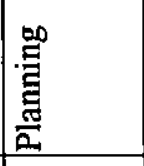 & 总 & 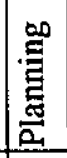 & 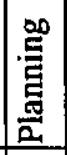 \\
\hline 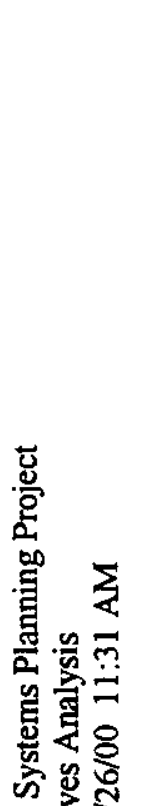 & & 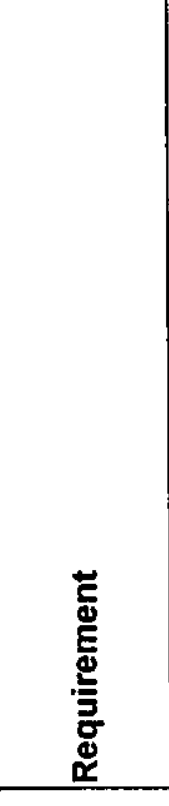 & 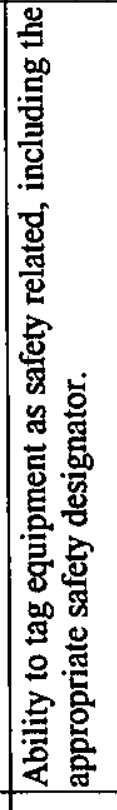 & 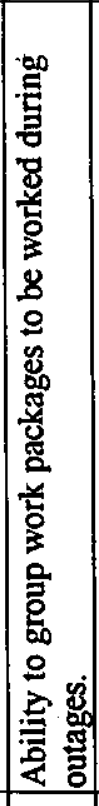 & 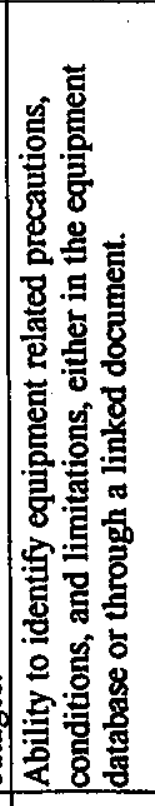 & 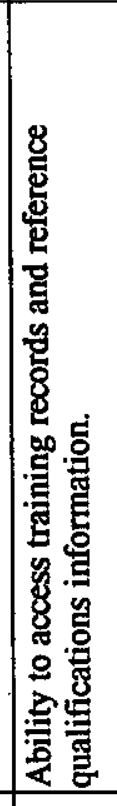 & 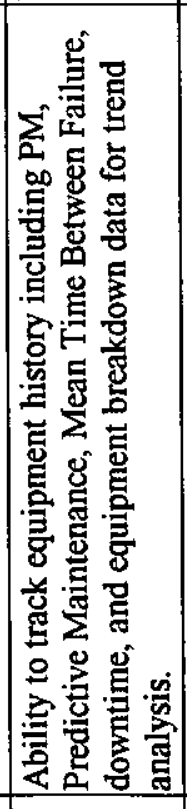 & 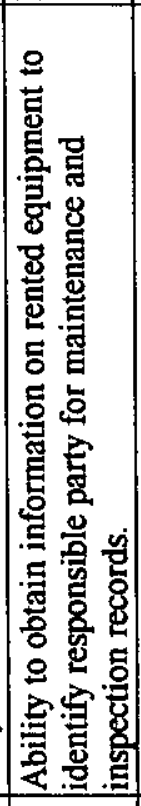 & 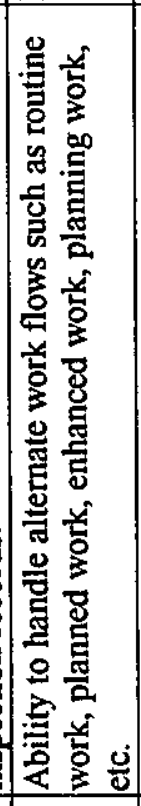 & 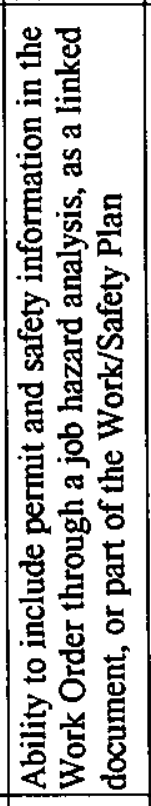 & 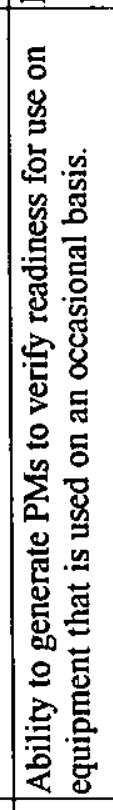 & 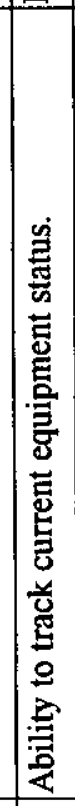 & 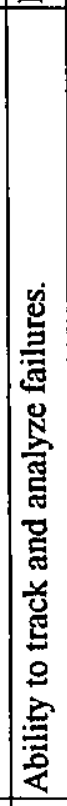 \\
\hline 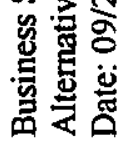 & & $\begin{array}{l}\mathscr{2} \\
0 \\
0\end{array}$ & $\stackrel{m}{\stackrel{m}{\sim}}$ & 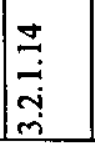 & $\begin{array}{l}n \\
\ddot{n} \\
m \\
m\end{array}$ & & ت્ & 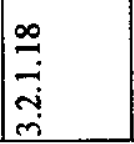 & $\frac{a}{a}$ & i̊ & $\begin{array}{c}\vec{y} \\
\stackrel{n}{\sim} \\
\sim \\
m\end{array}$ & ָָ & ָ̧ר \\
\hline
\end{tabular}




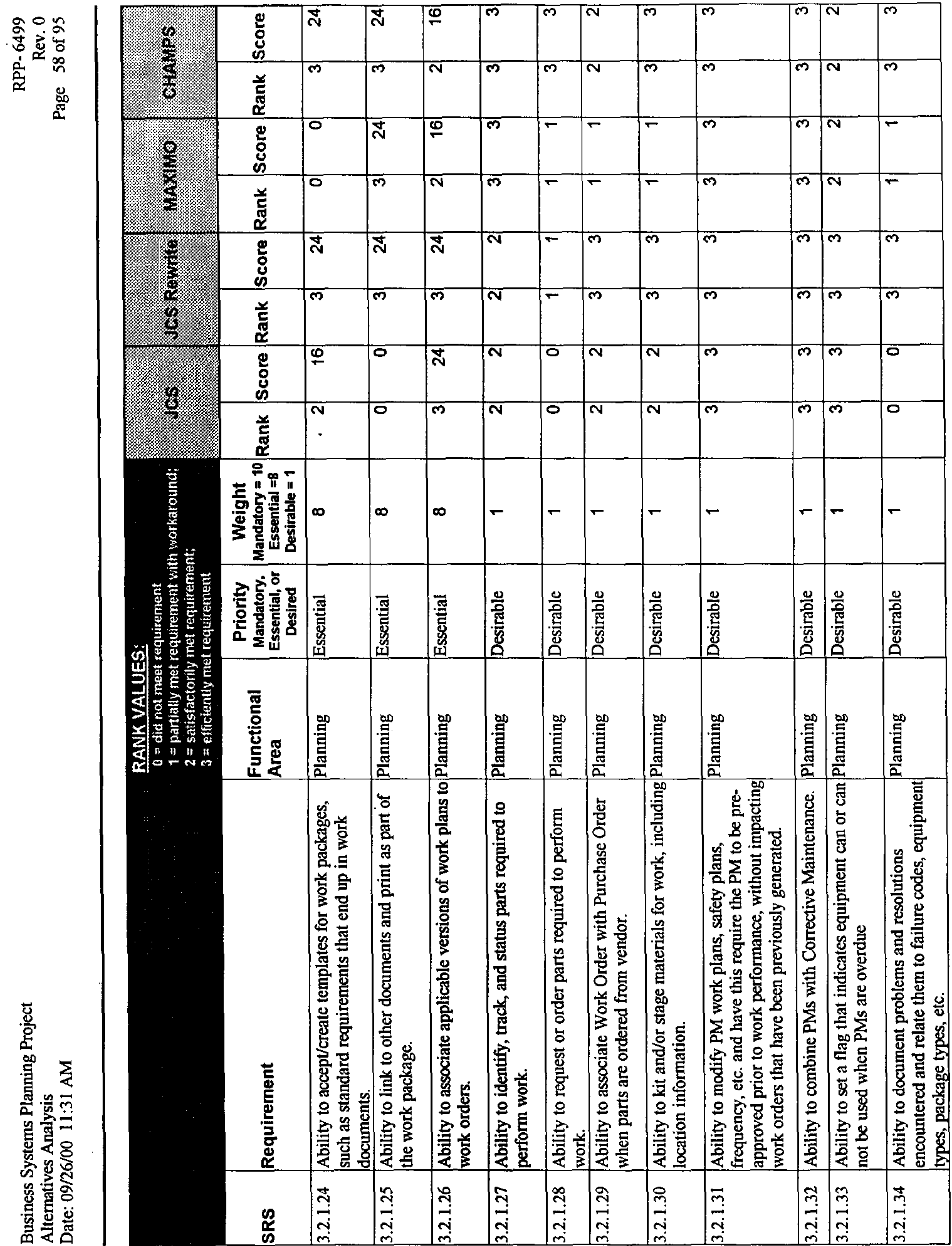




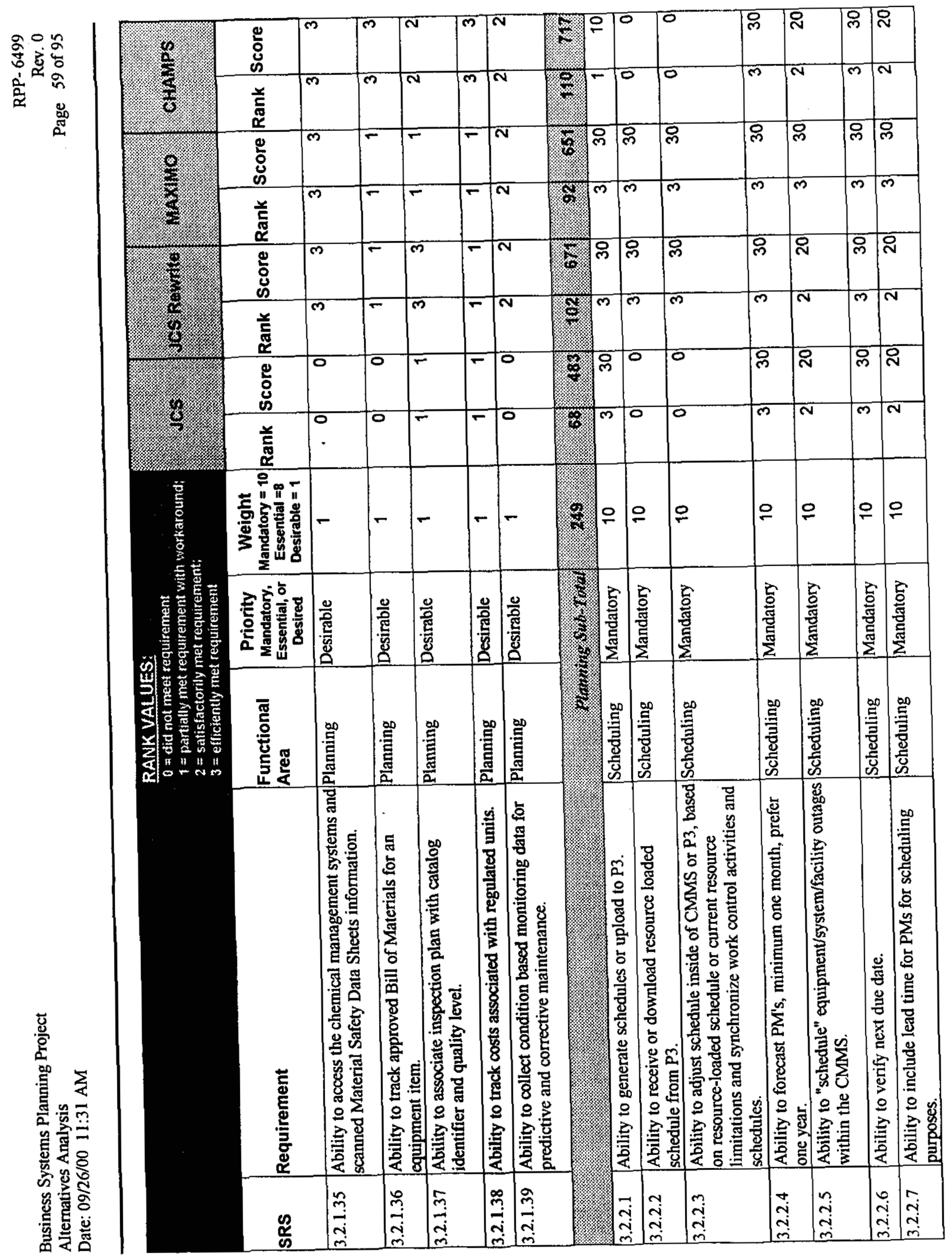




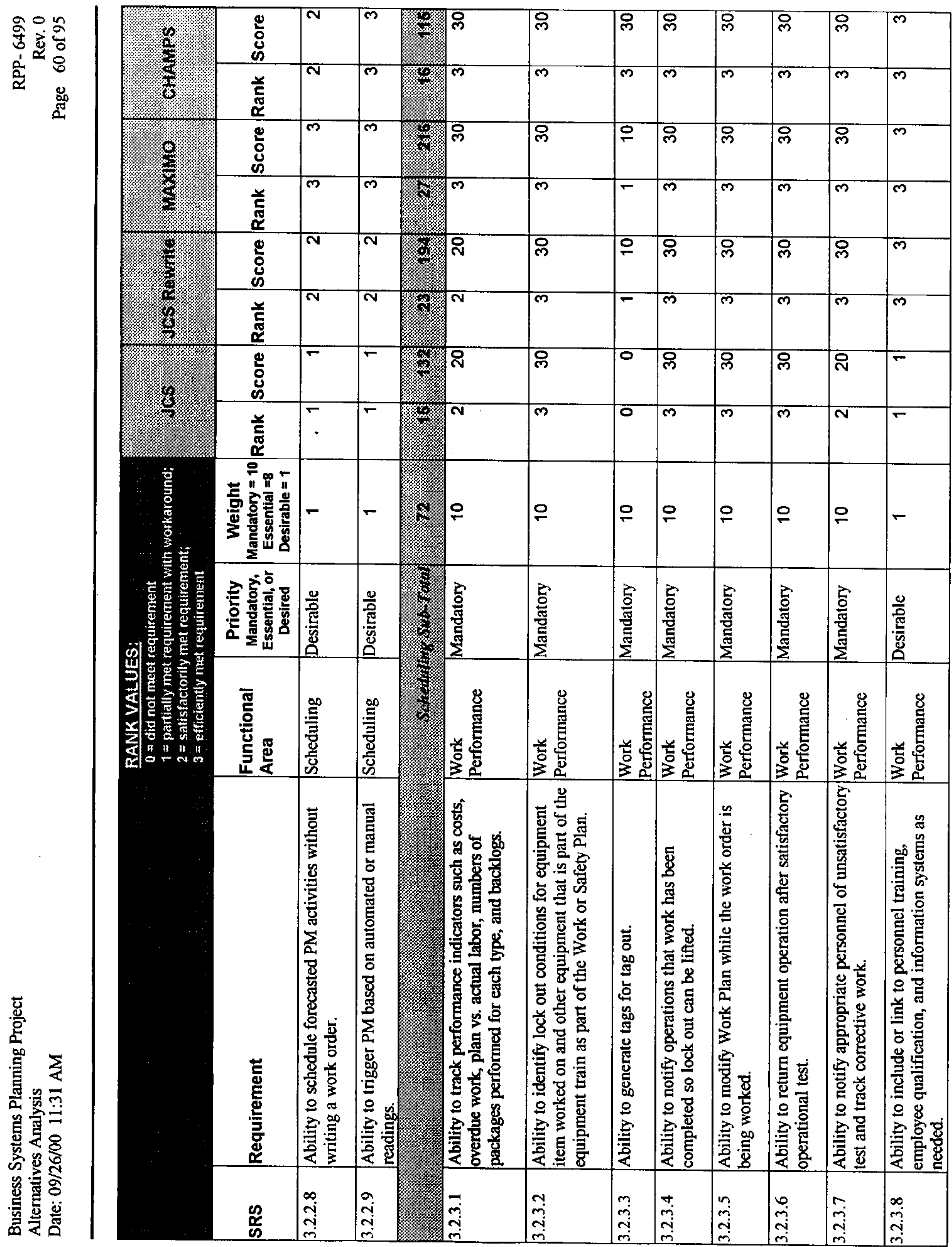




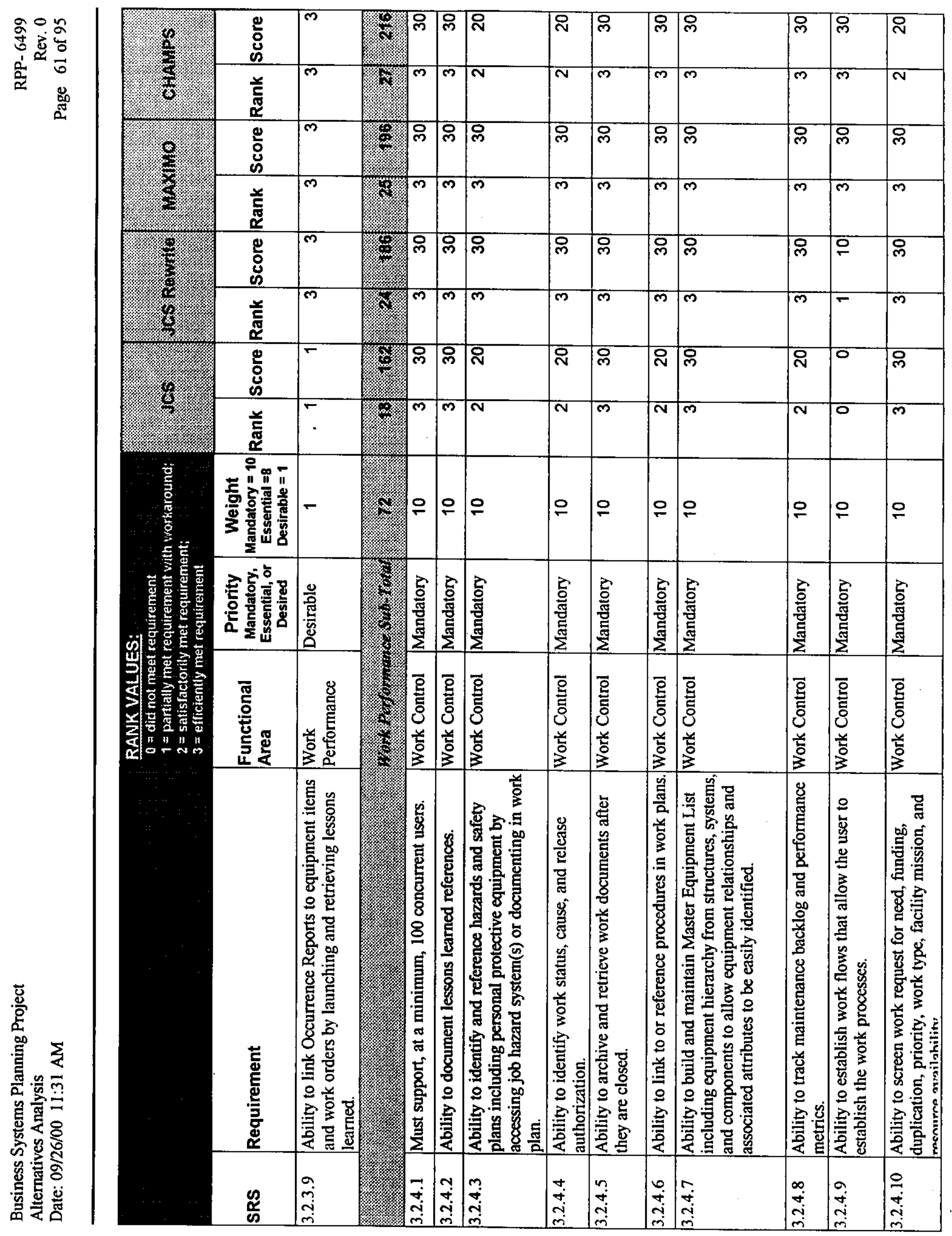




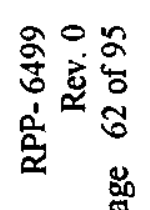

\begin{tabular}{|c|c|c|c|c|c|c|c|c|c|c|c|c|c|c|c|}
\hline \multirow{2}{*}{ 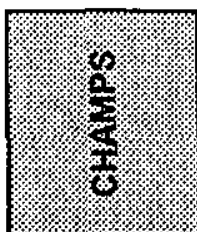 } & 过 & & 요 & স্ল & י্ল & 尺্ & 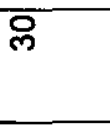 & স্লি & প్ల & 요 & 足 & 유 & $\infty$ & $\infty$ & $\vec{N}$ \\
\hline & 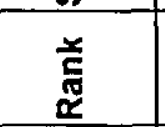 & & $m$ & $m$ & $m$ & N & m & $m$ & $m$ & $m$ & $\bar{N}$ & $N$ & $F$ & $=$ & $m$ \\
\hline \multirow{2}{*}{ 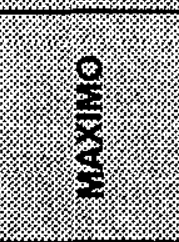 } & $\begin{array}{l}0 \\
0 \\
0\end{array}$ & & י্ল & 요 & 요 & 요 & 요 & Pי & 요 & י & i & 尺 & $\infty$ & $\oplus$ & 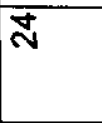 \\
\hline & $\begin{array}{l}\text { 兰 } \\
\text { 范 } \\
\end{array}$ & & $m$ & $m$ & $m$ & m & m & $m$ & $m$ & $m$ & $\bar{N}$ & $N$ & $F$ & $N$ & $m$ \\
\hline \multirow{2}{*}{ 1. } & 范 & & প & 品 & স্ল & স্ল & 요 & י & י & 品 & 品 & O & $\mathscr{O}$ & N & N \\
\hline & 弟 & & m & $m$ & $m$ & m & m & $m$ & $m$ & $m$ & m & m & $N$ & $m$ & m \\
\hline \multirow{2}{*}{ 衫 } & $\begin{array}{l}0 \\
0 \\
0\end{array}$ & & म्ल & 品 & প్ల & 只 & স & י্ল & p & 品 & Pि & 유 & 0 & $\mathscr{\theta}$ & ম \\
\hline & $\begin{array}{l}\text { 兰 } \\
\text { 焉 } \\
\end{array}$ & $\cdot$ & m & m & m & $m$ & क & $m$ & m & $m$ & m & $N$ & 0 & $N$ & $m$ \\
\hline \multirow{5}{*}{ 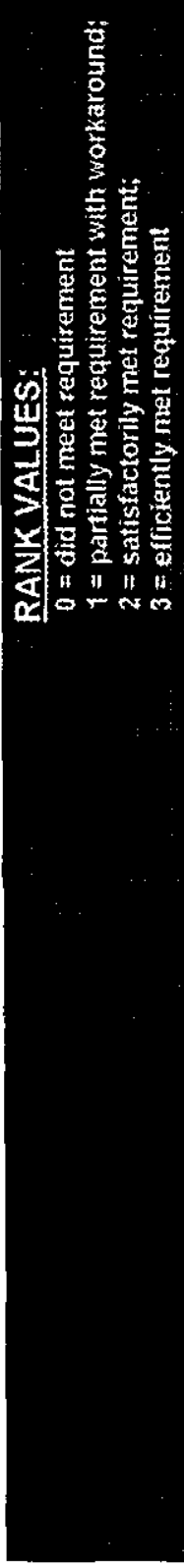 } & 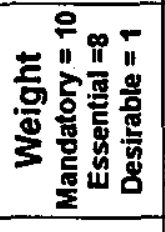 & & 음 & 유 & 으 & 웅 & 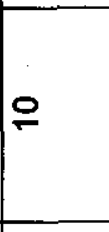 & 으 & 음 & $\stackrel{ }{\circ}$ & 음 & $\stackrel{\circ}{\circ}$ & $\infty$ & $\infty$ & $\infty$ \\
\hline & 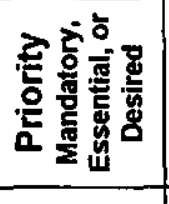 & & 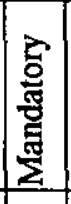 & 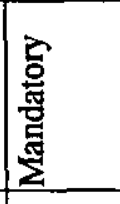 & 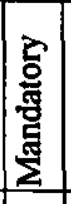 & 홍 & 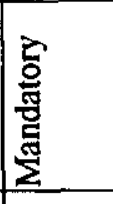 & 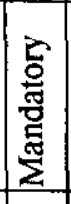 & 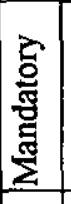 & 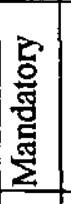 & 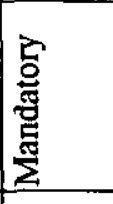 & 它 & 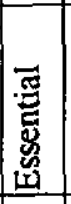 & 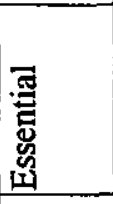 & 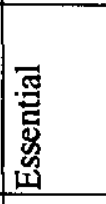 \\
\hline & 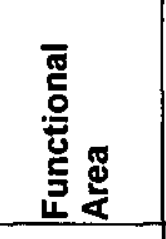 & & 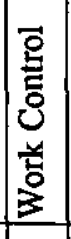 & $\begin{array}{l}\overline{0} \\
0 \\
0 \\
0 \\
0 \\
0 \\
0\end{array}$ & 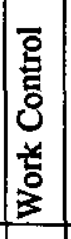 & 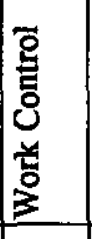 & 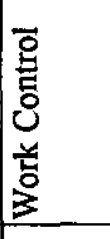 & 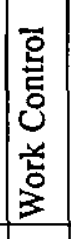 & 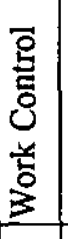 & 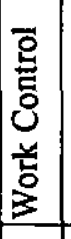 & 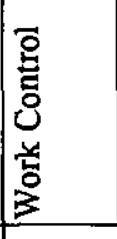 & 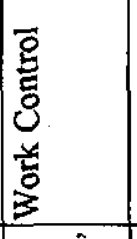 & 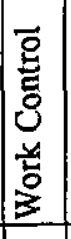 & 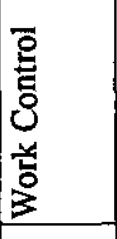 & 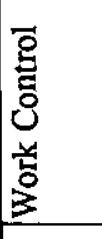 \\
\hline & 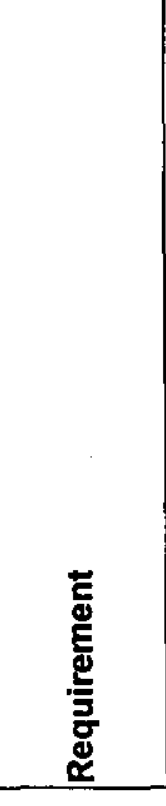 & 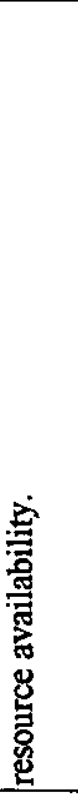 & 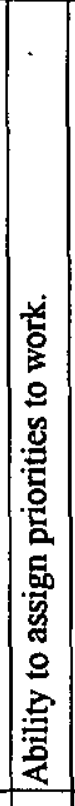 & 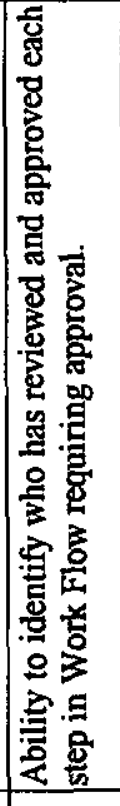 & 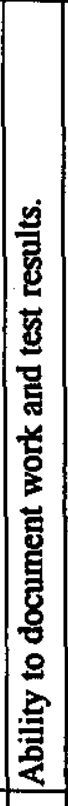 & 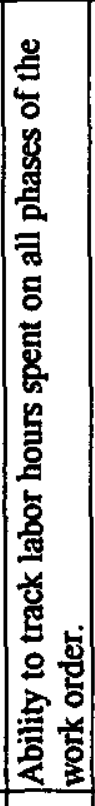 & 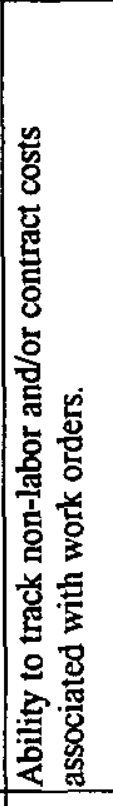 & 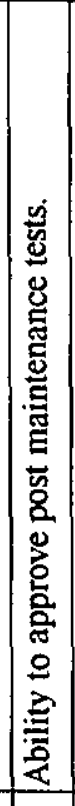 & 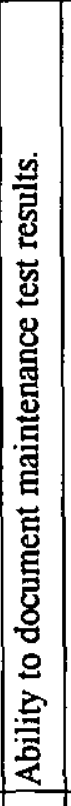 & 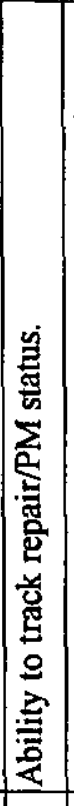 & 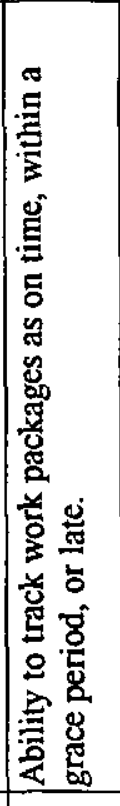 & 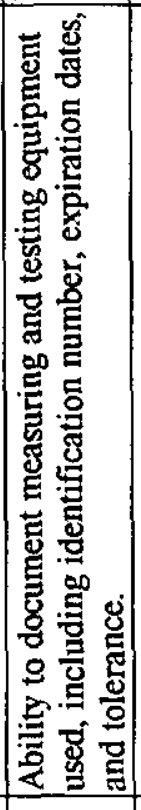 & 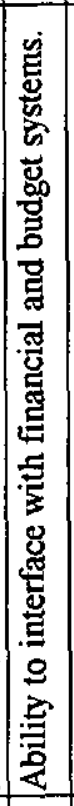 & 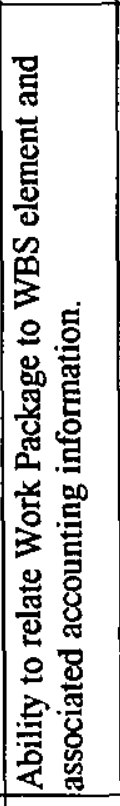 & 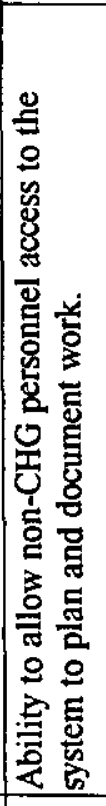 \\
\hline & 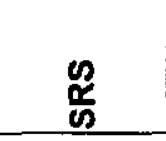 & & $\begin{array}{l}\exists \\
\dot{\sim} \\
\sim \\
m\end{array}$ & $\begin{array}{l}\tilde{J} \\
\dot{j} \\
\ddot{\sim} \\
m\end{array}$ & \begin{tabular}{c}
$m$ \\
\hdashline \\
$\dot{d}$ \\
$\tilde{m}$ \\
$m$
\end{tabular} & 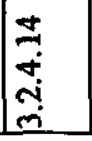 & \begin{tabular}{l}
$n$ \\
\hdashline \\
$\dot{n}$ \\
$\tilde{n}$ \\
$m$
\end{tabular} & $\mid$\begin{tabular}{c}
0 \\
\hdashline \\
$\dot{a}$ \\
$m$ \\
$m$
\end{tabular} & 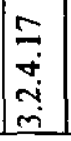 & $\begin{array}{l}\infty \\
\ddot{+} \\
\tilde{j} \\
\tilde{m}\end{array}$ & $\begin{array}{l}a \\
\dot{j} \\
\dot{i} \\
\dot{m}\end{array}$ & 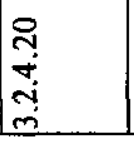 & $\begin{array}{l}\vec{N} \\
\dot{v} \\
\tilde{u} \\
\tilde{m}\end{array}$ & $\begin{array}{l}\tilde{N} \\
\stackrel{\sim}{\sim} \\
\tilde{m}\end{array}$ & $\begin{array}{r}\tilde{y} \\
\ddot{i} \\
\tilde{n} \\
\tilde{m}\end{array}$ \\
\hline
\end{tabular}




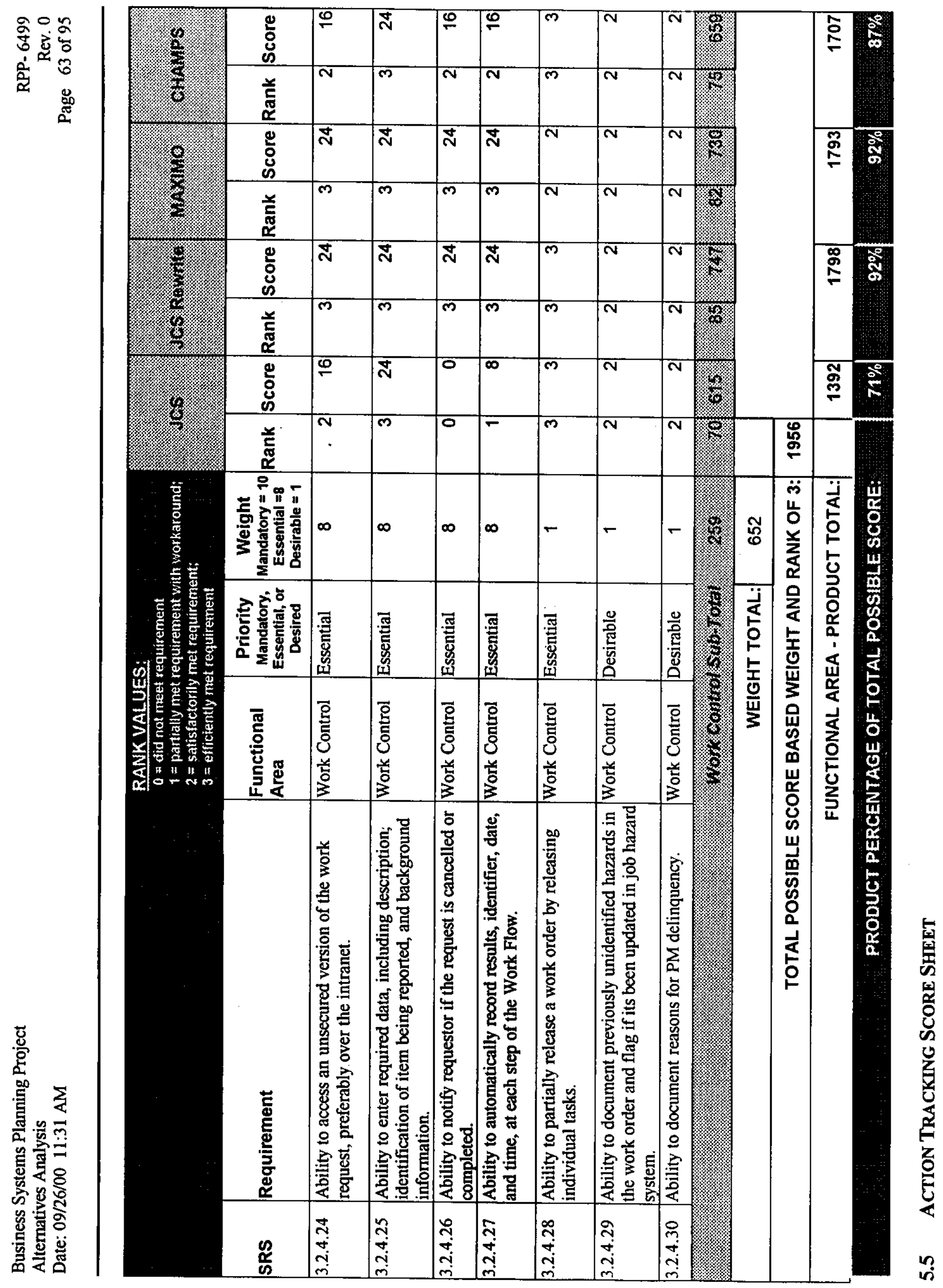




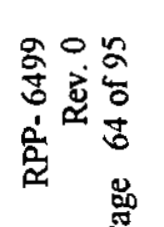

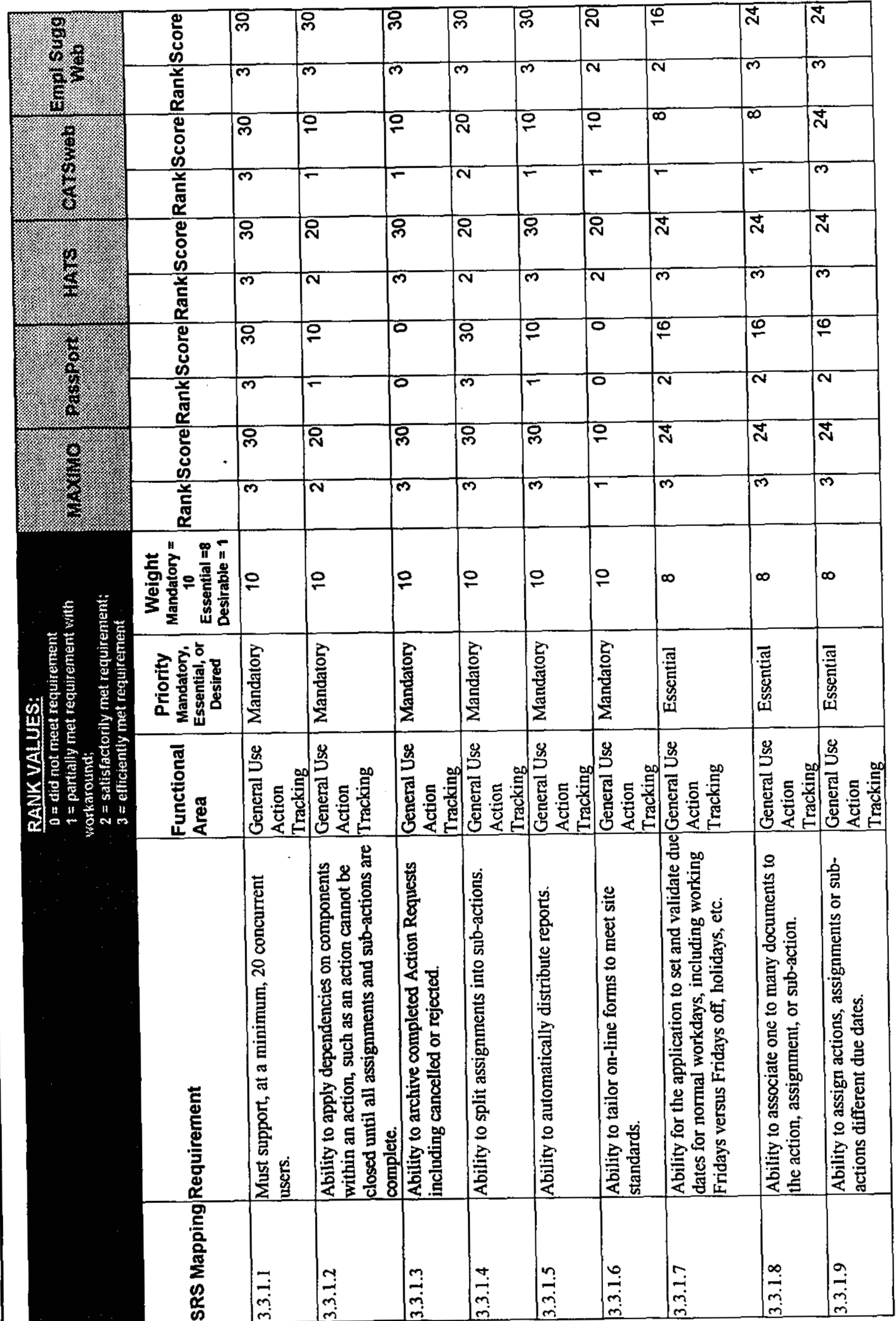




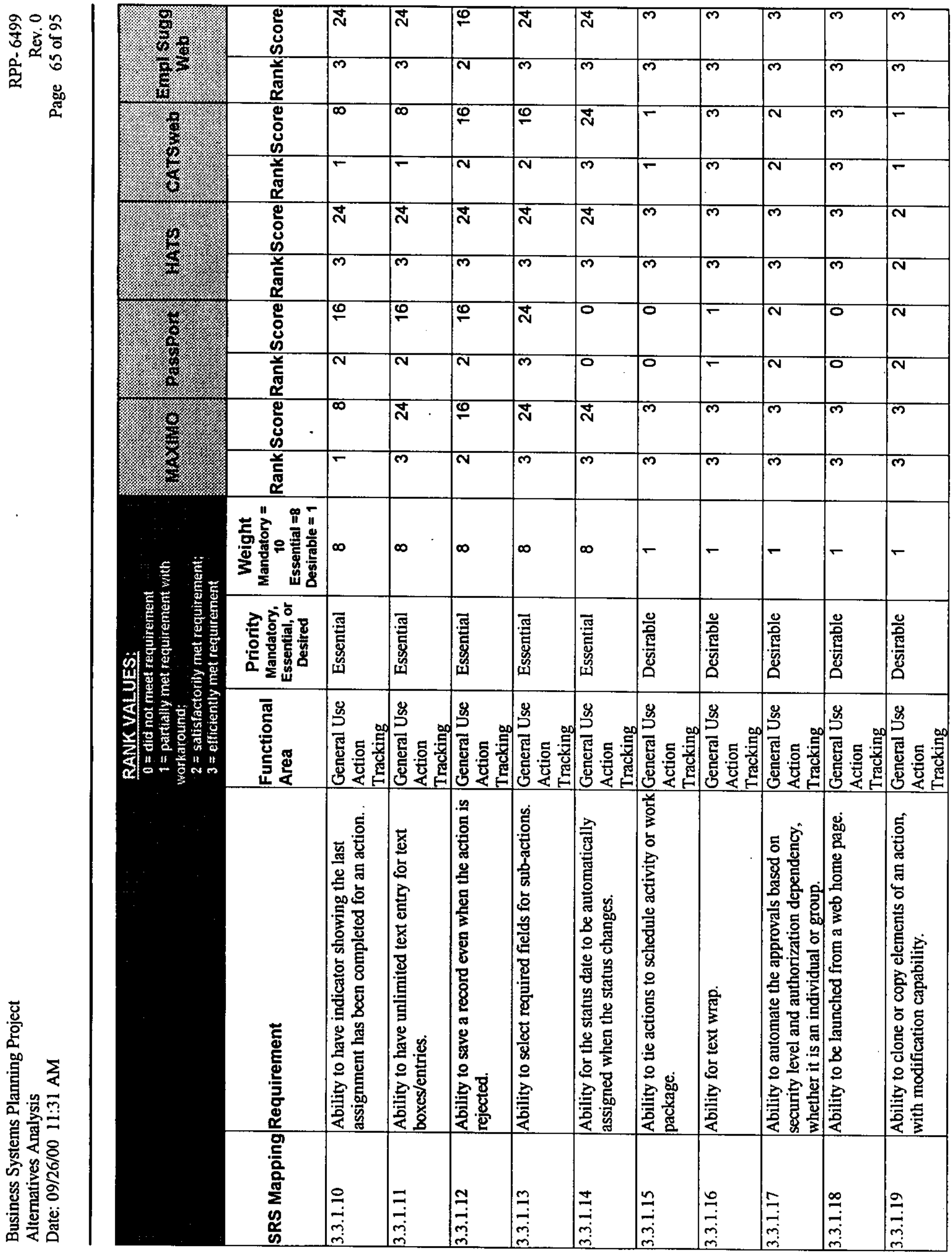




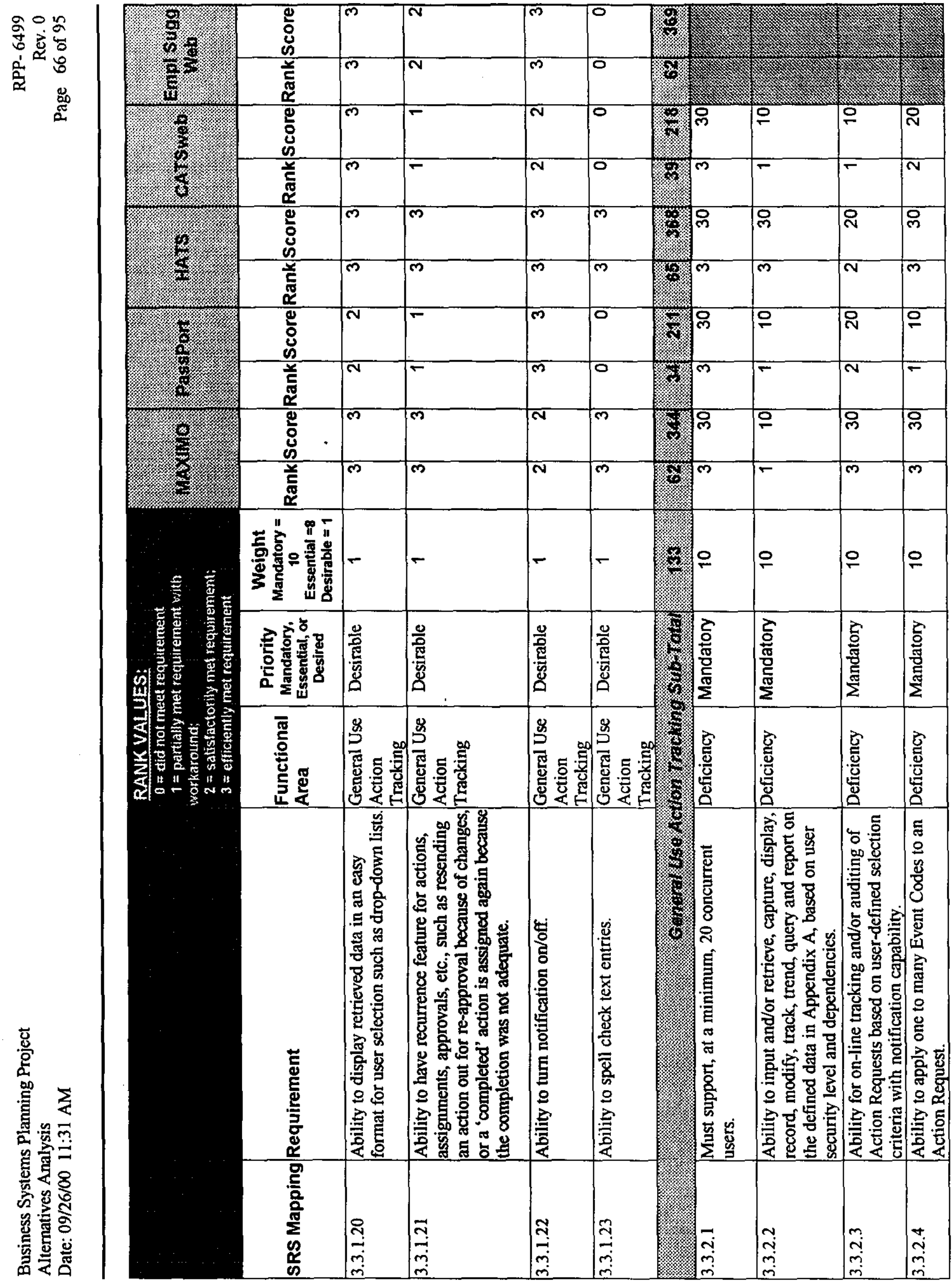




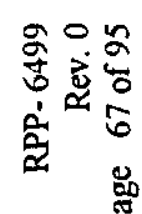

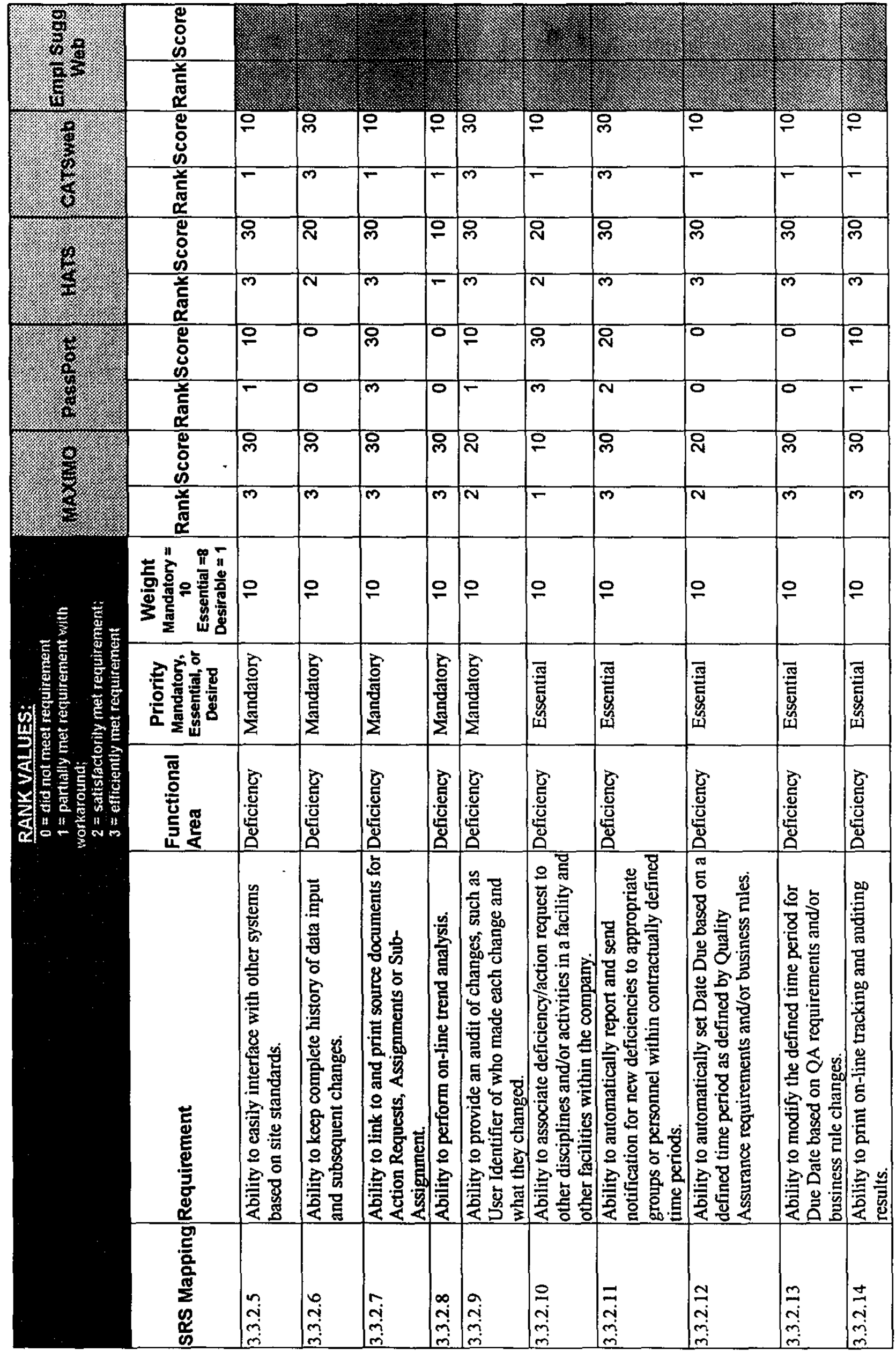




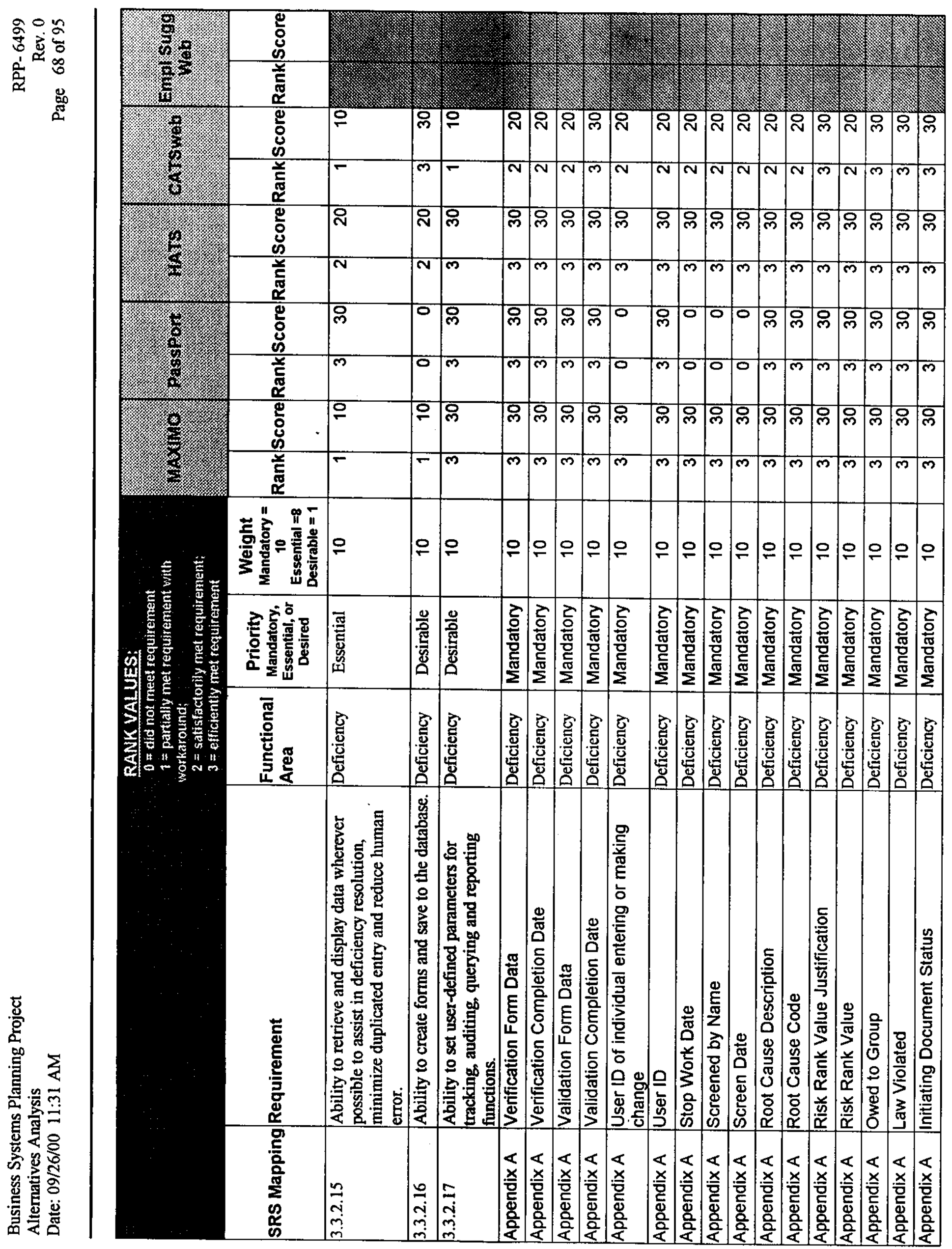




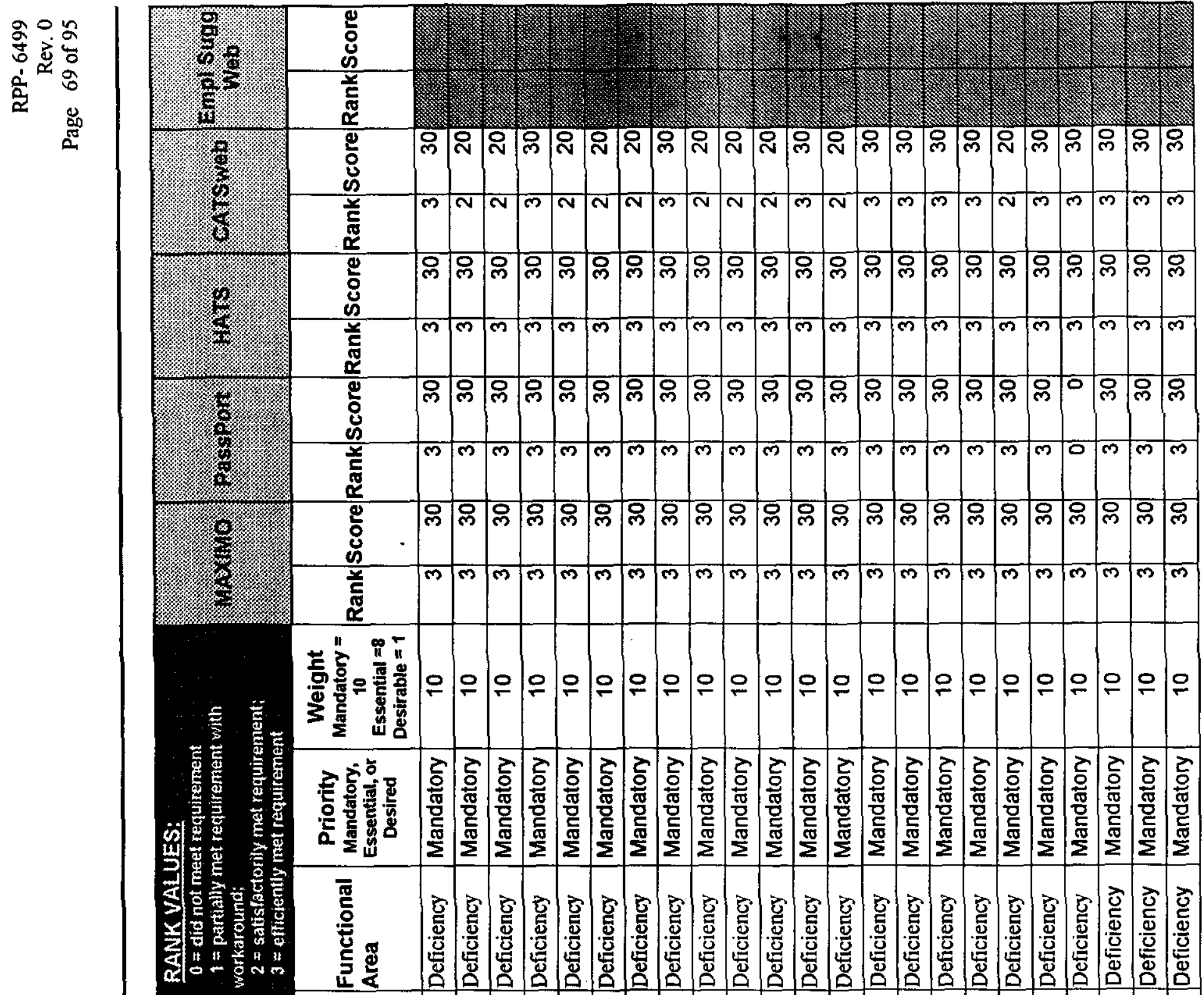

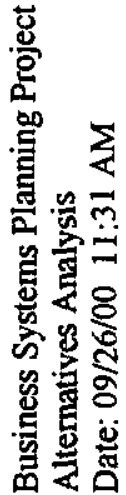

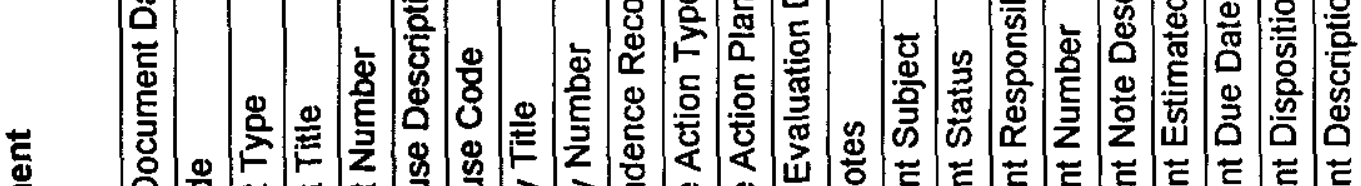
O) 莺 焉 焉

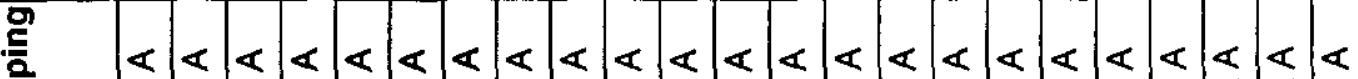

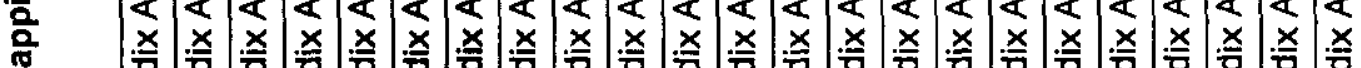

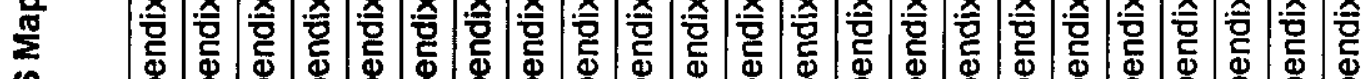

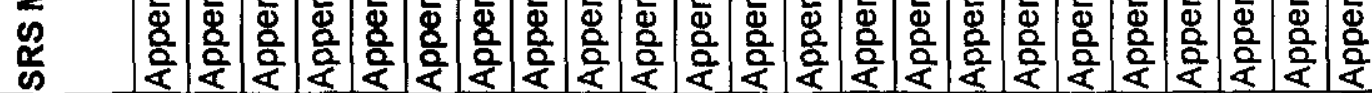




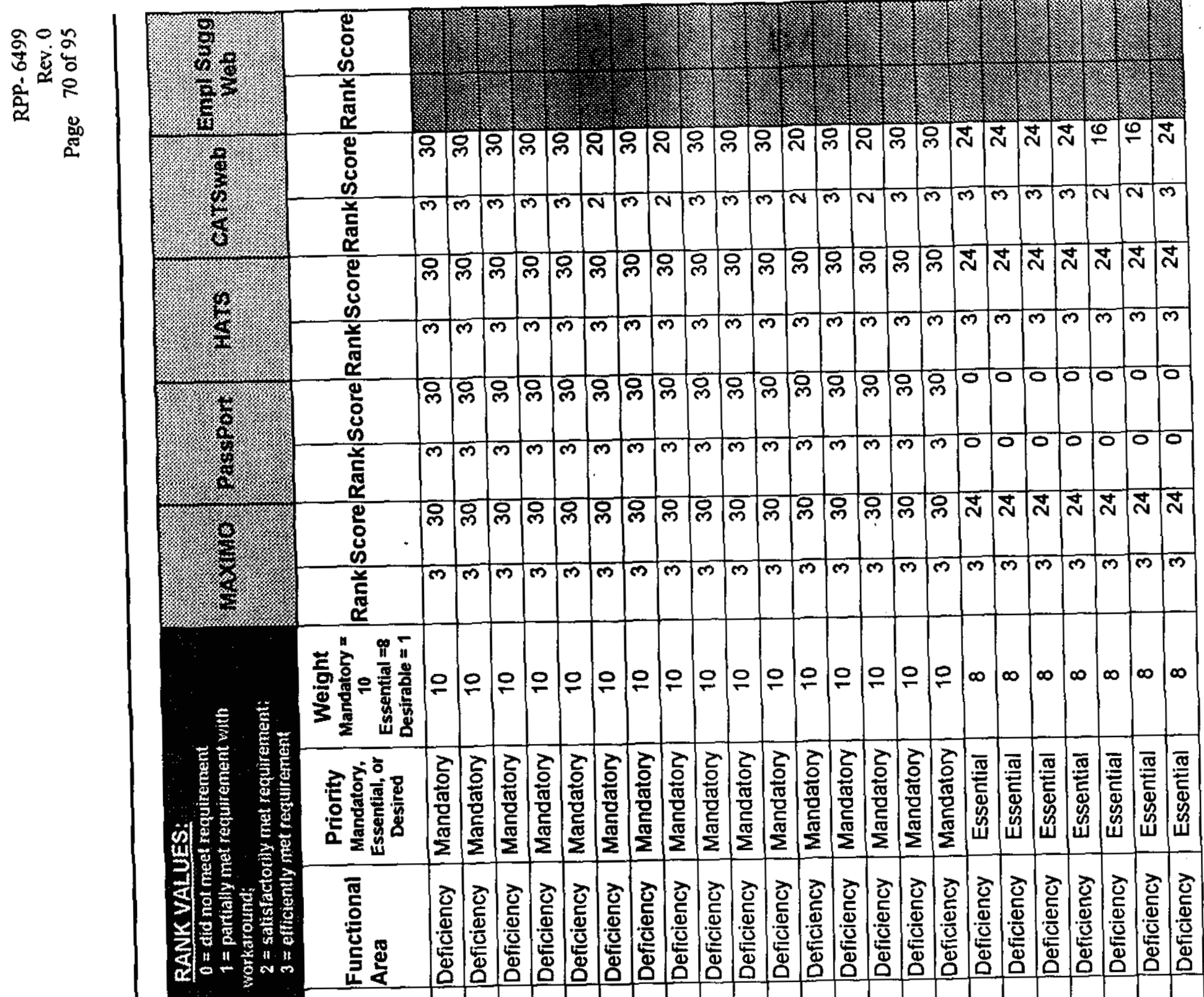

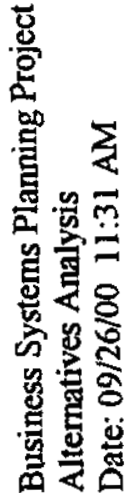

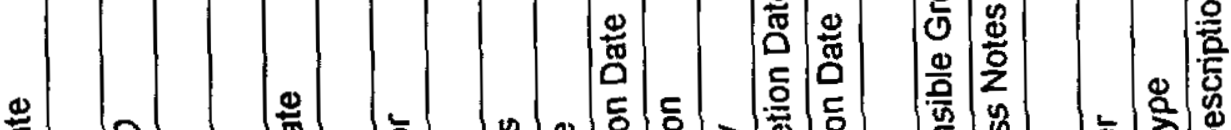
离

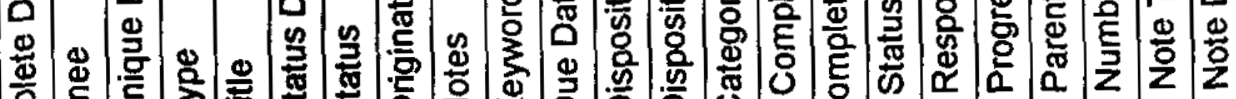

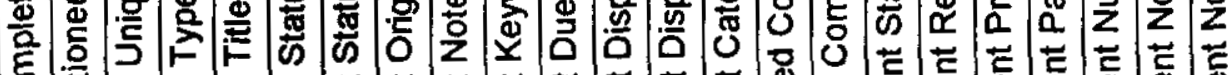

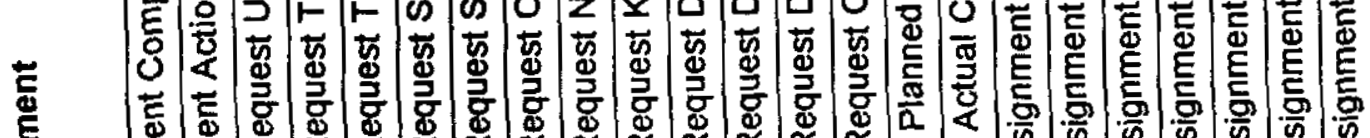
E E 兽

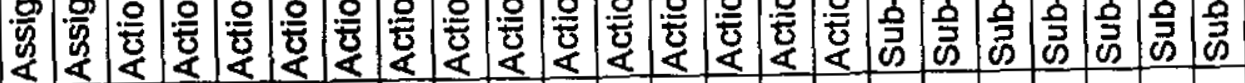
官

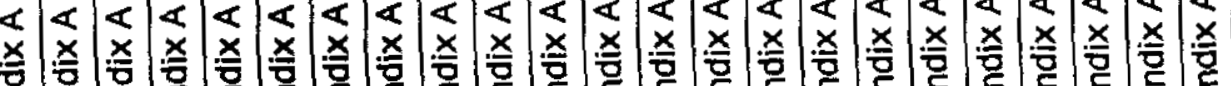
흘

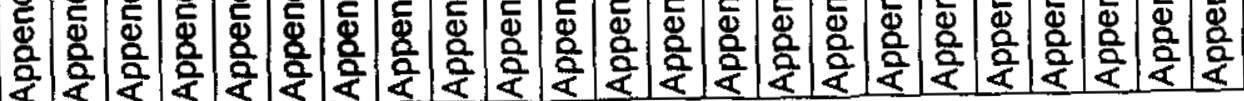




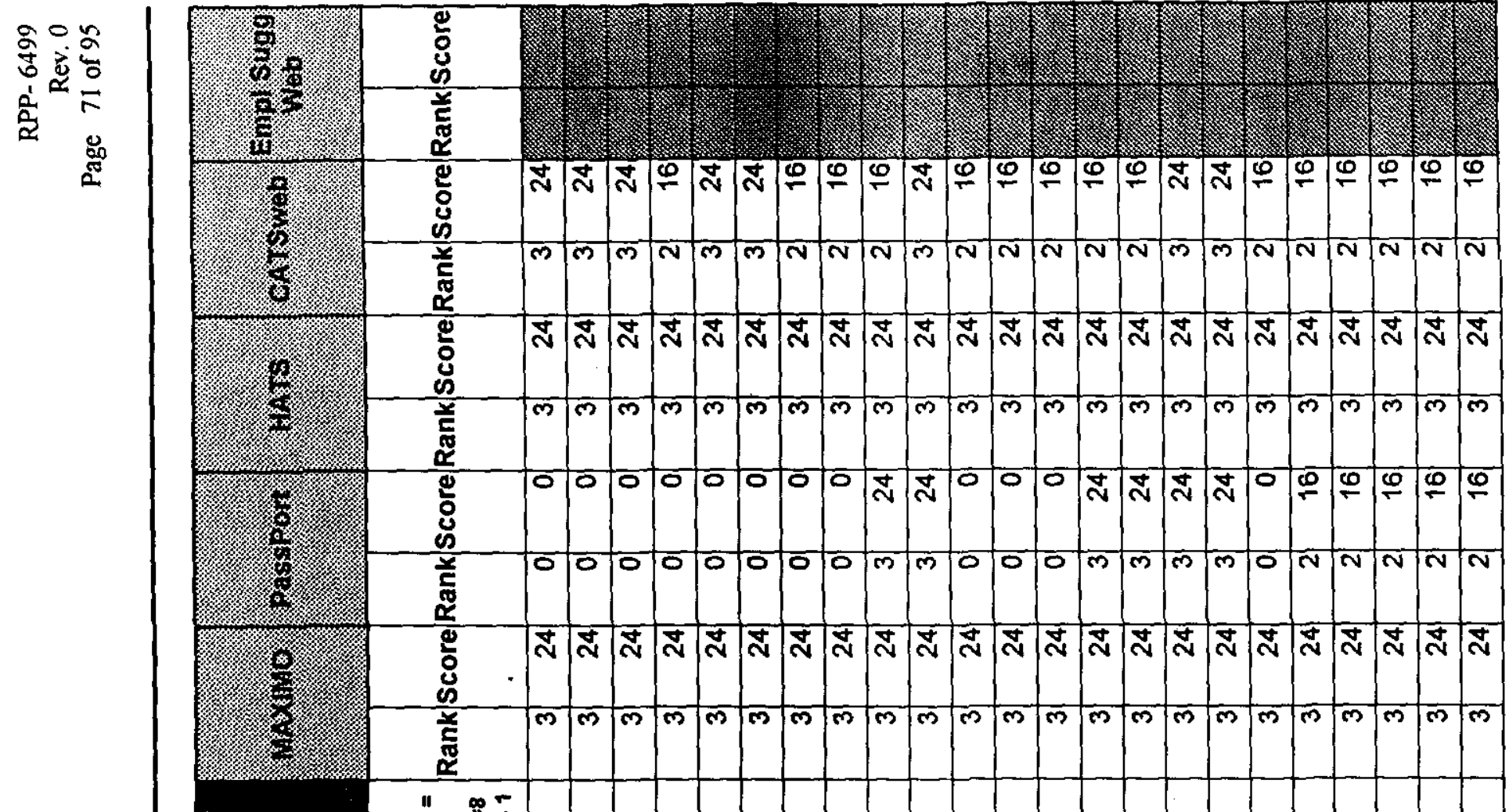

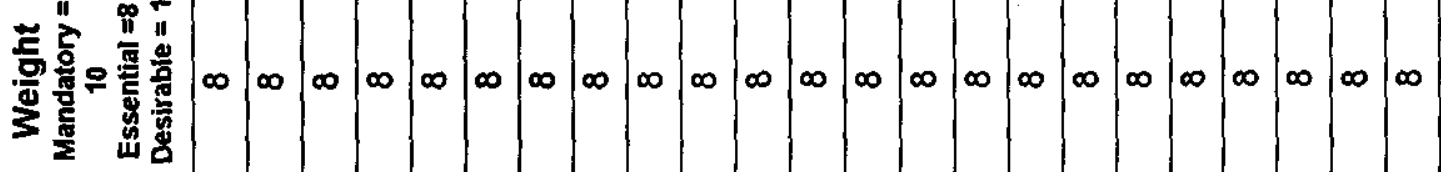

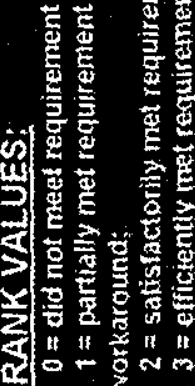

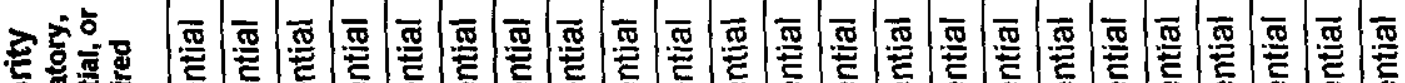

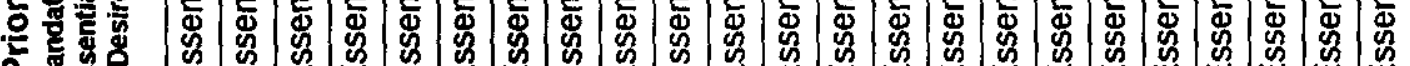

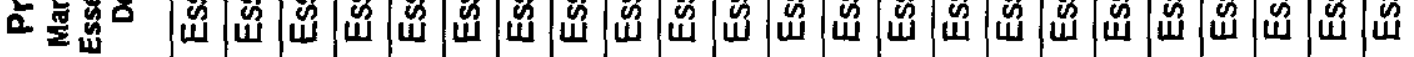
ज उ

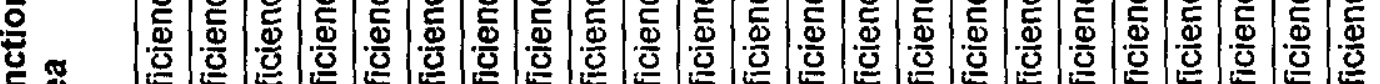
声管 峞

ธ

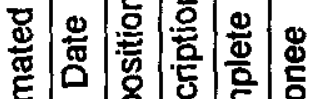
吾

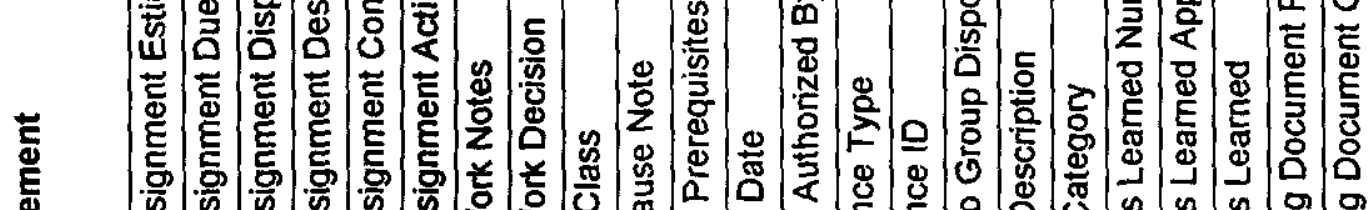

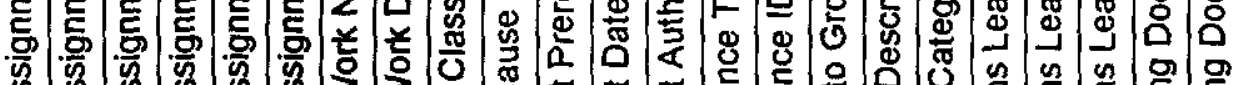

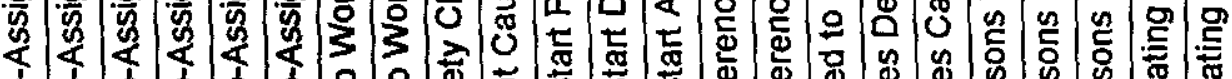
恶 立 言 $|<|<|<|<|<|<|<|<|<|<|<|<|<|<|<|<|<|<|<|<|<|<\mid<$ 定

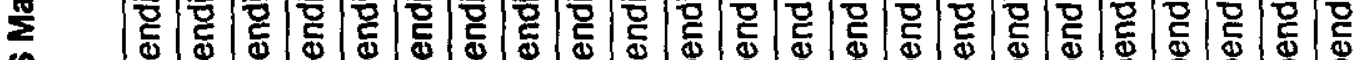

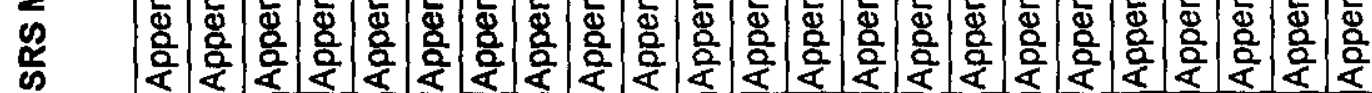




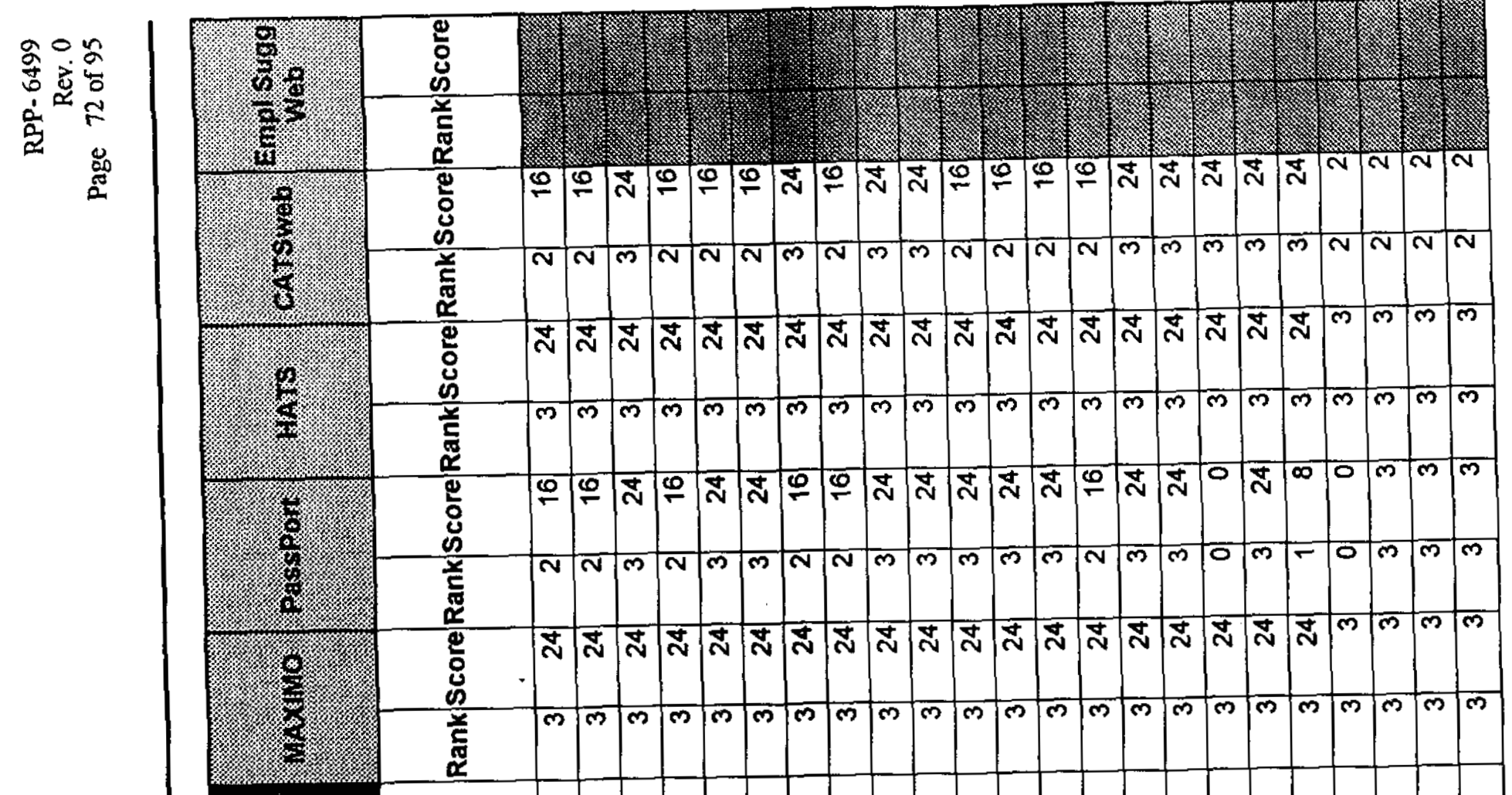

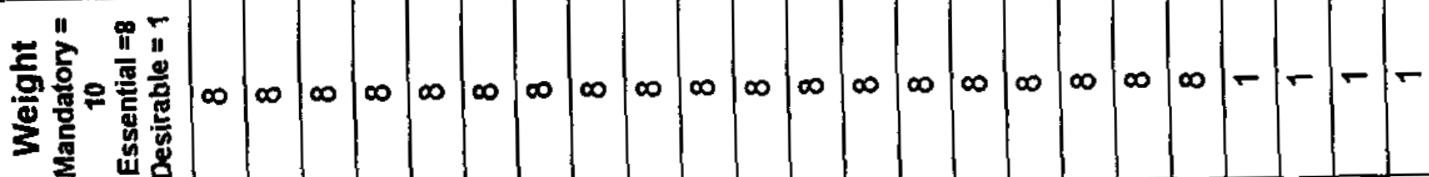

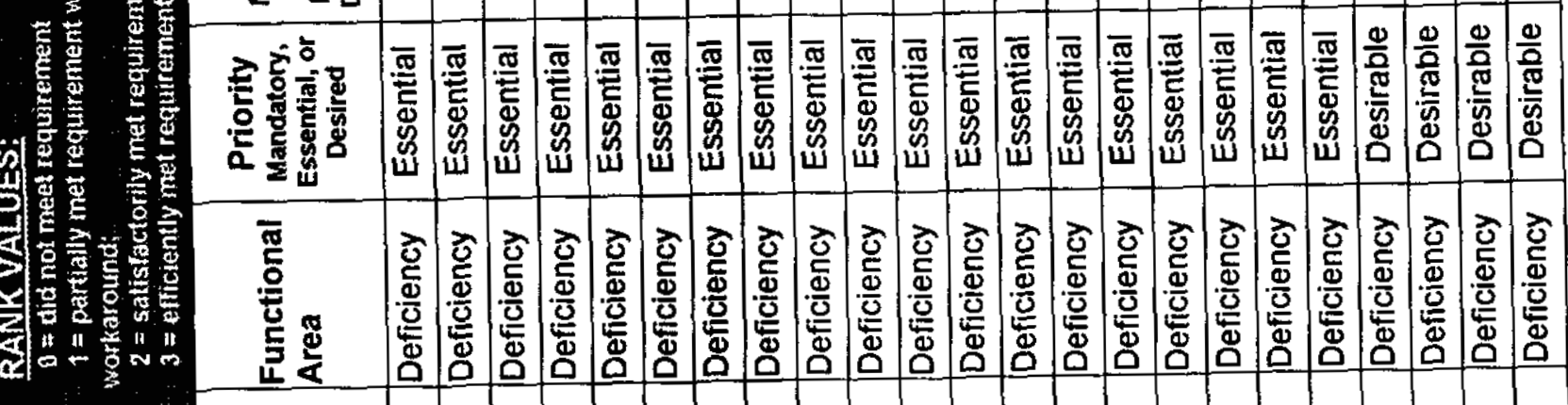

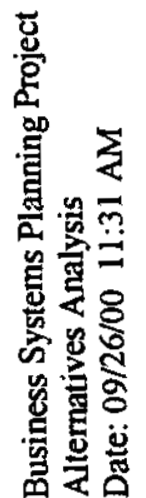

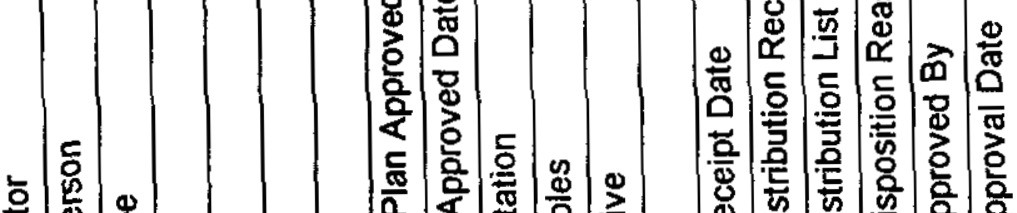

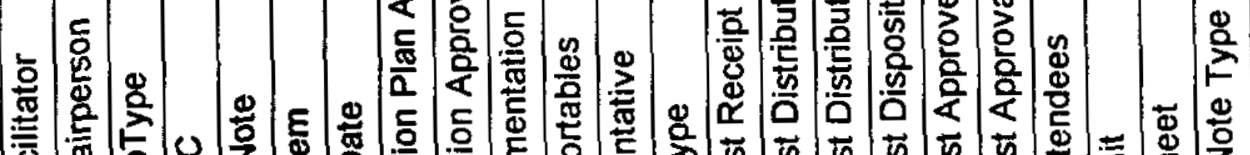

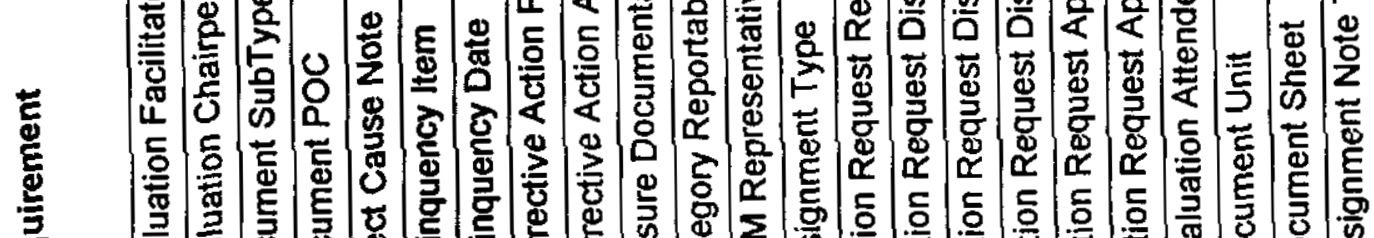

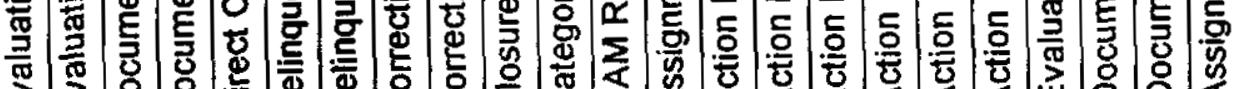

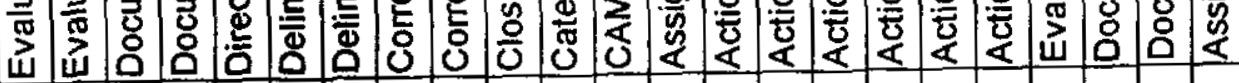

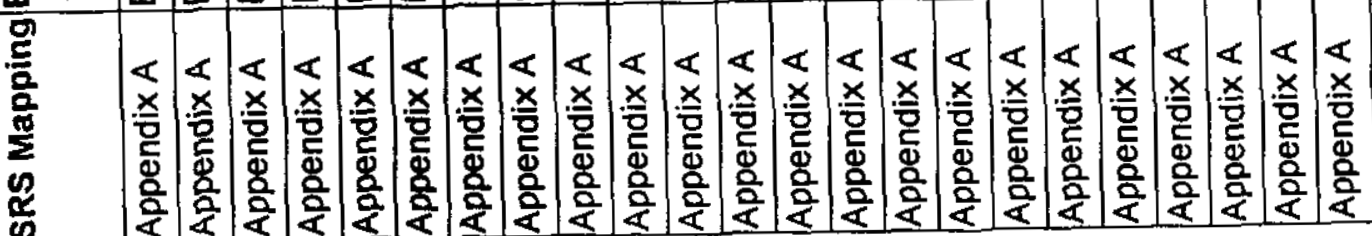




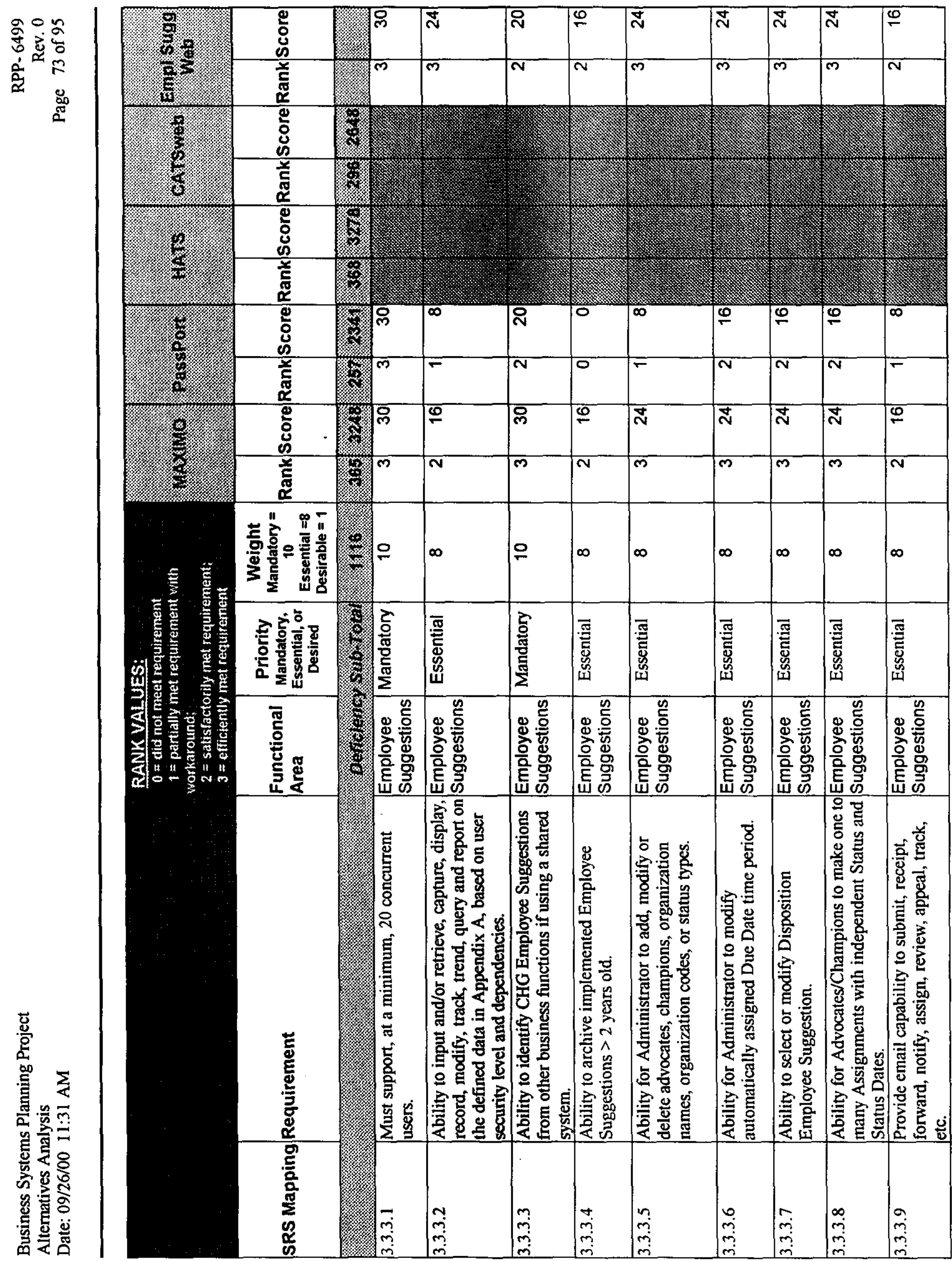




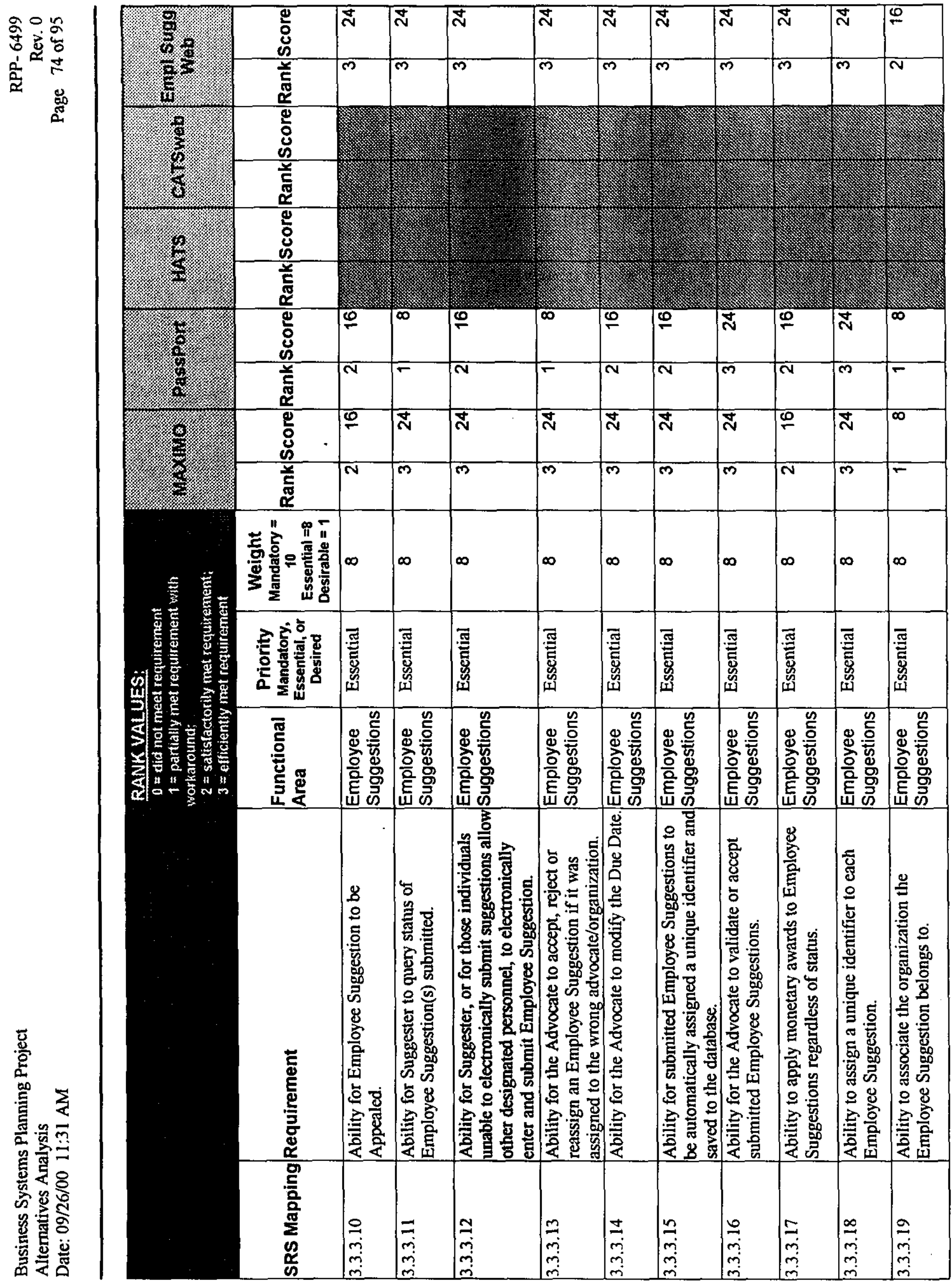




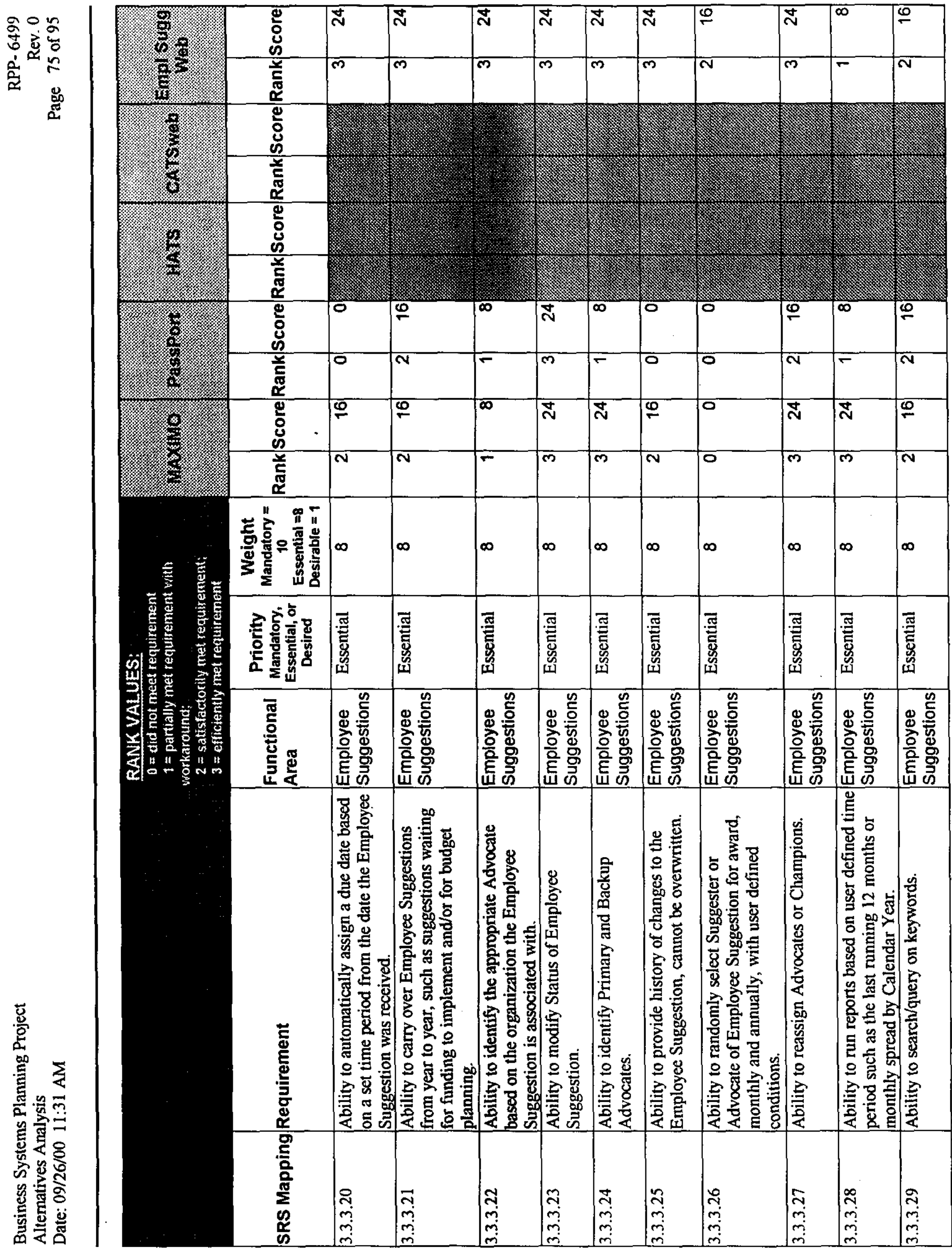




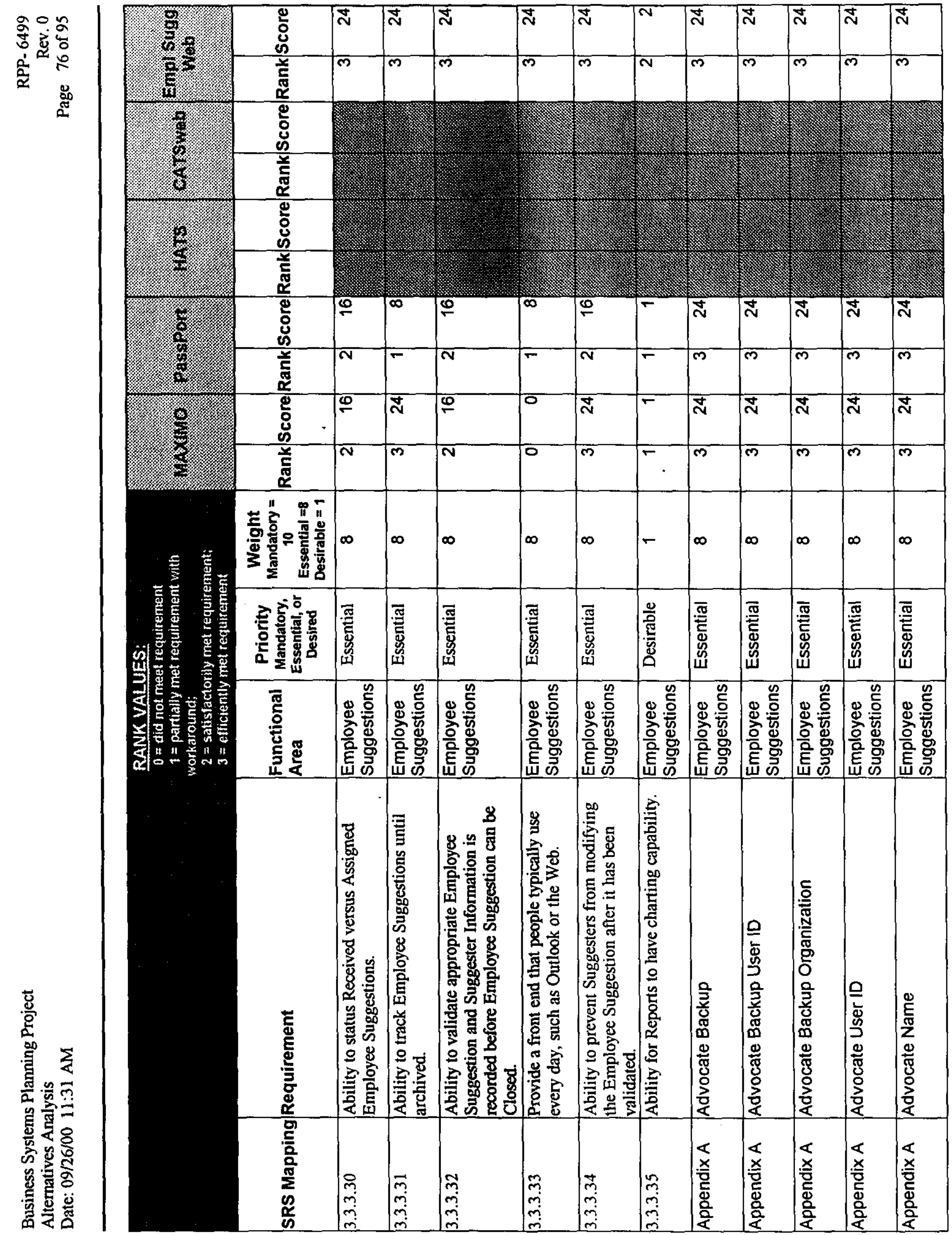




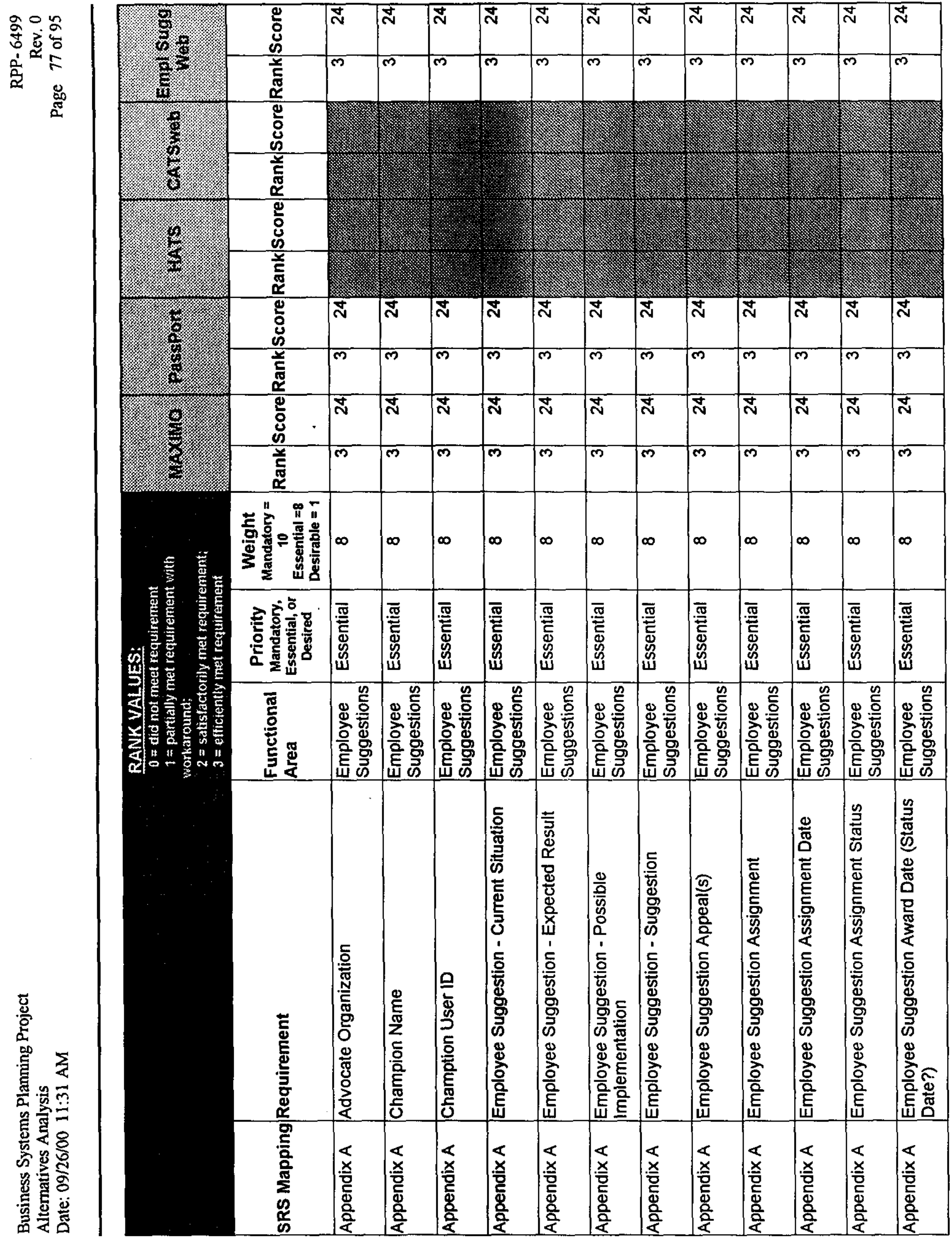




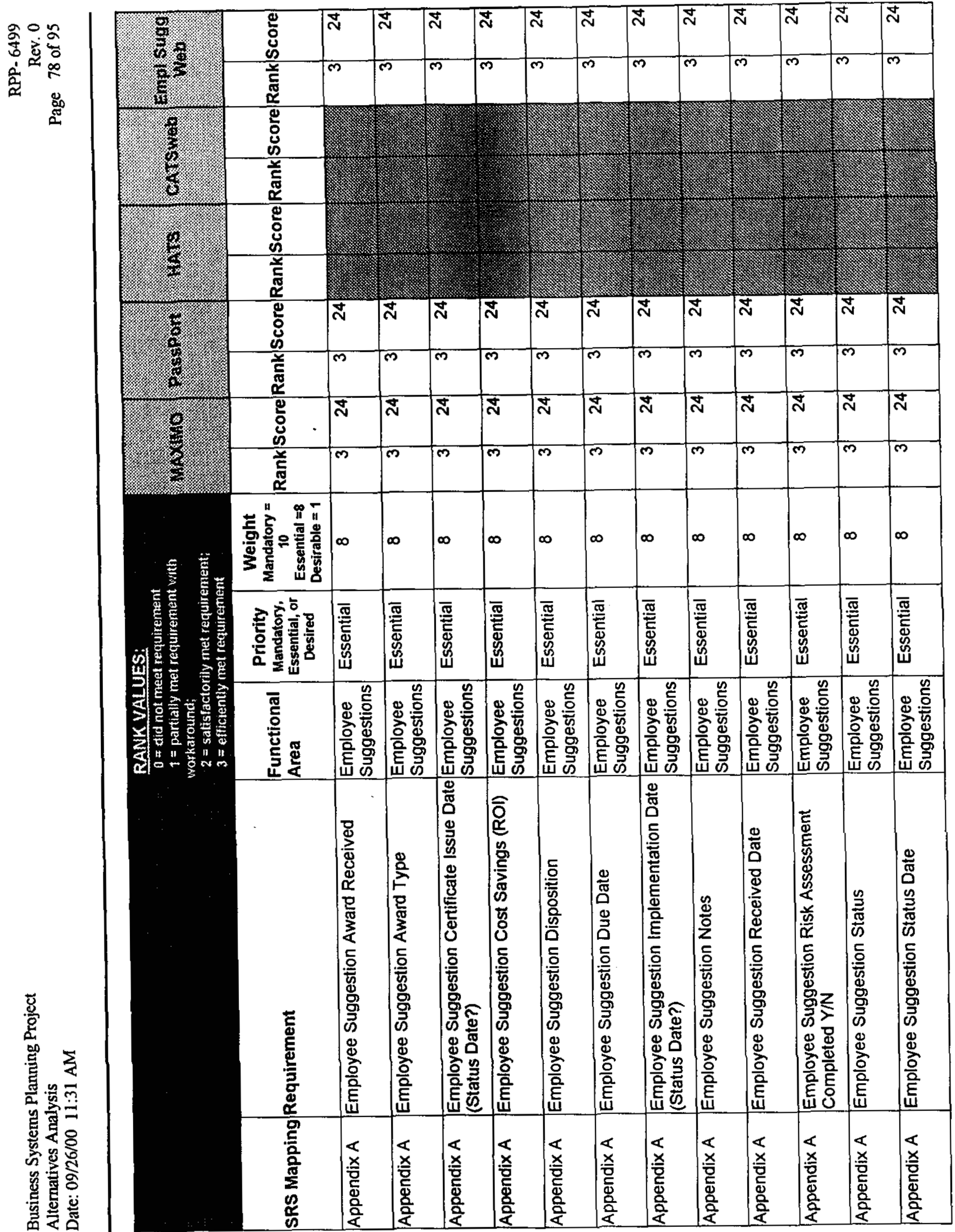




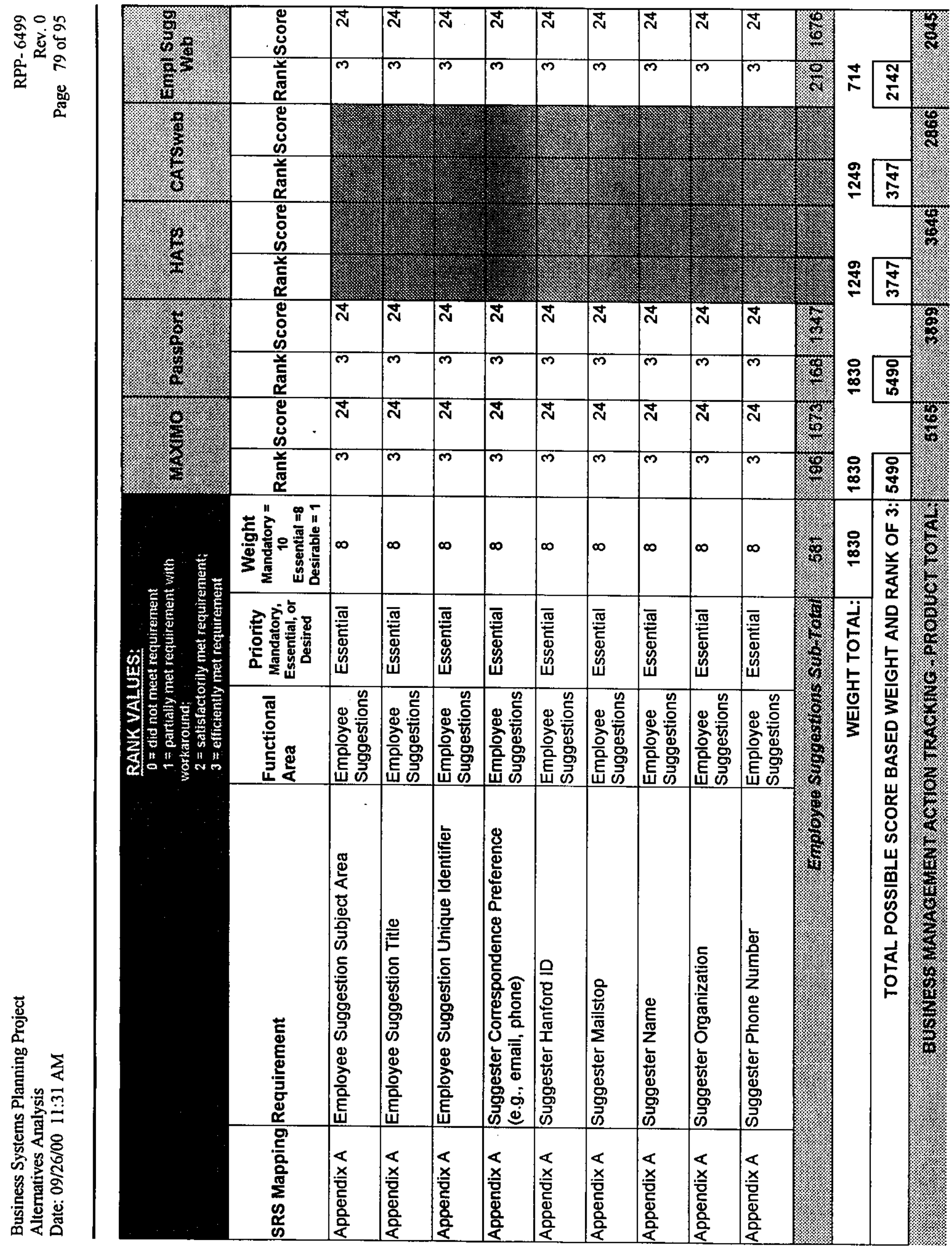




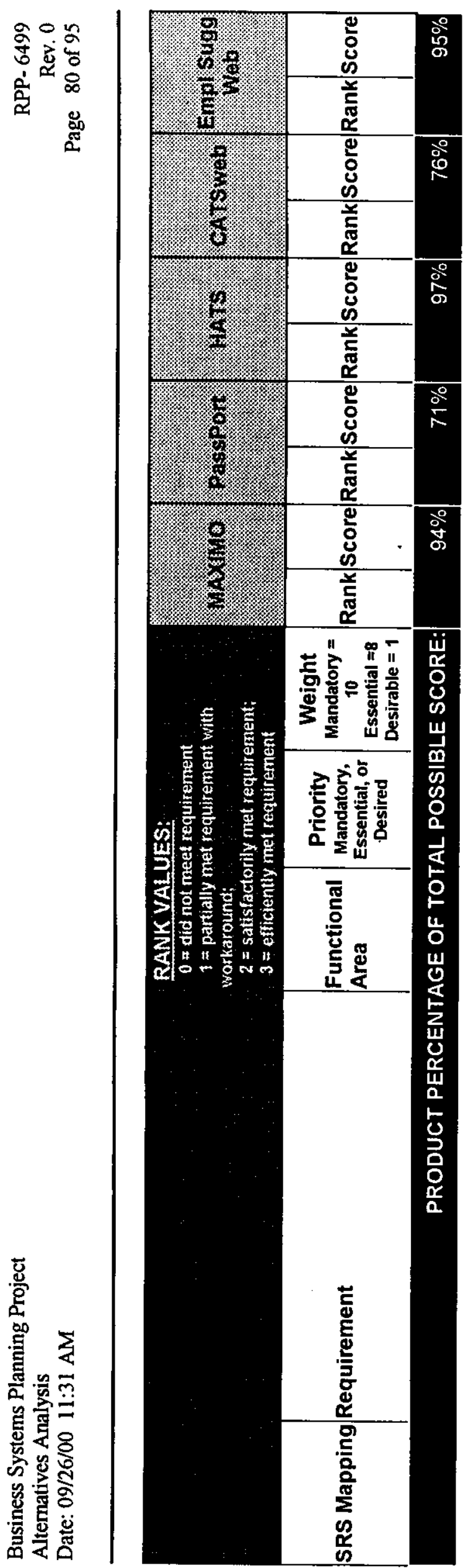









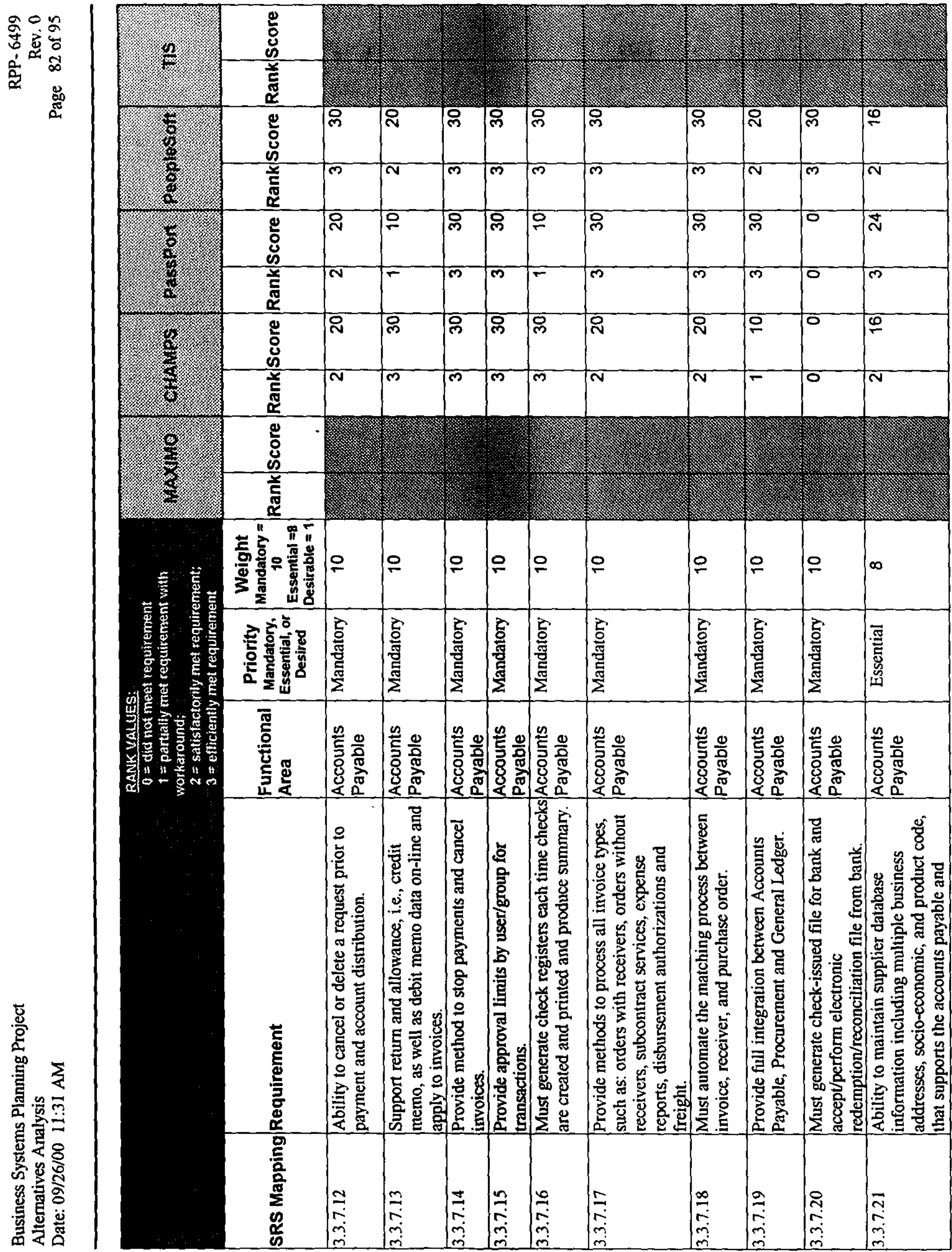




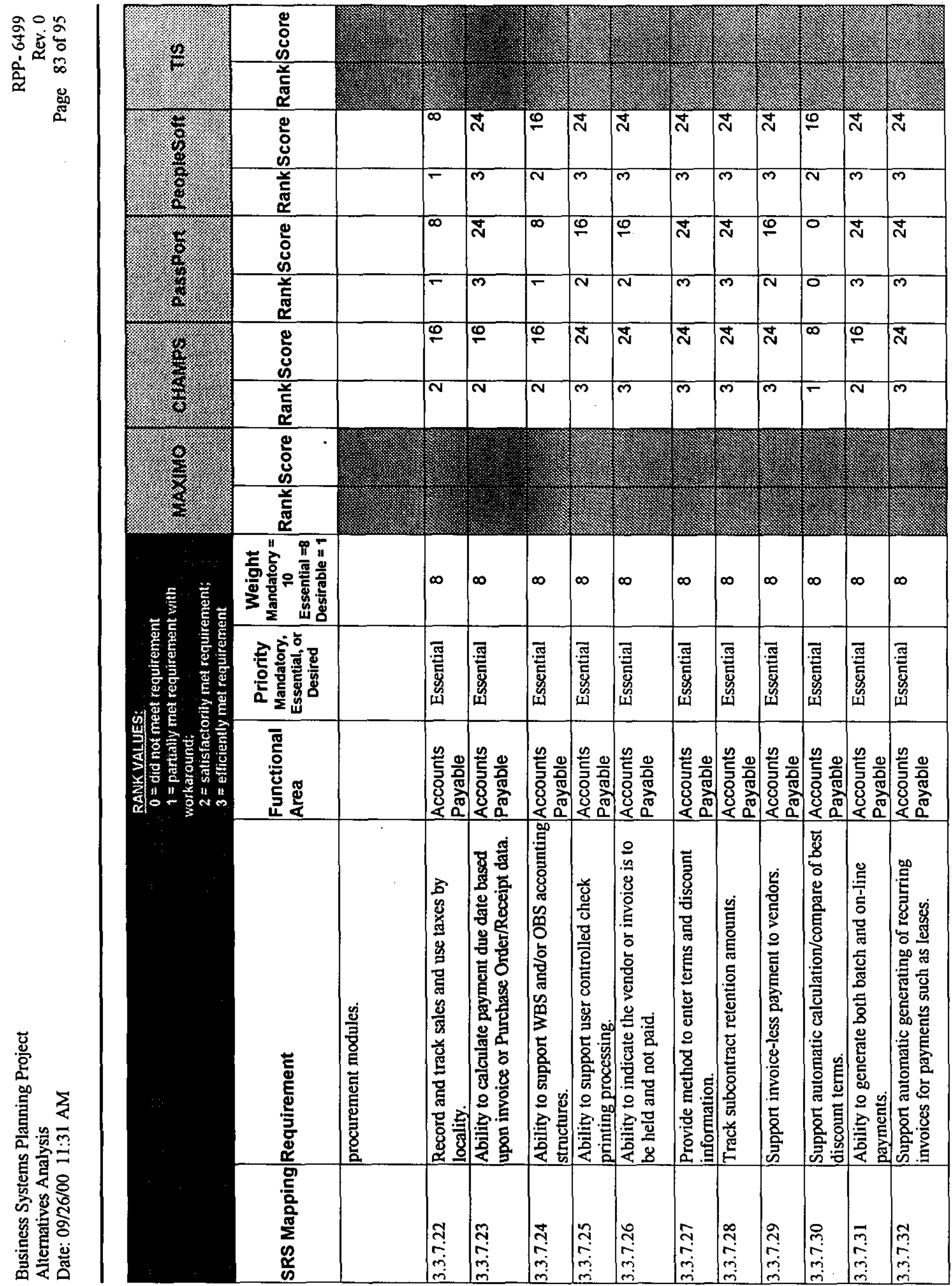




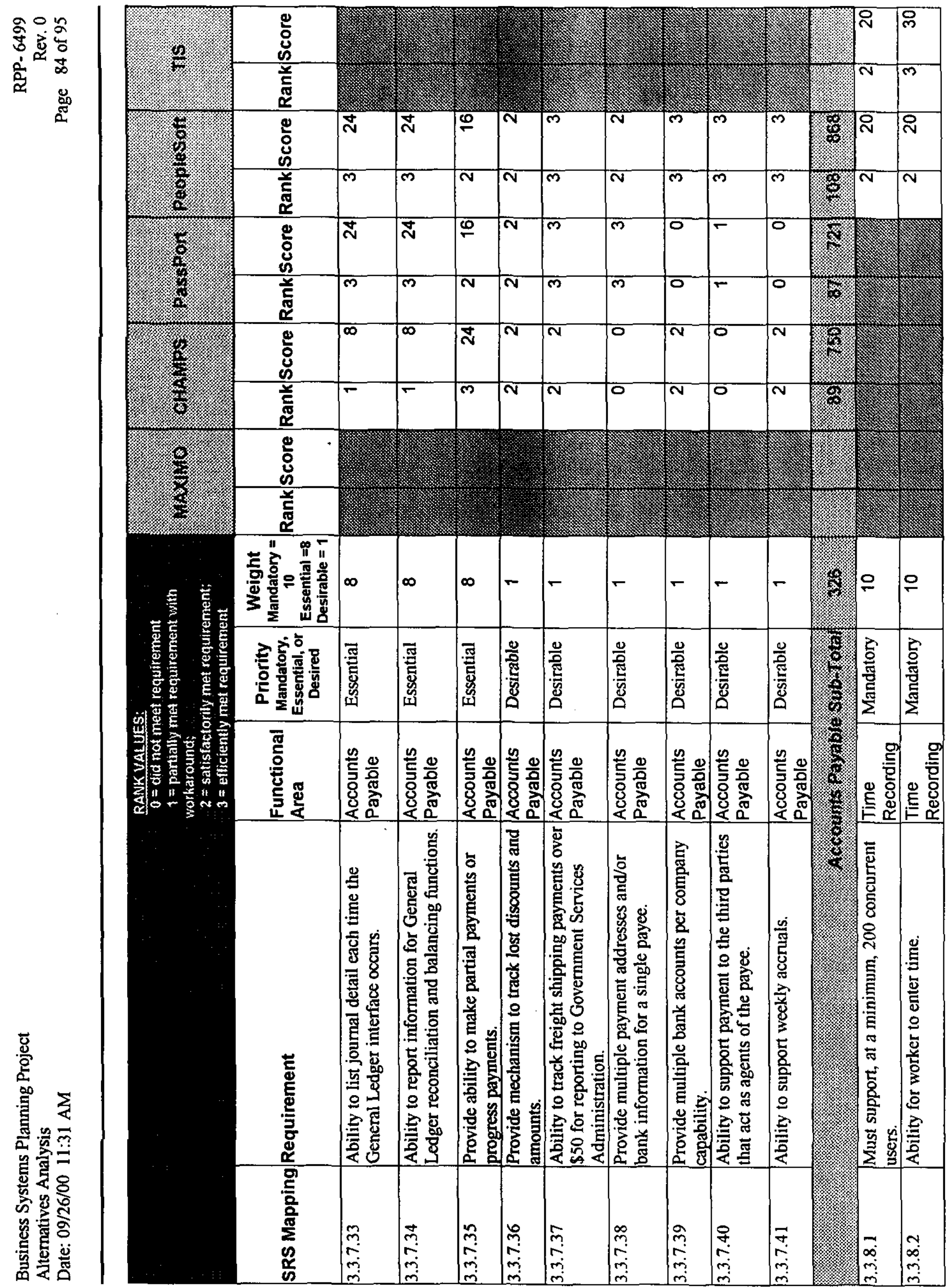




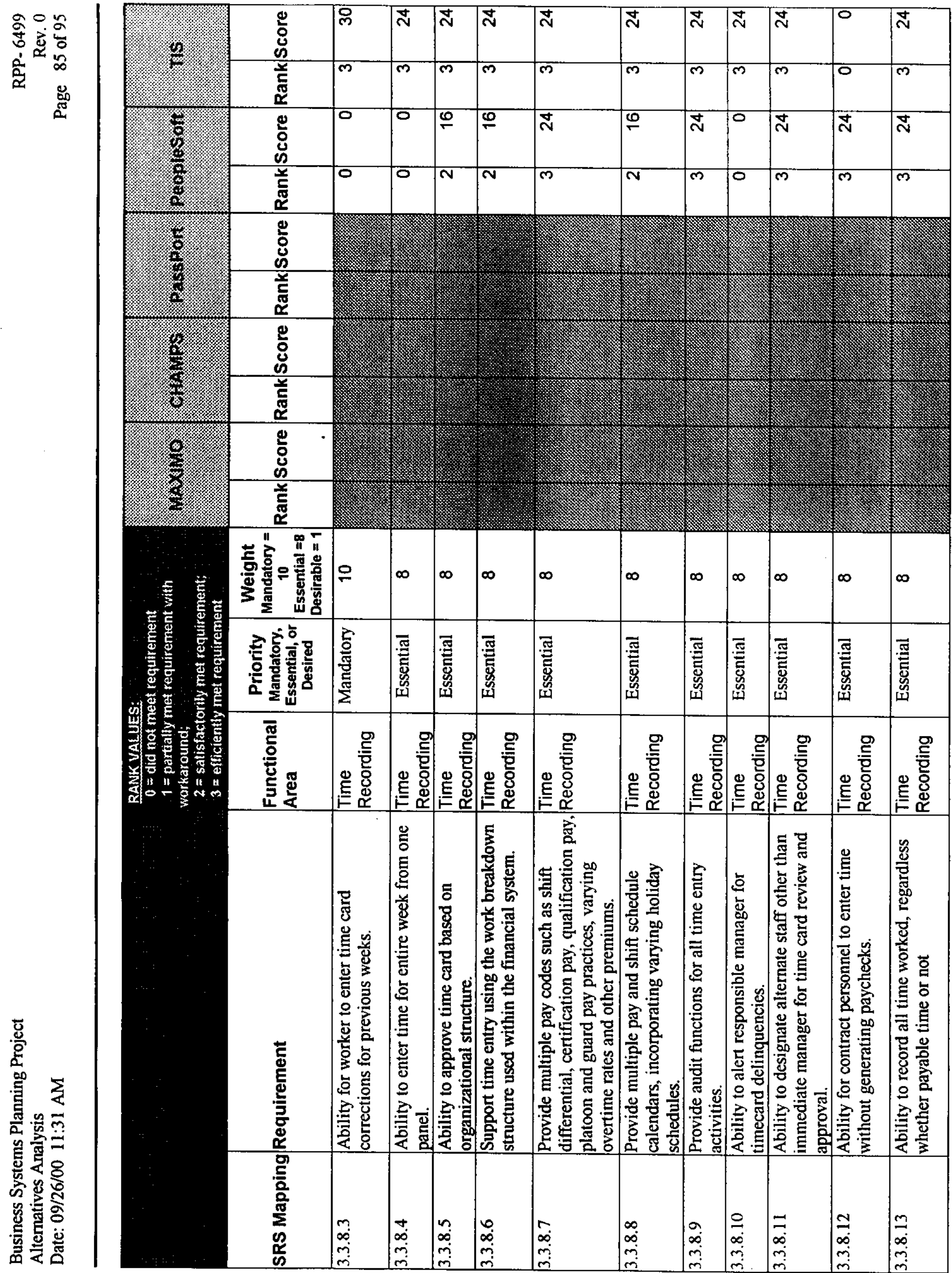




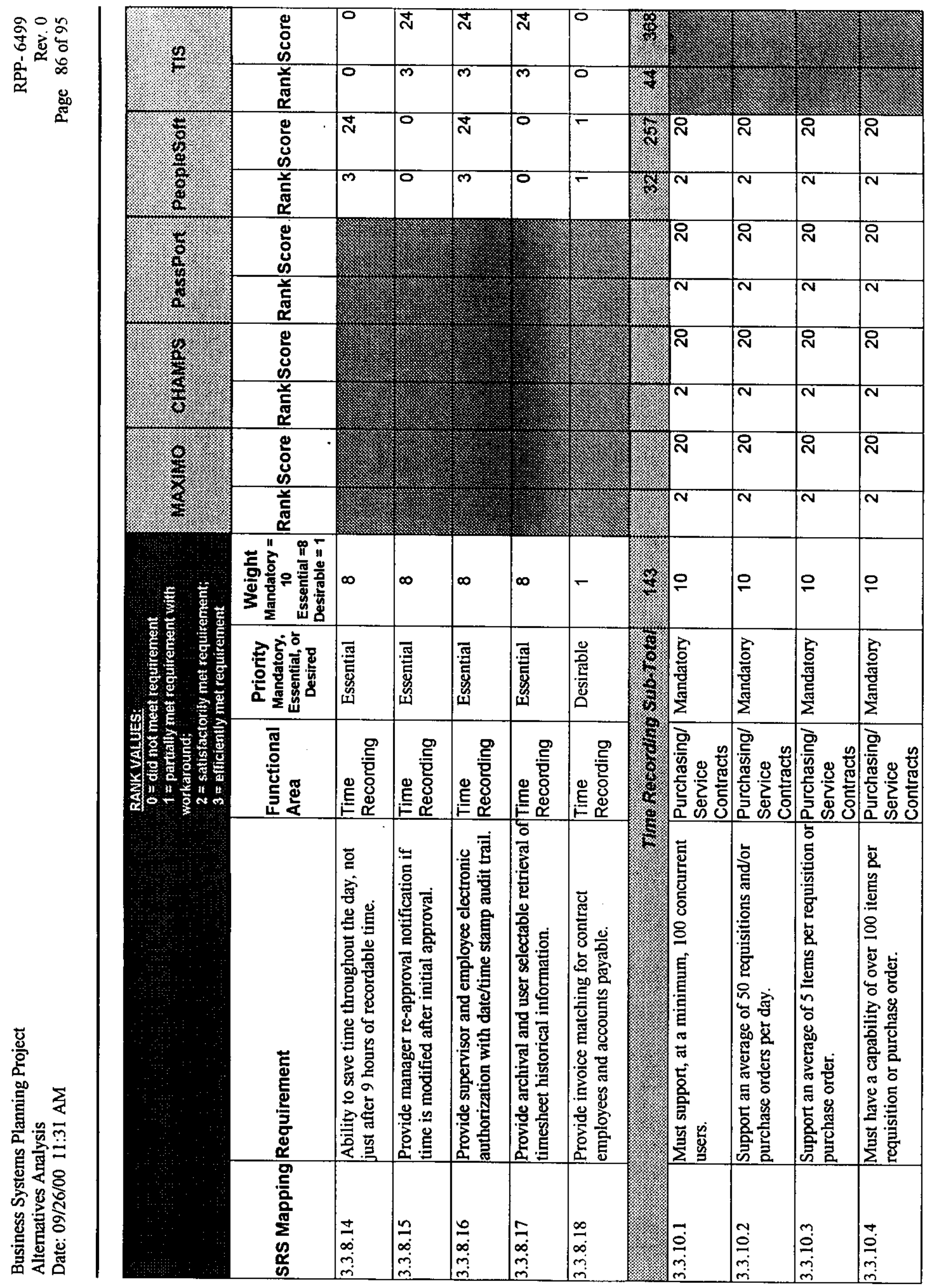




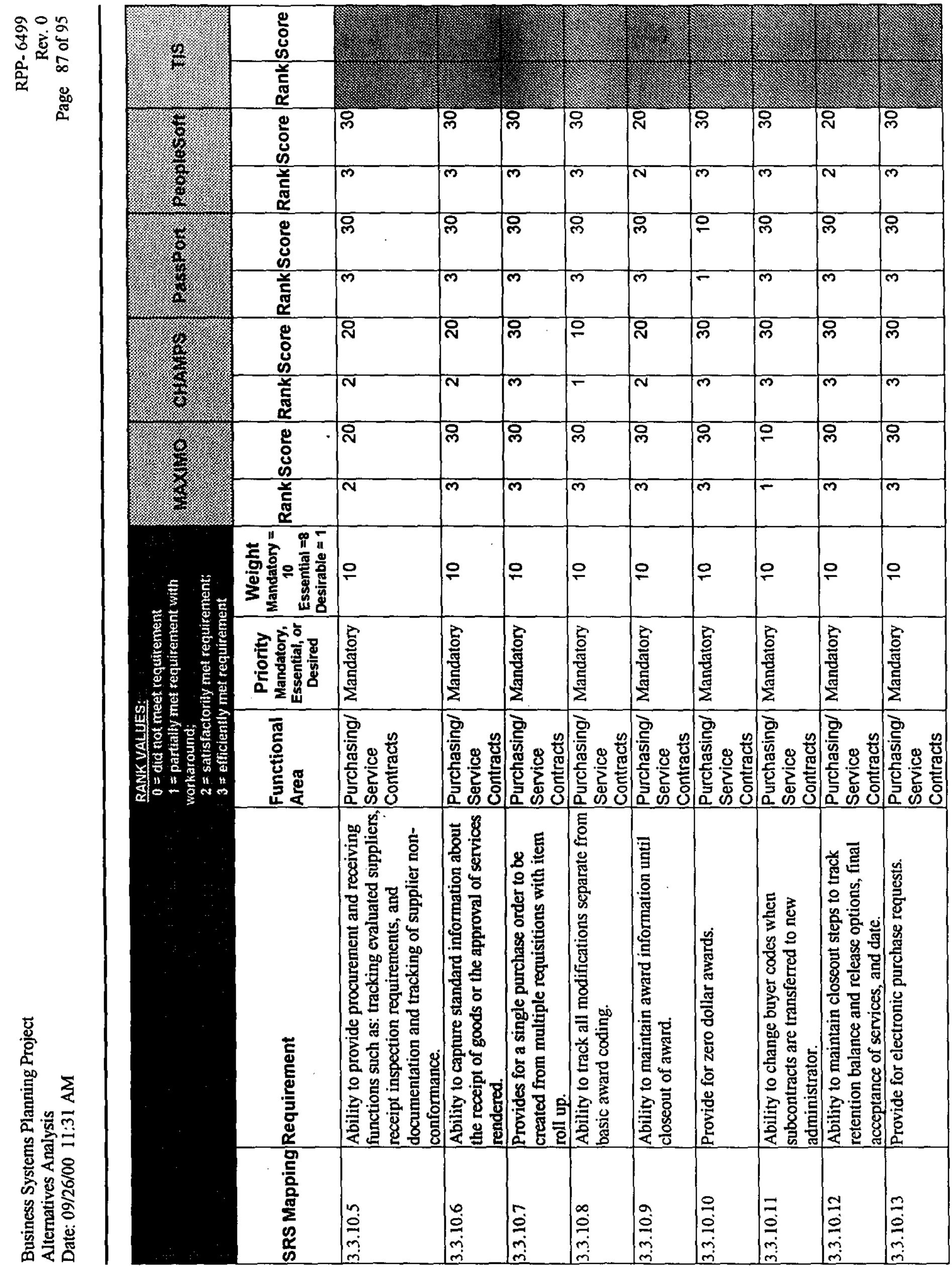




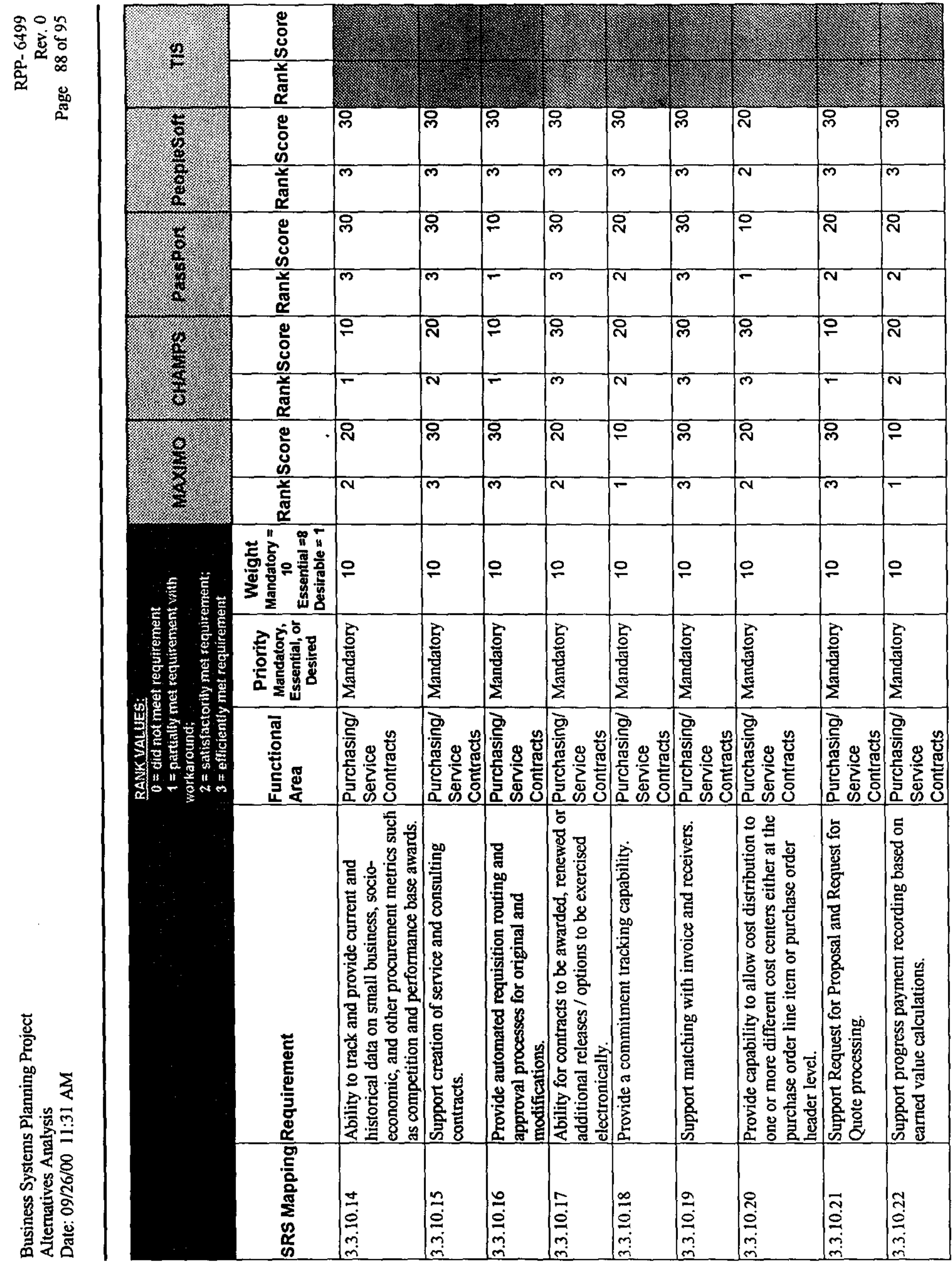




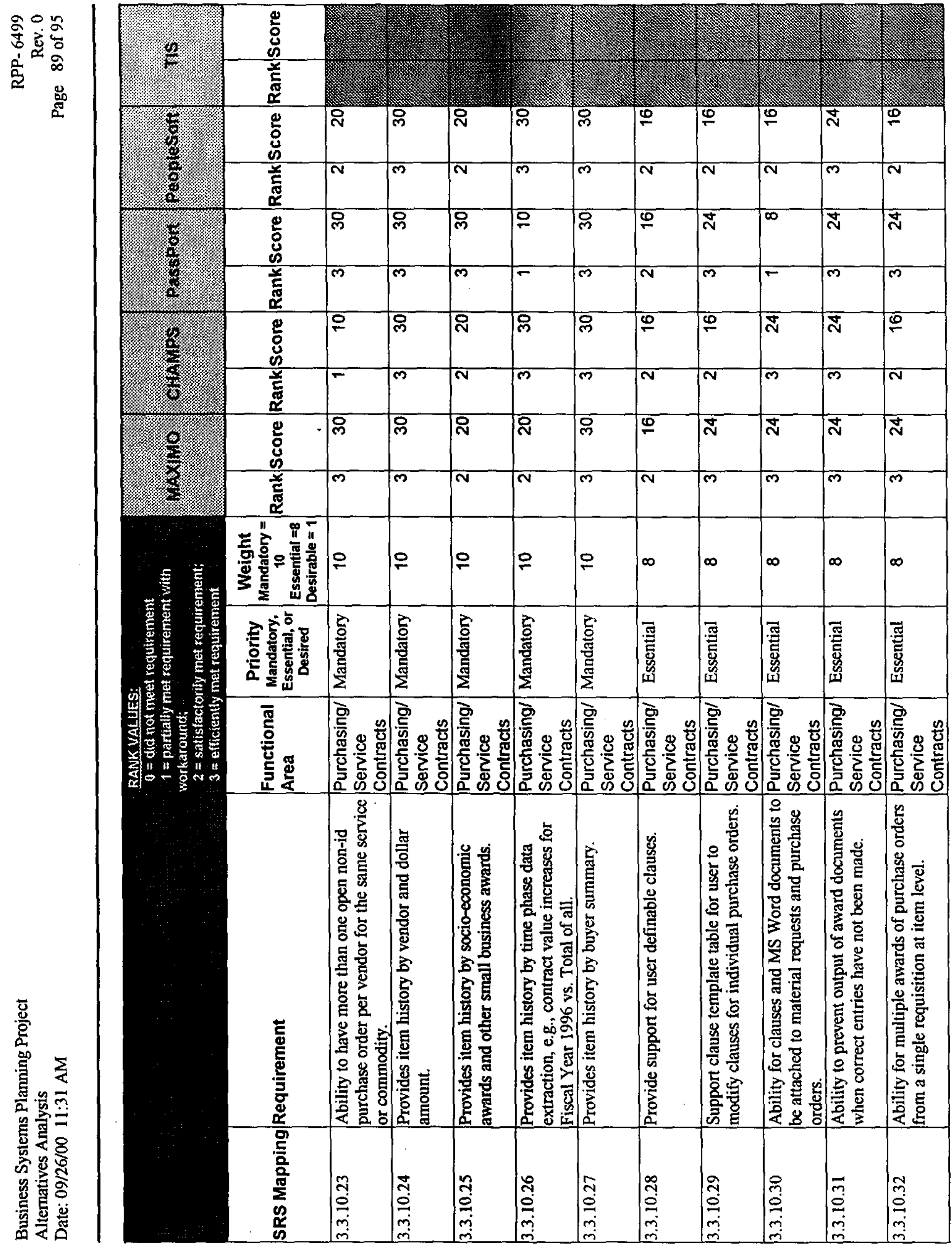




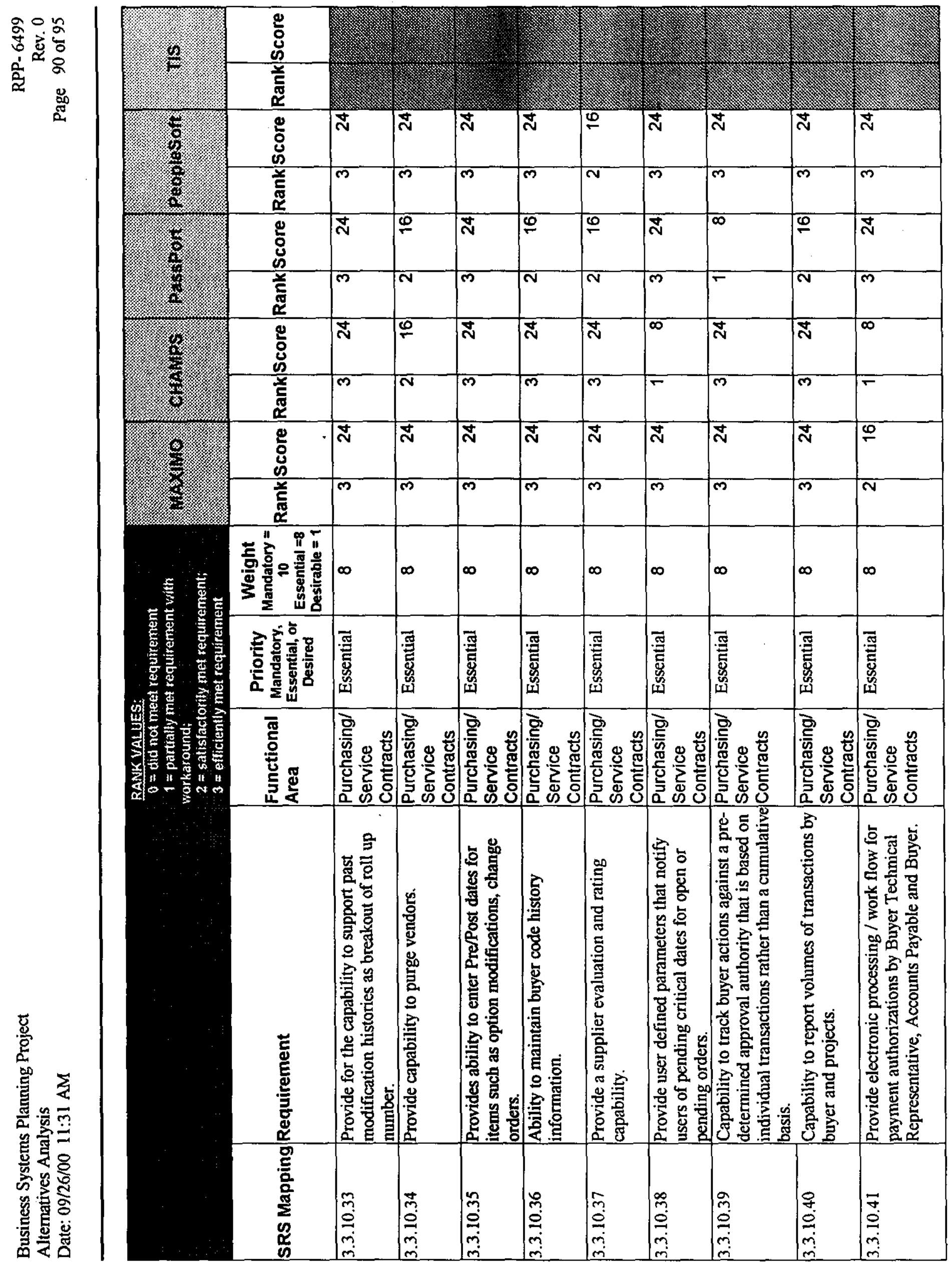




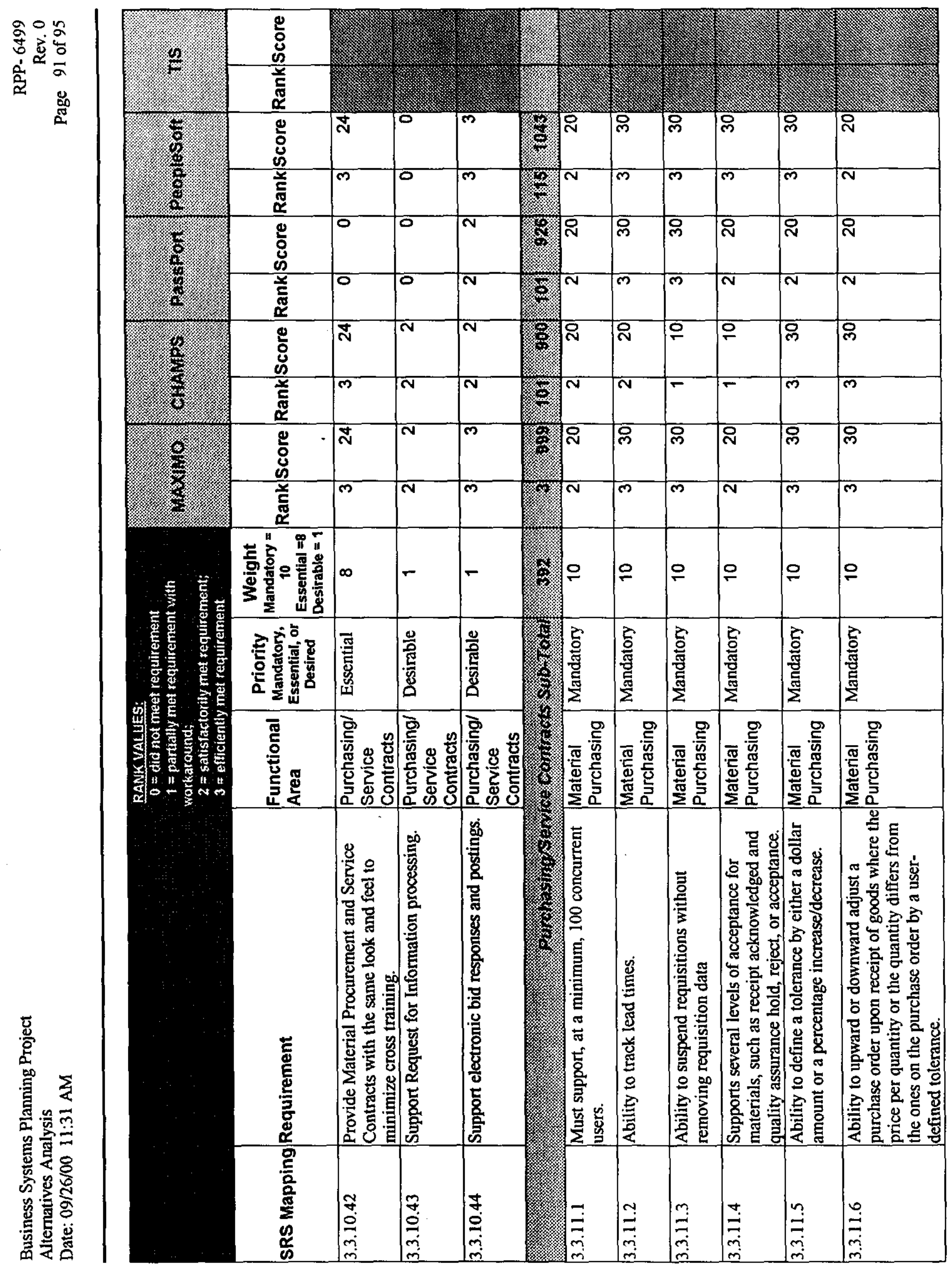




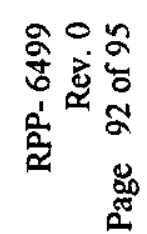

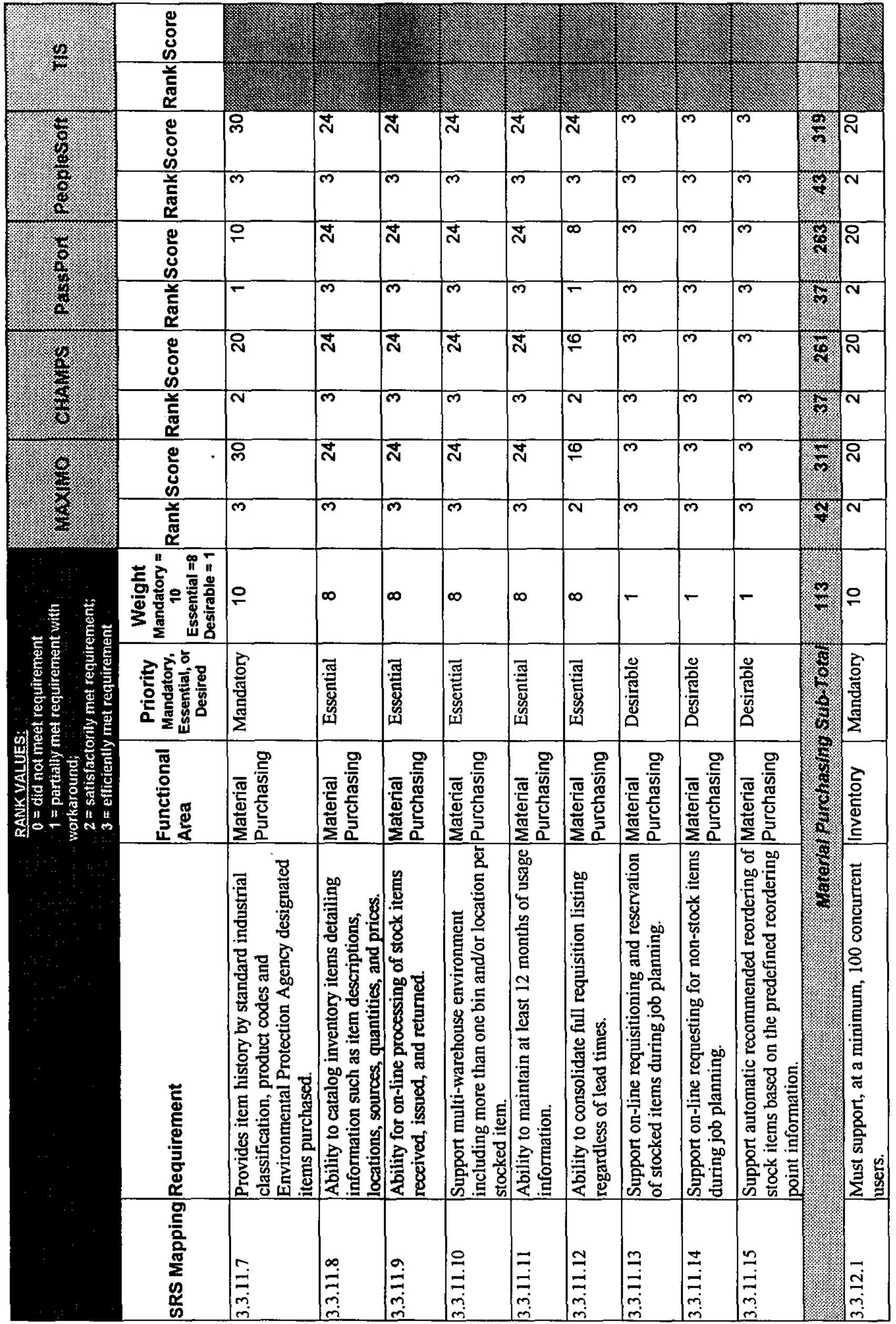




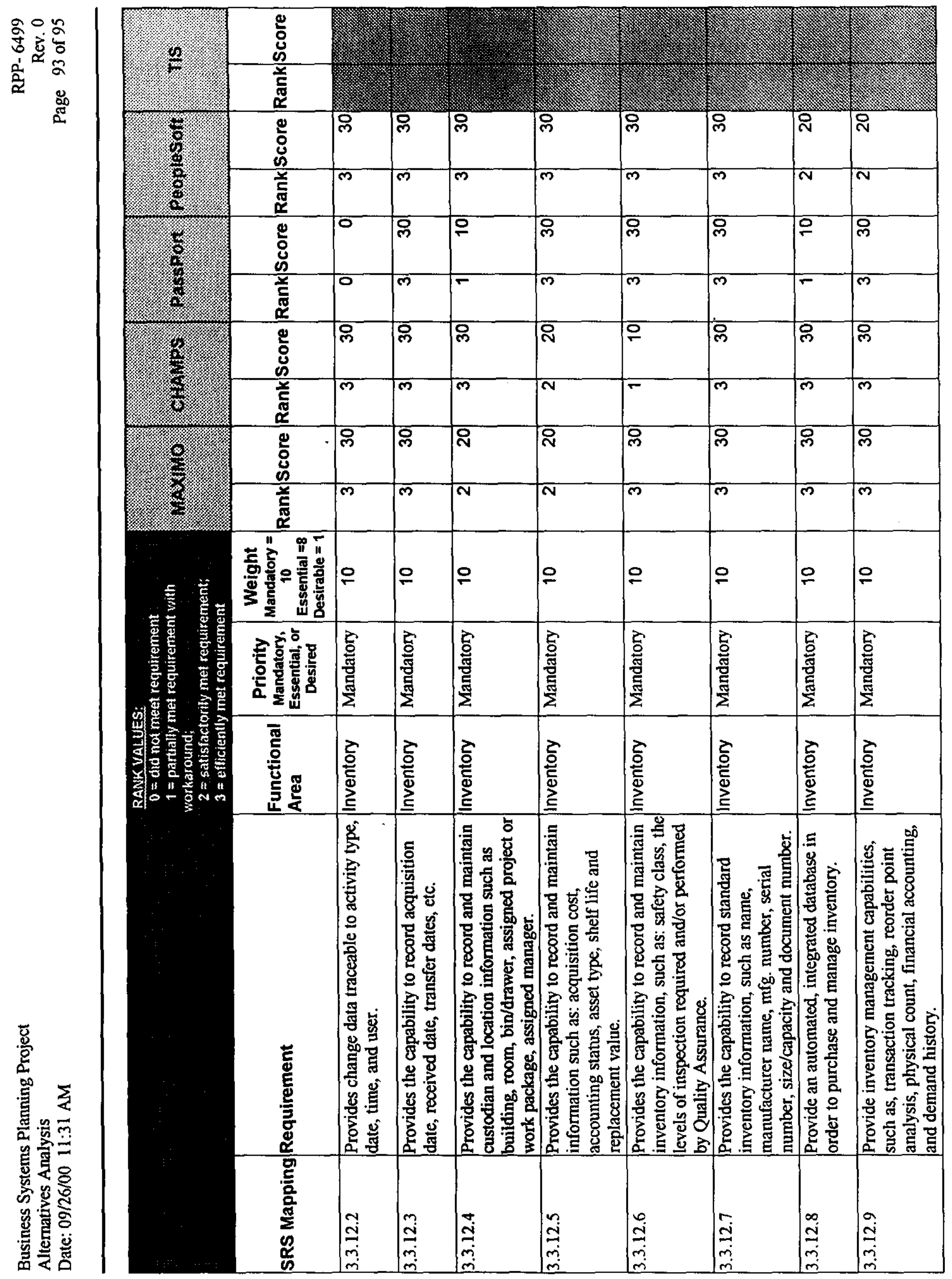




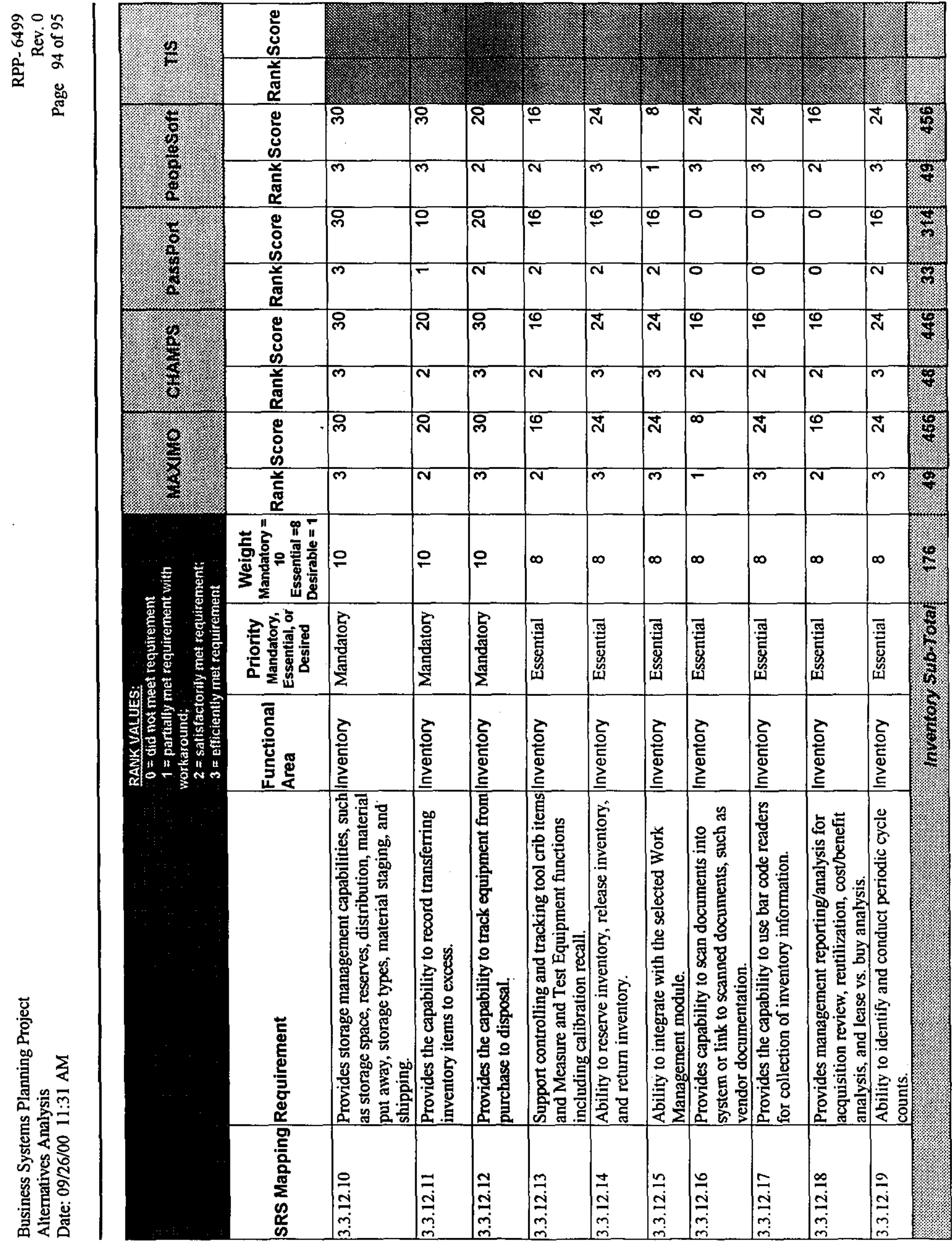




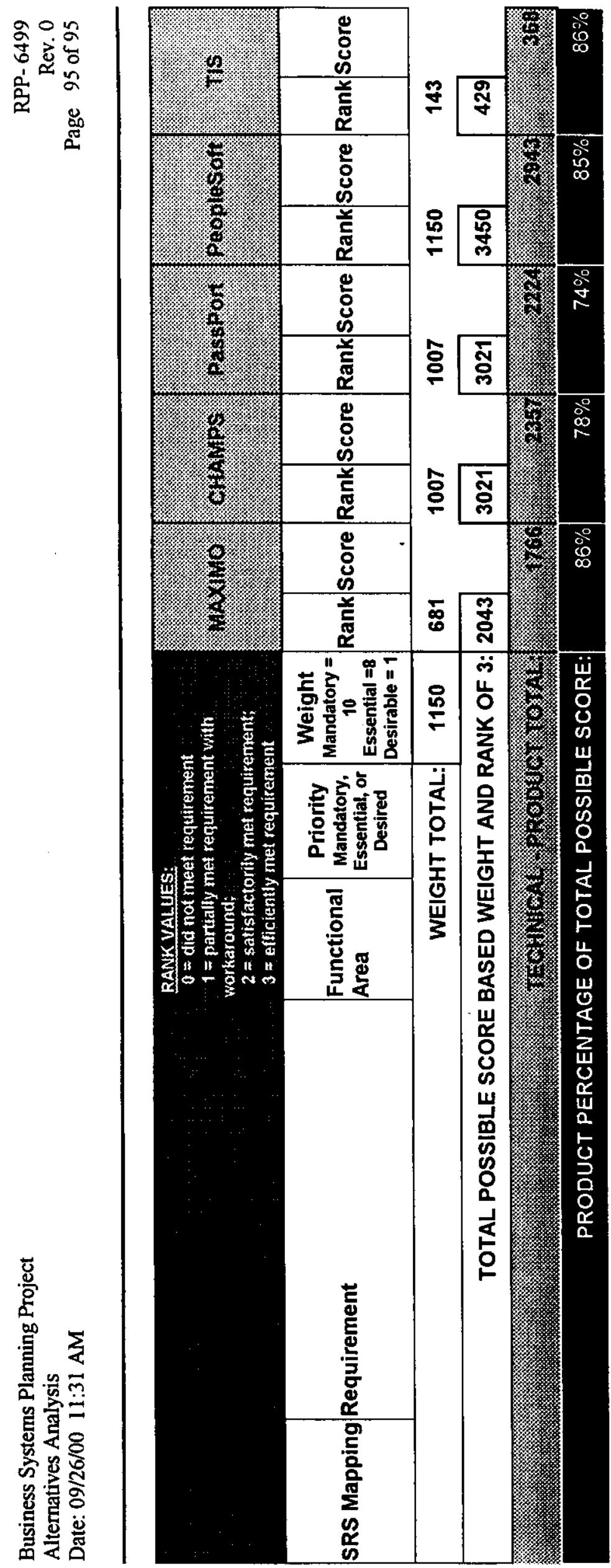

